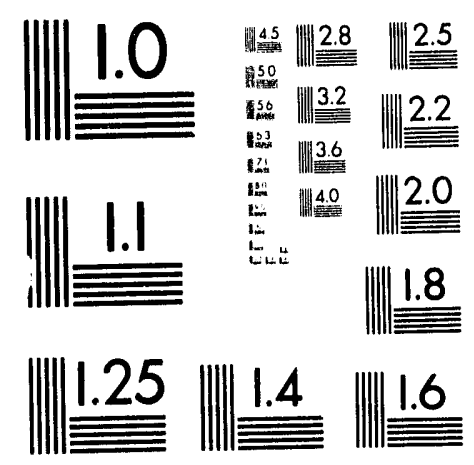



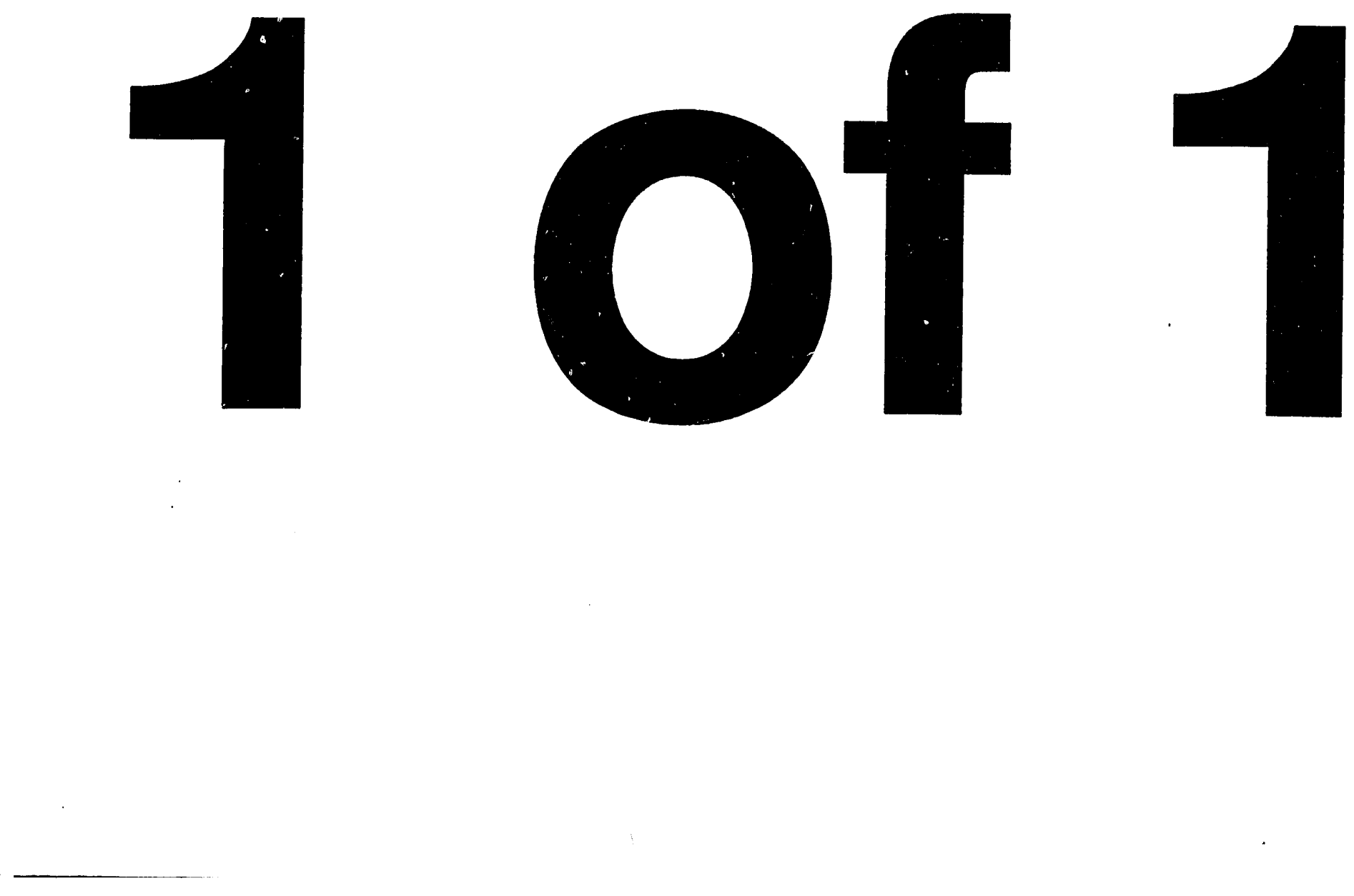


\section{The Current Bases \\ for \\ Roof Fall Prediction at WIPP \\ and a \\ Preliminary Prediction \\ for \\ SPDV Room 2}

October 1993

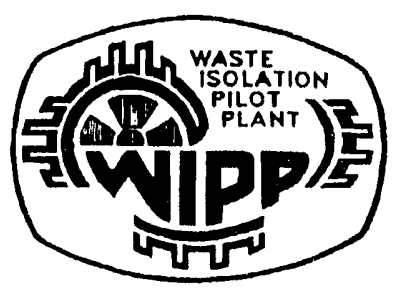

Morm

DISTRIBUTION OF THIS DOCUMENT IS UNLIMITED 


\section{TABLE OF CONTENTS}

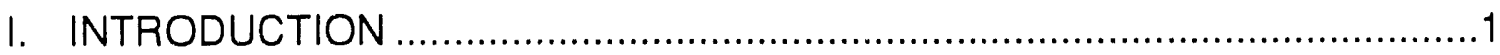

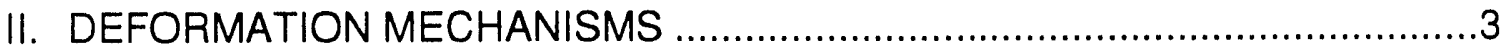

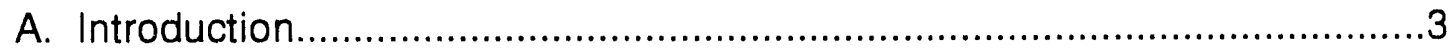

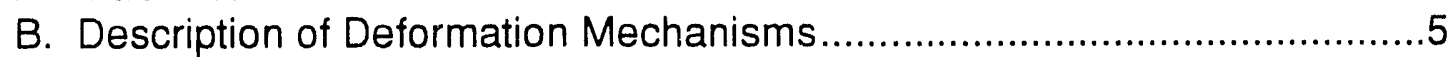

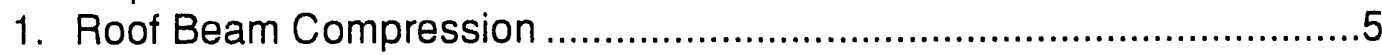

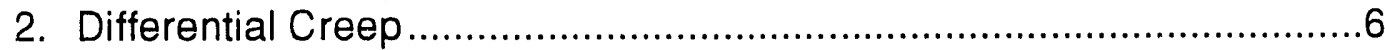

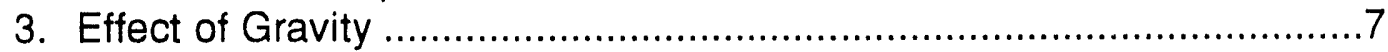

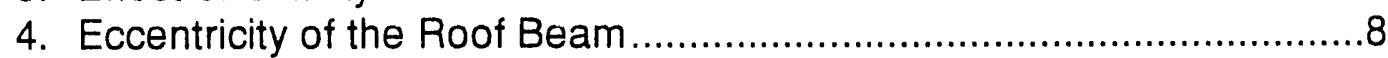

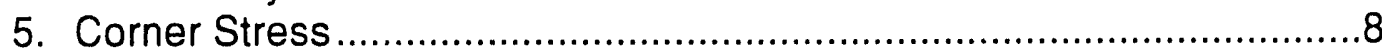

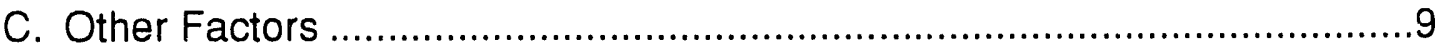

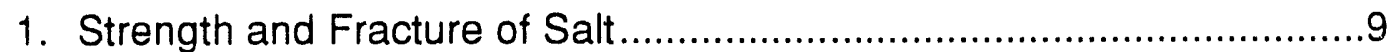

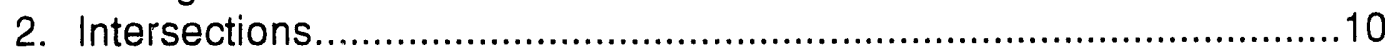

3. Excavation Sequence and Panel Effects ........................................11

III. EXPERIENCE FROM THE SPDV ROOM 1 ROOF FALL ...........................13

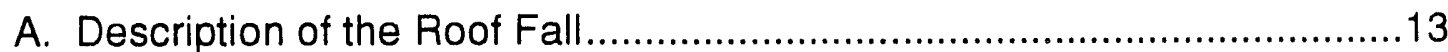

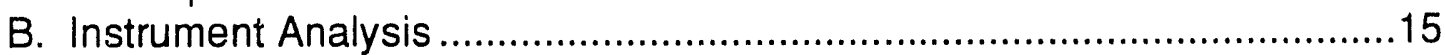

C. Deformation History ..........................................................................17

D. Correlation of Deformation History to Deformation Mechanisms .............19

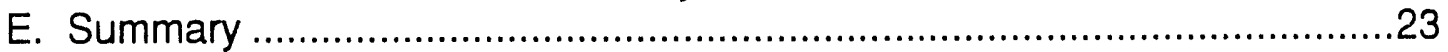

1. Assessment of SPDV Room 1 Behavior ........................................23

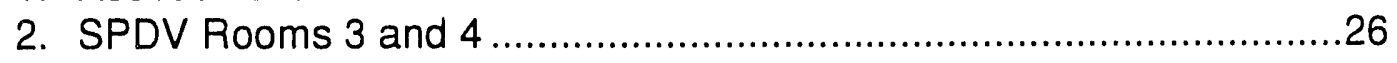

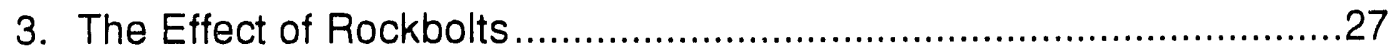

IV. PLAN FOR PREDICTION OF FUTURE ROOF FALLS ...........................29

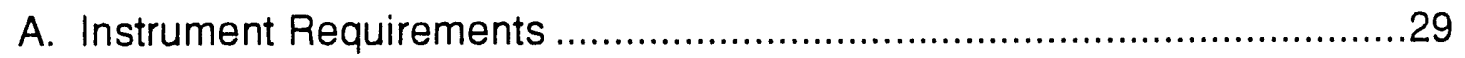

B. Procedure for Detecting and Monitoring Potential Roof Falls ..................30

C. Prediction for SPDV Room 2 ...............................................................

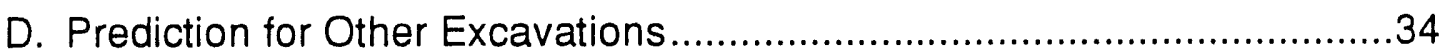

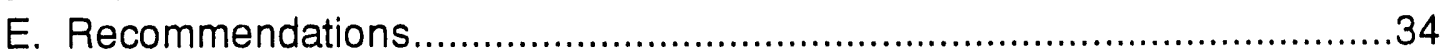

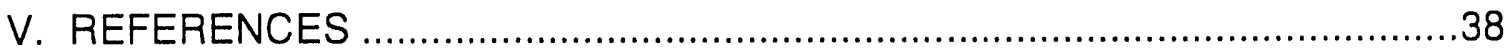




\section{LIST OF TABLES}

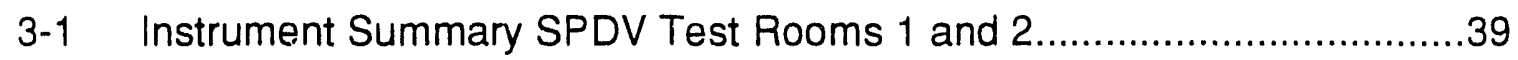

3-2 Excavation Effects Program Data Horizontal Offset Distribution.............41 


\section{LIST OF FIGURES}

2-1 Waste Isolation Pilot Plant Site Stratigraphy ......................................43

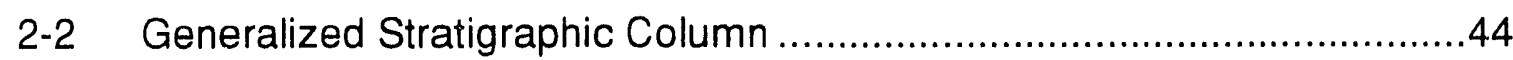

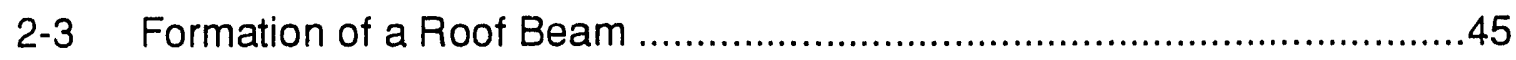

2-4 Concentration of Compressive Stresses in the Roof Beam....................46

2-5(a) Failure Mode of a Rock Sample in Uniaxial Compression

2-5(b) Failure Mode of the Roof Beam Under Compressive Forces..................47

2-6 Fracture Development Due to Roof Creep Mechanism.........................48

2-7 Failure of the Roof Beam in a Layered Rock Mass ................................49

2-8 Axial Force in the Roof Beam Acting Eccentrically on the Roof Beam.....50

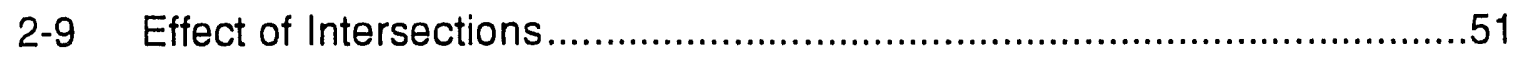

2-10 Local and Global Stress Arches …..................................................52

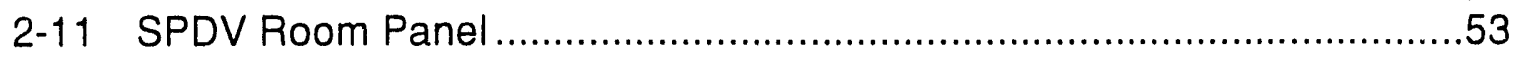

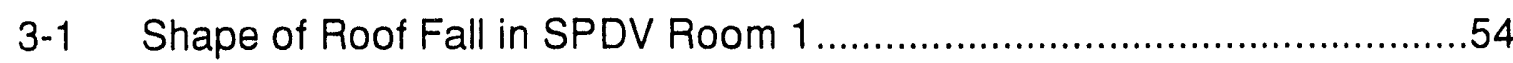

3-2 Excavation Effects Program Data SPDV Rooms 1 and 2 ......................55

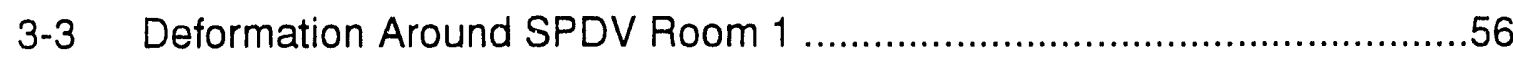

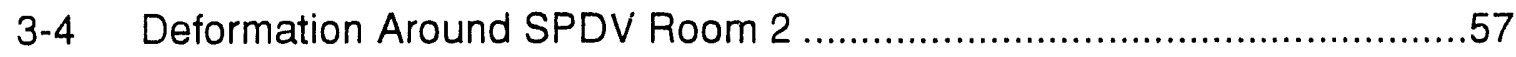

3-5 Asymmetric Convergence Around SPDV Room 1 ...............................58

3-6 Asymmetric Convergence Around SPDV Room 2 …............................59

3-7 Roof To Floor Convergence Rates SPDV Rooms 1 and 2....................60

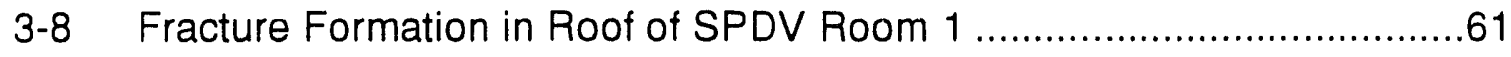

3-9 Advanced Fracture Formation in Roof of SPDV Room 1 .......................62

3-10 Deformation of Roof Beam After Initial Fracturing ..................................63 


\section{LIST OF FIGURES (continued)}

3-11 Convergence Data From N1420 Drift ...............................................64

3-12 SPDV Room 2 Roof Fall Prediction Using Curve Fitting ........................65

3-13 EEP Data Comparison SPDV Rooms 1 and 2...................................66 


\section{THE CURRENT BASES FOR ROOF FALL PREDICTION AT WIPP \\ AND A PRELIMINARY PREDICTION FOR SPDV ROOM 2}

\section{INTRODUCTION}

This document presents the current bases for roof fall prediction at the Waste Isolation Pilot Plant (WIPP) and a preliminary prediction of the date of a roof fall in SPDV Test Room 2. The ability to correctly assess the stability of the excavations at the WIPP is necessary to protect the safety of site workers, the environment, and the integrity of in situ experiments that use transuranic mixed waste. A roof fall is the extreme case of instability. Although roof falls are not expected to occur in maintained excavations at the WIPP, roof falls have been allowed to occur in unused, barricaded rooms so that the pre-collapse behavior of the rooms could be studied.

Professionals with experience in salt understand that predicting the performance of unsupported excavations in salt can be challenging. General patterns and trends are easily discerned, but there are always variations that are difficult to anticipate. However, it is possible to predict the performance of an excavation based on a combination of rock mechanics theory, the past performance of similar excavations, and monitoring via instrumentation and fracture mapping. The level of understanding of deformation mechanisms and of ground support techniques at the WIPP has advanced to the point where roof falls should not occur unless the fall is desired for rock mechanics study. 
This document presents a discussion of some deformation mechanisms that can be expected around excavations in bedded salt at the WIPP. The geomechanical instrument data and fracture maps from the Site and Preliminary Design Validation (SPDV) room area have been analyzed to determine the deformation history of the rooms and to identify precursors to the SPDV Room 1 roof fall. The deformation history of the excavations as recorded by the instruments was then correlated with these proposed deformation mechanisms, providing a basis for prediction of roof falls in other locations. Finally, the means used at the WIPP to identify and monitor unstable ground are discussed.

Throughout this document, "Room 1" and "Room 2" refer to SPDV Rooms 1 and 2 unless otherwise stated. 


\section{DEFORMATION MECHANISMS}

\section{A. Introduction}

The underground facility at the WIPP is located 2,150 feet below the surface in bedded salt of the Permian Salado Formation of southeast New Mexico. The generalized stratigraphy including the facility level is given in Figure 2-1. Over 1,000 feet of impermeable evaporite deposits separate the facility horizon from overlying sedimentary formations, and 2,000 feet of evaporites lie below the facility horizon and provide a barrier against underlying Permian limestones and sandstones.

The facility horizon lies within a 40 foot evaporite sequence consisting of halite, argillaceous halite, and polyhalite (Figure 2-2). Observations indicate that these beds are laterally continuous. A persistent 20 to 32 inch thick bed of anhydrite and polyhalite, identified as Marker Bed 139 (MB139), lies about five feet below the repository floor. Lateral variability in composition and thickness within this anhydrite bed exists at both the site and on the regional scale. Undulations up to six inches in the surface of MB139 have been observed in cores taken from the facility horizon.

The bottom of MB139 is subhorizontal and underlain by clay E. Anhydrite "a.," about eight inches thick, is about 13 feet above the repository roof and is underlain by clay $\mathrm{H}$. Anhydrite "b," two and half inches thick, is about 6.5 feet above the roof and is underlain by clay $G$. Clays $G, H$ and $E$ are all less than one inch thick. A diffused clay, clay $F$, is exposed in the ribs just below the roof.

After excavation of an opening, stresses in the surrounding rock are relieved and redistributed. The stress redistribution depends on the material properties of the 
rock mass and properties of discontinuities such as clay seams as well as the size, geometry, and stratigraphic location of both the individual excavation and any nearby excavations.

In rock salt, the excavation responds initially by elastic deformation due to stress redistribution, and subsequently by inelastic, time-dependent deformation due to deviatoric stresses. As a result of this time-dependent behavior, which is called creep, the surrounding rock mass tends to slowly move toward and into the opening.

As mentioned before, three major clay seams, $E, G$ and $H$, are located near the repository horizon (Figure 2-2). In situ observations show that the clay seams have a high moisture content. These clay seams are usually less than an inch thick. Their mechanical properties are drastically different from the surrounding salt. Clay seams can be assumed to have negligible tensile strength and very low shear strength compared to the surrounding rock salt. Therefore, these clay seams constitute planes of weakness along which shearing and separation can easily take place. They also strongly influence the magnitude and orientation of the stress distribution around the openings.

Compared to the surrounding rock salt, MB139 is a stiff and brittle layer. As the salt mass moves towards the excavation, stress concentrations develop in MB139. When these stresses reach a critical level, fractures develop in the Marker Bed, propagate through the floor salt layer, and eventually may extend to the floor of the room resulting in floor heave. 


\section{B. Description of Deformation Mechanisms}

The state of stress and the associated strain and displacement fields around an opening are quite complicated and can only be analyzed through comprehensive and detailed computer modeling using techniques such as finite element and finite difference methods. However, to obtain a basic understanding of the mechanisms causing deformation and possibly collapse of a typical WIPP room, it is useful to postulate some simple mechanisms and compare them to underground observations and measurements. The mechanisms proposed here should be considered as a representation of the current understanding of the deformation processes at the WIPP and as tools to be used in the analysis of excavation stability. They are certainly simplifications of the very complex forces acting on the complex geologic materials. However, they are sufficient for the purposes of this document.

It is emphasized that these deformation mechanisms may become active at different times after the excavation, and their effects may or may not be superimposed. Furthermore, some of the aspects of one mechanism may be part of the cause for one or more others. Therefore, the proposed mechanisms and the resulting deformations should not be viewed as totally independent. They are presented here separately for the sole purpose of enhancing the understanding of the excavation performance. In this document, the word "failure" is defined as reduction of ability to maintain stress.

\section{Roof Beam Compression}

As the rooms are excavated, the in situ stresses normal to the perimeter of the excavation are relieved, and far-field stresses tend to push the salt mass toward the opening. Initially, the surrounding rock mass reacts as an elastic 
homogeneous medium. Therefore, the horizontal stresses at the midroof would be much less than the initial far-field stresses (see Hoek and Brown, 1980). Because the clay seams do not provide much, if any, shear resistance, the salt between clay $G$ in the roof and clay $E$ below the floor moves horizontally towards the excavation faster than the adjacent layers. This movement concentrates the stresses on those portions of the layer remaining after the excavation, i.e., the portion between the roof and clay G, salled the roof beam, and the portion between the floor and clay E, called the floor beam (Figure 2-3).

If it is assumed that the clay seams are frictionless, the sum of the far field horizontal stresses acting on the layer between clays $G$ and $H$ should ideally be resisted and therefore in equilibrium with the sum of the horizontal forces acting on the roof beam and floor beams (Figure 2-4). The concentration of compressive stresses in the roof and floor beams may reach values high enough to cause (or at least initiate) compressive failure. The failure mode in the roof beam due to compressive stresses would resemble the failure of a rock specimen in a laboratory uniaxial (unconfined) compression test. The mode of failure in an unconfined compression test is typically a shear failure on a diagonal plane (Figure 2-5).

\section{Differential Creep}

In the vertical direction there are no planes of weakness to facilitate the movement of salt toward the excavation. In the midroof, the salt mass can move freely into the excavation. However near the rib line the extrusion of the roof salt into the excavation is resisted by the presence of the pillars (Figure 2-6). This phenomenon may induce large shear strains in the roof close to the ribs, and these strains in turn cause damage to the rock salt and generate a zone of weakness. The precise orientation and magnitude of these shear stresses are 
very difficult to evaluate and they probably vary over time. The frequently observed sharply curved deflection of the roof near the upper corners may be caused by this mechanism. The differential creep mechanism is probably most active immediately after excavation of the room because the high unrelieved stresses cause very high creep rates then. In addition, this phenomenon may induce sufficient deflection to cause eccentric loading in the roof beam, a factor examined more closely in section 4 .

\section{Effect of Gravity}

Gravity can have a substantial and continuous effect on the performance of openings. After the rooms are excavated, the roof beam is subjected to a gravity load perpendicular to its main axis. This is often the main cause of roof collapse for openings in a layered rock mass (Figure 2-7). If axial forces were absent, tensile cracks could develop in the midspan at the bottom of the beam and along the ribs at the top of the roof beam, due to bending of the roof beam. Roof fractures of this type are not seen in WIPP roums.

Shear stresses due to 1.) compression of the beam, 2.) the differential creep of the roof toward the opening, and 3.) the weight of the beam probably act together on some planes. This interaction increases the potential for diagonal cracking with the mode of failure starting from the corners of the beam and extending diagonally upward towards the midspan of the beam. The roof beam weight is in effect immediately upon the excavation of the opening. However, the effects of stresses due to roof beam compression and differential creep of the roof develop with time. Therefore, the maximum shear stresses, caused by interaction and summation of the effects of the three mechanisms, will likely take some time to develop, possibly several years. 
The effect of gravity after the development of the failure zones in the roof beam is different. At that time, gravity will cause the detached roof material to act as a dead weight. The resulting behavior will then be plate-like (i.e., threedimensional) with support supplied by the remaining intact material on surfaces normal to the long axis of the room.

\section{Eccentricity of the roof beam}

Eccentricity could develop in the roof beam due to uneven creep of the roof and bending of the roof beam under its weight. This eccentricity taken in combination with the axial force in the roof beam could generaie significant, perhaps localized, additional bending in the roof beam (Figure 2-8). The effect

of this mechanism can only start after substantial initial bending and sagging develop.

\section{Corner stress}

The effect of sharp corners on stress distribution has te extensively studied. Perfectly sharp angular corners theoretically generate infinite stresses. However, the corners of rooms are usually slightly rounded. The radius of the curvature in the corners of most WIPP excavations is specified to be 18 inches. Obert and Duvall (1967) show that the concentration of stresses in a corner is a function of the ratio of the radius of curvature of the corner to the height or width of the opening as well as of the principal stress ratio. The stress concentration resulting from this curvature in combination with the differential creep mechanism may be responsible for the initiation of diagonal fractures from the corners of the roof beam rather than the development of a continuous plastic type of deformation. 


\section{Other Factors}

\section{Strength and fracture of salt}

Many researchers have studied the viscoelastic and viscoplastic properties of salt (see Munson et al., 1989). The strength and failure criteria of rock salt, however, have not received much attention, although progress has been made recently on the development of a failure model for salt (Chan et al., 1992).

The strength of a rock mass is a function not only of the magnitude of the load, but also the rate at which the load is applied. The latter factor may be more dominant or influential in some rocks than others. Experience shows that the strength of rock salt is particularly dependent on time and loading rate.

A salt mass has a regular crystalline structure. This crystalline structure strongly influences the response of the salt mass to any external force. In addition, given sufficient time and proper stress conditions, salt crystals have the ability (as part of the creep deformation process) to reshape and restructure themselves, similar to the behavior of ice in glaciers. This property of salt contrasts noticeably with other rock types traditionally dealt with in rock mechanics.

Most rock types are composed of some type of brittle granular materials that have been cemented together in a geological process. Disturbances or weakness zones generated in brittle materials are usually permanent and irreversible. However, a salt mass can recrystallize and therefore heal itself under a confining load. If a crack develops in a salt mass due to a sudden change in the stress field, there is a potential for the surrounding crystals to deform, fill the gap and regain crystalline continuity. Therefore, criteria that have 
been established in the mechanics of hard rock for the initiation and propagation of cracks may not be valid in salt.

The mode of general failure in salt is different from hard rock. At low confining stresses a sample of hard rock fails on a plane in the form of a shear band. This usually results in a distinct failure mode at a relatively distinct stress magnitude. Under high confining stresses the same sample disintegrates and crushes homogeneously. In contrast, even at quite low confining stress a relatively slowly loaded cylindrical sample of salt deforms continuously into a barrel shape that still has a substantial load-bearing capacity. At high loading rates, salt fails much like hard rock. In salt, therefore, the definition and determination of the failure stress and mode is more complex than in hard rock. Finally, the type and amount of impurities in the salt mass (mostly dispersed clay) will also influence the mechanical behavior of salt.

\section{Intersections}

At the WIPP, roof conditions of intersections are better than that of locations remote from intersections. In the middle of the rooms, conditions are very close to the plane strain case. The pillars move toward the opening, perpendicular to the ribs and therefore exert pressure directly on the roof beam (Figure 2-9), whereas in the intersections, the salt mass is less confined and has more freedom when creeping toward the openings, leading to less local concentration of stresses in the corners, resulting in less creep and failure in the roof beam.

Furthermore, vertical deflection of the roof toward the excavation in the intersections is much smoother than at the mid-room positions. As explained earlier, in the mid-length position in the room, the ribs strongly resist the vertical 
creep of the roof toward the excavation resulting in formation of a local zone of high stress and consequent differential deformation. However, at the intersections, the roof deflection is only resisted by the four pillar corners. Due to the lack of confinement, the corners of the pillars fracture soon after excavation, as observed underground. The corners of the pillars in the intersections do not effectively resist the creep of the roof toward the excavation, therefore the resistance is transferred more gradually toward the pillar interior. Thus, the creep of the roof toward the excavation in the intersections does not develop intense shear zones likely to cause roof fracturing.

\section{Excavation Sequence and Panel Effects}

The sequence of excavation of different rooms within a panel and the final location of the different excavations with respect to each other influence the timing and magnitude of stress distribution around the rooms. This could cause fracturing and possibly collapse of an otherwise stable roof.

After the initial excavation, the stress around the opening is redistributed and quickly adjusts itself to the opening. Due to the viscoplastic properties of salt, the state of stress in the surrounding rock mass changes continuously as the salt mass creeps, thereby modifying the concentration of stresses caused by the excavation. As a result, the next opening is not excavated in a virgin stress field. Instead, it is excavated in the induced stress zone created by the previous excavation. In turn, the new excavation will affect the distribution of stresses around the previous excavation.

The final state of stress distribution around each opening depends on its position with respect to other openings. In general, immediately after 
excavation, stress arches form around each opening, thus transferring the load previously passing through each room to adjacent pillars (Figure 2-10a). As a result, stress concentrates in the pillars. In a panel area, the initial magnitude of the stress concentration in the panel pillars would be larger than the stresses in the abutments, because these abutments can be considered infinitely large. Therefore the panel pillars should yield faster than the abutments, causing the formation of a larger global arch spanning all the excavations. The global arch partially transfers the load of the extended panel roof to the abutments (Figure 210b). This mechanism may have been responsible for the additional concentration of the roof damage in SPDV Room 1 (Figure 2-11). 


\section{EXPERIENCE FROM THE SPDV ROOM 1 ROOF FALL}

This section describes the large roof fall that occurred in SPDV Room 1, and provides a discussion of the geomechanical instrument data and visual observations from the room. This is the only large (i.e., room-scale) fall which has occurred at the WIPP. The instrument data are used to describe the deformation history of SPDV Room 1. The deformation history is then correlated to the generic deformation mechanisms discussed in Section II. Although it appears that the roof fall itself was an anomaly in that the roof fell long before any other room, the general fracture and deformation patterns seen in SPDV Room 1 before the fall are believed to be similar to other location in the WIPP.

The SPDV Rooms were excavated in 1983 to the same dimensions as the waste storage rooms. The performance of the SPDV Rooms was used to validate the design of the storage rooms. Design criteria for storage rooms were based primarily on total closure and waste retrievability. The rooms were originally required to remain stable and not exceed certain deformation limits for the five year Test Phase plus time to retrieve the waste. While closure rates in the SPDV Rooms were found to be larger than anticipated, the design was considered validated with modifications to the geometry of the waste stack. Roof fracturing was not considered a problem if rockbolts were installed.

\section{A. Description of the Roof Fall}

A 700 ton roof fall occurred in SPDV Room 1 on February 4, 1991. The section that fell was approximately 33 feet wide by seven feet high by 180 feet long, had a triangular cross-section, and was located primarily in the north end of the room (Figure 3-1). The time and shape of the roof fall was accurately predicted using the methods discussed in this document. Furthermore, the potential for a roof 
fall in SPDV Room 1 was identified and the room was cleared and barricaded two years before the roof fell. This room had been instrumented shortly after its excavation in March of 1983 and was closely monitored until the roof fall. Table 3-1 summarizes the instruments that have been installed in Rooms 1 and 2.

The conditions of the roof, floor, and walls of the SPDV rooms were surveyed quarterly since their excavation until they were closed. Initially, the only fracturing of note around the excavation was shallow (less than six inches deep) spalls which were typically removed by hand. Spalls that were too large for removal were rockbolted, usually with two foot long bolts. After about two years, consistent low angle fractures that originated in the roof near the ribs were noted in the north and center sections of Room 1. In 1986, three years after excavation, the Excavation Effects Program (EEP) boreholes were drilled in the south end and the center of Room 1. The EEP data indicated that the low angle fractures near the ribs extended some distance up and towards the centerline of the room (Figure 3-2). However, the EEP boreholes could not determine if the fractures extended all the way to clay $G$.

By 1988 , the fracturing had become much worse, and there were other signs of large roof movements such as bent bulkheads and posts. Up to this time, borehole extensometer data were also indicating that the rates of displacement in the roof were increasing. Unfortunately, all the borehole extensometers in the roof of SPDV Room 1 had failed by this time, probably due to excessive lateral deformation which was observed in adjacent observation boreholes. A work package was prepared to replace the extensometers. In the meantime, manual vertical convergence gauges were installed at the quarter span points near the 
center of the room as a partial substitute. The convergence gauges showed that the roof was deforming asymmetrically--the east side of the room was closing about twice as fast as the west side. While drilling the boreholes for the replacement extensometers, it became obvious that diagonal fractures on either side of the room were connected to each other and to the separation that was developing at clay $G$. Dust from drilling was emerging from boreholes as far as thirty feet away. It was at this time (Mav1989), that the room was decommissioned and evacuated. Before the room was permanently barricaded, four remotely read roof-to-floor wire convergence meters were installed in the north end. These instruments functioned until the roof fell.

\section{B. Instrument analysis}

All the available instrument and geologic data for the area in and around SPDV Rooms 1 and 2 were reviewed. Preliminary analyses narrowed the scope of the analyses to instruments inside Rooms 1 and 2 (see item 1 below). Most instruments failed well before the rock fall; so the deformation history is incomplete (see Table 3-1). Except for the wire convergence meters that were installed shortly before the fall, all instruments were located in the center of the rooms. Plots of relevant instrument data are shown in Appendix $A$.

Examination of the instrument data led to the following observations:

1. Instruments outside SPDV Test Room 1, including those at the intersections at the ends of the room, do not show any change in trend due to the roof fall itself. It is possible that a more gradual change started some time before the actual fall, but it has not been detected. 
2. The clay seam bay of the roof extensometers had greater strain than the collar bay for the center instruments in Rooms 1 and 2 and for the extensometers adjacent to the shared pillar (Figures 3-3 and 3-4). The clay seam bay strain was lower than the collar bay strain in the extensometers furthest away from the common pillar. (The east extensometer in Room 1 and the west extensometer in Room 2.)

3. Roof to floor convergence for both rooms was highest on the side away from the shared pillar (Figures 3-5 and 3-6).

4. By 2 and 3 above, the side of the room with the greatest clay seam separation had the lowest vertical convergence.

5. Roof extensometers in SPDV Room 1 show an abrupt increase in clay seam separation rate beginning approximately in January 1986 (Figure 3-3). Only the east roof extensometer in SPDV Room 2 shows a definite rate increase at that time (Figure 3-4). This is the instrument closest to Room 1. The rate for the center extensometer in Room 2 begins increasing sometime after January 1986, perhaps as much as a year later. The rate for the west extensometer does not have an obvious increase. There appears to be a slight increase in roof-to-floor convergence rate in both rooms about January 1986 (Figure 3-7). This phenomenon does not appear to affect the rib displacements in either room.

6. The Room 1 center roof extensometer and the vertical convergence meters in both rooms show a further and different rate increase beginning approximately January 1988 . The other roof extensometers were no longer 
functioning at this time, so the area extent of this phenomenon cannot be determined. The increase is greater for roof-to-floor closure than for the extensometer.

7. The extensometers in both rooms which had the clay bay strain greater than the collar bay strain (west and center in Room 1, east and center in Room 2) showed that condition since installation, which indicates that it may have persisted since excavation.

8. Displacement rates in Room 1 were always higher than in Room 2.

9. The roof to floor closure rate in Rooms 1 and 2 began steadily increasing at least three years before the roof fall (Figure 3-7).

\section{Deformation History}

The January 1986 and January 1988 events described above are most significant. The increase in clay seam separation and closure rate in January 1986 may be a manifestation of the fractures or a fracture zone on one side of the beam reaching clay $G$, setting up a cantilever, and partially relieving horizontal compression of the beam (Figure 3-8). Because it is extremely unlikely that the mechanical properties and the loading of the roof beams are perfectly symmetrical, one side of the roof can be expected to fracture before the other. The weight of the cantilever would cause the free end of the cantilever to move downward faster than the fixed end. The fractured side of the beam would have the highest bay strains between the back and clay $\mathrm{G}$. The center and the

side without the fractures would have the highest bay strains across clay $G$. The cantilever would cause rate increases in all the clay-spanning bays, but the 
greatest increases would be near the center of the room (i.e., at the top of the free end of the beam).

The fractures on one side would separate the roof beam into two parts that behave independently. The cantilevered side of the roof beam would move almost as a whole towards the fracture. One manifestation of this movement pattern would be the development of horizontal offset at the center of the roof beam, with the rock below clay $G$ moving towards the fracture relative to the rock above clay G. This pattern is often noted in EEP array boreholes (see Figure 32). Table 3-2 summarizes the distribution of horizontal offsets at clay $G$ in the EEP data set. Note that most locations show the asymmetric distribution. The locations with low total offset magnitude on the side holes are likely to not be asymmetric. This indicates that the asymmetric offset distribution usually requires some time to initiate. The effects of the cantilever explain items 2 through 5 above.

The displacement rate increases in January 1988 may be a manifestation of fractures extending from the back finally reaching clay $G$ on both sides of the roof beam, setting up a wedge supported primarily by the north and south ends (Figure 3-9). The additional loading due to the dead-weight of the wedge would cause the increase in convergence rate. The separation of the slab from the rest of the roof beam would probably reduce the rate of clay seam separation at the sides and increase the rate at the center, because the top of the slab would be within the clay seam bay of the center roof extensometer, and below the clay bay on the sides. The side (quarter-span) roof extensometers were not functioning in January 1988, but the center extensometer shows an increased rate. The effects of the wedge-shaped slab explain item 6 above. 
At this point the slab is supported primarily on the north and south ends, i.e., with surfaces normal to the roadway. The slab probably continued to grow in the north/south direction, increasing its weight, while at the same time it was becoming more fractured, reducing its overall strength. Both these factors probably combined and continued to the point when the decreasing strength of the beam was insufficient to support the increasing dead-weight load, causing a relatively sudden roof fall.

The events (in January 1986 and January 1988) which caused the changes in trends in the instrument data for Room 1 are explained by the above sequence. The question remains, why do the January 1986 and January 1988 events appear in the instrument data for Room 2 if they are caused by specific physical changes in Room 1? There are two possibilities. One is that similar fracture patterns developed in Room 2 at almost exactly the same time as Room 1. The other is that the fracturing in Room 1 altered the state of stress around Room 2 such that it had to respond to these changes. Item 7 above suggests that the roof beams in both rooms were pre-disposed from the time of excavation to develop the fracture patterns described above, but the instrument data cannot explain either why one room or one side fractures first. What they do show is that one side of the roof beam in both rooms was mechanically weaker from the very beginning.

\section{Correlation of Deformation History to Deformation Mechanisms}

The deformation and fracturing of the roof beam determined from the instrument response can be explained as the result of several of the generic deformation mechanisms discussed earlier. The deformation mechanisms acting on the roof of the SPDV Test Rooms must explain the following observations: 
The mechanism(s) must:

1. Weaken the roof beam near one or both ribs, induce tensile stress near the ribs, or both.

2. Cause fractures or a fractured zone to develop on an angle from the roof/rib junction to near the centerline at clay $G$.

3. Cause both sides of the roof beam to move horizontally towards the center.

4. Cause the ceriter of the roof beam to be displaced asymmetrically.

5. Explain why Room 1 failed first and any linkage between Rooms 1 and 2.

6. Be applicable to some extent to nearly all excavations at the same stratigraphic location.

\section{Explanation for Observation 1:}

The differential creep and corner stress mechanisms both cause tensile stress to develop in the roof near the ribs, which in turn weakens the roof near the ribs. In fact, both mechanisms are very likely closely linked, because the high stress caused by the effect of corners will cause high creep rates near the ribs.

\section{Explanation for Observation 2:}

The differential creep, roof beam compression, and corner stress mechanisms combine to cause diagonal fractures. The roof beam compression mechanism puts the roof beam into compression. The most likely compressive failure is one (or two) diagonal fracture(s). By Observation 1, the sides of the roof beam are weakened. Therefore, diagonal fractures would tend to develop in the beam near the ribs. 


\section{Explanation for Observation 3:}

The roof beam compression mechanism accounts for the lateral movement of the ends of the roof beam towards the center of the beam.

\section{Explanation for Observation 4:}

The asyminetric horizontal offset distribution is a result of the formation of a predominant diagonal fracture on one side of the roof beam. This causes the center of the roof beam to become offset horizontally towards the predominant fracture. The fracturing and horizontal displacements were explained in Observations 2 and 3.

\section{Explanation for Observation 5:}

The instrument data indicate that Room 1 was deforming faster than Room 2 from the beginning. It can then be assumed that the roof of Room 1 was weakened more and faster than that of Room 2 from the very beginning. This may be an effect of the stress distribution around the entire four-room panel, the position of Room 1 in the excavation sequence, the geology of the roof, or a combination of all these. Minor differences in the strength of the roof beam could also have a significant effect.

The structural link, as evidenced in the coincident changes in deformation rates in both rooms, can be explained by several mechanisms. Substantial changes in the strength and loading of the roof beam in Room 1 would redistribute stress around Room 1, including in the pillar between Rooms 1 and 2. If the new stress distribution affecting Room 2 reduced the horizontal stress in the Room 2 roof beam, it could reduce confinement of partially supported slabs that would amplify the effect of gravity on the loose slabs, causing faster movement. Alternatively, 
if the new stress distribution affecting Room 2 increased the horizontal stress in the Room 2 roof beam, it could increase horizontal displacement of the ends of the Room 2 roof beam, increasing fracturing and deformation rates. In either case, it is reasonable to conclude that the increase in displacement rates should be positive (i.e., accelerating), because the increased stress/increased fracturing/increased displacement cycle would lead to more rapid roof deterioration.

The best explanation is that the developing failure of the Room 1 roof beam caused a stress redistribution the effect of which was to reduce the horizontal compressive forces on the Room 2 roof beam. This means that the primary mode of failure in the Room 2 roof became increasing separation along existing fractures, rather than the formation of new fractures. This would explain why the progressive failure of the roof in Room 2 has taken so much longer than Room 1. However, because Room 1 had a roof collapse so early relative to all other similar-sized rooms at the WIPP, it may be quite possible that Room 1 is geomechanically atypical.

\section{Explanation for Observation 6:}

The differential creep, roof beam compression, and corner stress mechanisms are independent of drift size and are based on shape and stratigraphic location. That is to say, the general pattern of displacements and stress concentrations caused by these mechanisms are not dependent on drift size. Although the magnitude of displacements would be greater around a larger drift, the deformed shape of a large drift is essentially the same as that of smaller drifts. The same is true for stress. Stress magnitudes are probably a complex function of position and material properties. 


\section{E. Summary}

The roofs of SPDV Rooms 1 and 2 have undergone similar deformation histories. While instrument coverage of most other locations is not as thorough as of these rooms, there is strong evidence that the same deformation patterns are developing throughout the underground. The time from excavation to a roof fall (the stand up time) is dependent on several factors including (but not limited to) the strength of the roof beam and the load history of the roof beam. The strength is dependent on mechanical factors such as the total strain distribution in the roof beam and on various geological factors such as clay content and distribution and salt crystal size. The load history of the roof beam is also very site specific, depending on drift and pillar dimensions, the proximity to other excavations, and excavation sequence of the drift under study and the surrounding drifts. As a result of all of these factors, a wide range of stand-up times can be expected even for drifts of the same size and age. Therefore, the only reliable method to predict the remaining stand-up time for an excavation at present is to closely monitor that excavation.

\section{Assessment of SPDV Room 1 Behavior}

All rooms at the facility level with the roof below clay $G$ and the floor above clay E should perform similarly, the main difference being the time required to form fracture zones. The roof of excavations of that configuration deforms primarily by horizontal compression. Vertical creep in the roof and stress concentrations near the corners of the excavations weaken the ends of the roof beam, and fractures form preferentially in these zones of weakness. How fast the fractures form depends on the intensity of the stresses around the excavation and the strength of the roof beam. Stress intensity depends primarily on the geometry and size of the excavation and on the proximity of nearby excavations. Roof 
beam strength depends primarily on the material properties of the rock, the dimensions of the roof beam, the strain in the roof beam, and the shape of the deformed roof beam. Sagging or buckled roof beams would be much weaker than flatter beams due to the introduction of additional bending moments.

From the beginning, displacement rates in the roof of SPDV Room 1 were higher than in the other SPDV Rooms (see Figure 3-7). This means that either the stress concentration in the roof of SPDV Room 1 was unusually high or the strength of the roof beam was unusually low, compared to the other SPDV Rooms. This led to faster fracture development in the roof of Room 1. Bands of weakness formed on both sides of the roof near the ribs due to differential vertical displacement (creep) rates along the roof and to the concentration of stresses in the corners. The roof was in horizontal compression from the beginning, and the zones of weakness at the ends of the roof beam continued to grow as strain accumulated.

In early 1986 , the clay $G$ bay strain (separation) rates of the roof extensometers in Room 1 increased over a three or four month period (see Figure 3-3), indicating a significant change in loading or strength of the roof beam at that time. It is postulated that the increase resulted from the formation of a fairly consistent fracture or band of fractures on the east side of the roof beam. This effectively turned the roof beam into a cantilever relatively fixed on the west side and relatively free on the fractured east side. Exactly why the east side fractured first is not apparent. It does not appear to be related to the excavation sequence of the room or the panel of rooms. 
Other evidence for the formation of a cantilevered beam is found in the distribution of the clay seam bay strains, the roof-to-floor convergence rates, and the borehole fracture data. The clay seam bay strains (Figure 3-3) are higher at the center and the west side, which is consistent with the cantilevered section bending down into the excavation. The convergence rates (Figure 3-5) are higher on the east side which is consistent with the free end of the cantilever moving down faster than the middle or the fixed end. Finally, the borehole horizontal offset data show the center of the roof beam moving in the same direction as the fixed end of the cantilever, but in the opposite direction of the free end (Figure 3-2). This is consistent with the cantilevered part of the roof beam moving as one piece to the east and the stub on the east side of the roof beam moving slightly to the west.

This situation continued with fairly steady clay seam bay strain rates and only slightly increasing closure rates until early 1988, when the bay strain rates and closure rates again increased. It is postulated that this increase was caused by the development of another set of fractures on the west side of the roof beam. In other words, the cantilever broke at the formerly fixed end. This may be due to a combination of tensile stresses and the pre-existing band of weakness (Figure 310). The tensile stresses could be induced in the fixed end in several ways such as by deflection of the cantilever due to gravity or by the free end of the cantilever being forced downward on the old shear fracture on the east side by horizontal movement. It is likely that both sides of the roof beam formed bands of weakness well before the first major fracturing occurred. The tension induced in the roof beam by the deflecting cantilever probably combined with fractures and weaknesses formed previously. The fractures thus formed on both sides of 
the roof beam produced a wedge shaped slab primarily supported at the north and south ends.

Beginning with the formation of the wedge, and ending with the roof fall, convergence rates accelerated. It is likely that the wedge first formed in a small area or in several small unconnected areas. As the roof continued to deform, the length of the wedge (along the length of the room) grew, and the independent wedges connected. As the total length of the wedge grew, so did its weight, which put an increasing burden on what little support romained. Both the strain undergone by the supporting rock as well as its reduced confinement undoubtedly lowered the roof strength. This led to ever-increasing convergence rates (Figure 3-7). After the wedge formed, the deformation and continued fracturing of the wedge was due almost entirely to dead-weight gravity loading. It was then essentially acting independently from the stress field around the excavation as a whole. This is consistent with the lack of any measurable changes in creep rates at locations outside SPDV Room 1. For example, the extensometer and convergence points in the intersection of Room 1 and $\mathrm{N} 1420$ show no signs of the roof fall that occurred about forty feet away (Figure 3-11). This is solid evidence that gravity forces on the semi-detached wedge drove the final failure, and that properly installed ground support would prevent or significantly delay a similar roof fall.

\section{SPDV Rooms 3 and 4}

It is believed that the same deformation mechanisms which act on SPDV Rooms 1 and 2 are acting on SPDV Rooms 3 and 4 . SPDV Rooms 3 and 4 both exhibit similar deformation patterns as SPDV Rooms 1 and 2. Differences in 
performance between the four SPDV Rooms can be attributed to local stratigraphic changes, relative location in the panel, and excavation sequence.

SPDV Room 3 was barricaded in June of 1990. Because there was no remotely read instrumentation in SPDV Room 3 at that time, the behavior of the room over the last three years is unknown. However, fracturing in the north end of SPDV Room 3 was well developed. Ground probing radar images of the roof taken shortly before the room was barricaded showed a well developed wedge-shaped slab similar to SPDV Room 1. Although data from SPDV Room 3 is limited, conditions in the north end of the room may have been worse than in SPDV Room 2. The north end of SPDV Room 3 was rockbolted with ten foot bolts before it was closed. It is possible that the bolts have extended the life of the room by supporting the slab.

SPDV Room 4 is the only SPDV Room that is currently accessible. Although the deformation patterns are the same, fracturing is not well developed and convergence rates are relatively low in SPDV Room 4. SPDV Room 4 is also rockbolted with ten foot bolts. For these reasons it is believed that the useful life of SPDV Room 4 will be much longer than the other SPDV Rooms. With proper maintenance, the life of SPDV Room 4, or any WIPP excavation, could be extended indefinitely.

\section{The Effect of Rockbolts}

Stand up time of detaching roof slabs depends heavily on the ability to support or suspend their ever increasing weight. That ability can be enhanced significantly by properly installed roof support systems. Roofbolts can be expected to significantly reduce the extension and widening of fractures caused 
by the weight of the slab. The event of January 1988 in Room 1 was interpreted to have been the joining of fractures from both ribs to clay $G$, forming a detached wedge. It is likely that much of the increased displacement that occurred after January 1988 was due to the dilation of existing fractures caused by the dead weight of the slab. Depending on the type and installation pattern, roofbolts may have been able to slow or stop this later deterioration of the roof beam. The added stand-up time due to bolts would be determined by the deformation limits of the bolts. While bolts may restrict (or prevent) some fracture development, there is no evidence that they can impede creep displacements. 


\section{PLAN FOR PREDICTION OF FUTURE ROOF FALLS}

Previous sections discuss the deformation of excavations at WIPP in general and of SPDV Rooms 1 and 2 in particular, and how these deformations can lead to a roof fall. The best current method for estimating the remaining stand-up time of an excavation is monitoring instrumentation. This section discusses the types of instruments required and the methods to detect and monitor potentially unstable ground and to predict a roof fall.

\section{A. Instrumentation Requirements}

Instrument arrays in an excavation aid in prediction of the stand-up time by establishing the degree and rate of roof deterioration. The recommended optimal instrumentation package is:

- Multiple point borehcle extensometers (MPBX) installed at the center and quarter span points in the roof with anchors set immediately above and below clay seams.

- Vertical convergence stations at the center and quarter span points.

- Horizontal convergence station at the mid-height of the rib.

- Load cells on selected roof́bolts.

- Observation boreholes located near the MPBX holes with shear strips or similar instrumentation to monitor fracture formation.

All instruments should be remotely read to allow continued monitoring if access is restricted. This complete instrument package should be installed in areas that preliminary inspections have identified as potentially unstable (see next Section for procedure). It is assumed that appropriate ground support will be installed in addition to the instrumentation. A remote control vehicle capable of entering a 
closed area and of carrying cameras, portable convergence meters, radar antennae, etc., would be most useful.

The instrumentation in SPDV Room 2 falls far short of this ideal package. The instrumentation in Panel 1, Room 1, however, exceeds the optimal instrumentation package even though the excavation is currently stable. In fact, there are rock bolt load cells on all the one-inch diameter bolts (over 280 total), eight convergence stations, three roof extensometers, and three observation borehole arrays (fifteen boreholes) in Room 1. In addition to the instrumentation, the roof support system in Room 1, Panel 1, is unique in that it was designed to control a wedge-shaped roof slab identical to the slab that fell in SPDV Room 1. Should a large slab develop in Room 1, Panel 1, it would be detected long before it becomes detached, at which point it would be controlled by the roof support system. For this reason, the stability of the roof in Panel 1 , Room 1 , is not a concern, although it is intensely monitored.

\section{B. Procedure for Detecting and Monitoring Potential Roof Falls}

Because the main variables in the stand-up time of WIPP excavations, rock strength and loading, are extremely difficult to measure and are probably impossible to accurately determine analytically, the prediction of stand-up time for a given opening is a formidable task. Determining the roof beam strength at a specific location probably requires such detailed and extensive field information and laboratory testing that it would be difficult if not impossible to collect. The exact types, amount, and distribution of data and rock samples required are not known. Currently, installation and monitoring of the proper instrumentation is the best method available to assess remaining stand-up time. 
The general procedure is as follows:

1. Install a baseline array of vertical convergence gauges, at center and quarter spans.

2. Establish baseline rates.

3. Use baseline rates with field observations of fracturing to identify areas of concern requiring closer study.

4. Increase the reading frequency of the baseline gauges and other observations for the areas of concern.

5. If further analyses indicate decreasing stability, install the optimal instrumentation package suggested above at the most appropriate location.

6. Use data trends to estimate and refine the remaining stand-up time.

Regular inspections of ground conditions by operations and engineering personnel supplement the instrument data. Appropriate ground support will, of course, be installed in any areas suspected of instability. The deformation rates in SPDV Room 1 began increasing more than two years before the ground conditions became bad enough to warrant abandoning the room and almost four years before it fell. This long lead time (which is typical of salt) is more than enough tc allow detection and assessment of roof instabilities under the procedure outlined above. There would also be sufficient time to install rockbolts or other support and to assess its effectiveness. Because roofbolts may delay the final stages of failure, the time period between detection of instability and a roof fall could be extended by bolting.

\section{Prediction for SPDV Room 2}

SPDV Room 2 is the only monitored excavation at WIPP that is displaying signs of instability. New data from Room 2 are currently limited to vertical 
convergence gauges. Visual observations are extremely limited because the room is barricaded with fly ash blocks. Because no additional data can be obtained from Room 2, prediction of the remaining stand-up time must be based on the vertical convergence rate alone. Prediction using only these data is much more difficult than that using the data provided by the optimal instrumentation package.

Vertical convergence rates in SPDV Room 2 are accelerating slowly, with current maxima of over six inches per year. The convergence rates are not accelerating fast enough to achieve reasonable mathematical regression analysis results (Figure 3-7). Therefore, curve fitting at this time is limited to fitting by hand and obtaining a rough range of dates for the expected roof fall. At this time, it appears that a large roof fall (l.e., similar to that of SPDV Room 1) will occur between October 1993 and July 1995, with the highest likelihood in April 1994. These dates were obtained as follows:

1. The convergence rate data for SPDV Rooms 1 and 2 were plotted to the same scale (Figure 3-12).

2. Curves were fitted by hand to the SPDV Room 1 data.

3. Similar curves were fitted to the SPDV Room 2 data.

4. The date at which the curve fitted to the Room 2 data becomes vertical is the estimated date of the roof fall in Room 2.

5. High and low extremes are determined by fitting similar curves using the scatter in the rate data.

The convergence meter in SPDV Room 2 with the highest convergence rate was used for this analysis. This meter is located about 75 feet from the south end of 
the room, near the west rib. By this method, the roof fall is unlikely to occur before October 1993, but it could also happen well after April 1995. As time passes and the convergence rate pattern becomes clearer, curve fitting, both by hand and by regression analysis, will become more precise, and the range of dates of the prediction will narrow.

Another method consists of determining the dates when conditions in SPDV Room 1 were similar to the conditions in SPDV Room 2. Again using vertical convergence rate data from both rooms, the convergence rate in Room 1 was equal to the current convergence rate in Room 2, between four and five inches per year, between nine and 21 months before the roof fell, with twelve months most likely (Figure 3-7). This would place the Room 2 roof fall between January 1994 and January 1995, with April 1994 most likely. This is fairly consistent with the curve fitting results.

Using only fracture data from the Excavation Effects Program arrays at the center of both rooms, it appears that the state of fracturing in Room 2 in 1989 was similar to the state of fracturing in Room 1 in 1987 (Figure 3-13). The fractures in Room 2 have not been mapped since the room was closed four years ago. This subjective method suggests that in 1989 Room 2 was at least two years behind Room 1 in terms of fracture intensity, leading to the conclusion that the Room 2 roof would fall no sooner than two years after Room 1, i.e., in early 1993. However, as stated previously, deformations and fracturing in Room 2 have been slower than in Room 1 since the very beginning. Assuming that Room 2 will be at least eleven years old when the roof falls, and knowing that Room 1 was eight years old when it fell, it is not unreasonable to estimate that the roof in Room 2 is failing about $75 \%$ as fast as Room 1 . This would add 
about nine months to the fracturing-based prediction, indicating that the Room 2 roof will fall in early November 1993.

Changes take place slowly and as the time of the roof fall approaches, the prediction quality will improve and the range of dates will narrow. A major roof fall in SPDV Room 2 or in any other excavation in the facility level at WIPP will not occur abruptly. There will be months or years of warning from the geotechnical instrument data, which are watched carefully for signs of instability or other signs such as visual effects or bolt failures. Instrumentation and visual observations indicate that the access drifts to the SPDV panel are quite stable. As was shown earlier, the instrumentation immediately adjacent to SPDV Room 1 showed no effects of the roof fall. This indicates that, unless indications of instability develop in the access drifts themselves, there is no danger of roof collapse in an access drift due to instability in an adjacent room.

\section{Prediction for Other Excavations}

There are other excavations that may have approaching roof falls but which at present are inaccessible, not instrumented, or not observable. These include SPDV Room 3, the E140 drift south of S2180, Room B, the three A rooms, and the alcoves off Panel 1. Just as SPDV Room 2, these areas are all prohibited zones and pose no danger to personnel or equipment. These areas may be backfilled or otherwise remediated before a roof fall occurs.

\section{E. Recommendations}

As a result of this study, the following recommendations are made concerning the stability of the underground excavations. 
Safety. No safety precautions beyond those currently in effect need be taken at present regarding a potential roof fall in SPDV Room 2. The room will continue to be monitored and, if conditions change, appropriate recommendations for safety precautions will then be made. Other areas of the mine to which personnel have access are continually monitored. While the roofs in some locations are well fractured, no areas are presently suspected of being prone to a short-term roof fall.

Prediction. Roof fall prediction is difficult and is highly dependent on the amount and the quality of information that can be obtained from the excavations. The general procedure should be implemented as a standard practice. SPDV Room 2 will most likely fall about April 1994. This collapse is most likely during the period October 1993 to April 1995. This prediction will be reviewed and revised regularly.

Remote Entry Vehicle. A remotely controlled vehicle capable of entering areas deemed unsafe for personnel would allow continued collection of fracture and other information after a room is closed but before a roof fall occurs. For SPDV Room 2, the prediction is partially based on fracture data collected four years ago. A vehicle that could carry video, borehole cameras, radar or other equipment and that could install geomechanical instruments in the room would vastly increase the ability to understand what is going on in inaccessible areas. This would in turn improve the ability to predict future behavior in all excavations.

Improved Numerical Modeling Capabilities. There are no numerical models available at this time capable of explicitly modeling fracture development around 
excavations in salt, although research in this area is underway (Chan et al., 1992). The addition of fracture or failure criteria to models used at WIPP would improve both the modeling results and their predictive capability. This is a large and difficult task but one that would have safety and operational benefits.

Roofbolting Support. A further study of deformation mechanisms and in situ roofbolt behavior may identify means for significantly improved support system performance. The timing and pattern of bolting could be optimized so that support system efficiency is maximized and repair and renovation work is minimized.

Roofbolt Testing. Except for SPDV Room 2, the south end of SPDV Room 3, and the far south end of E140, all other drifts at WIPP are rockbolted. It is of significant cost and performance benefit to evaluate the effect of rockbolts on the failure process in the roof. Additional rockbolt testing programs should be developed that are geared towards quantifying the behavior of bolts in fractured ground. This testing could also optimize roof support design and time of installation.

Instrument Design. As the understanding of the failure process in the roof of WIPP excavations grows, so does the need for more specific information about how the roof is deformed, loaded, and failed. New geomechanical instruments (both to the project and perhaps to the industry) may need to be developed to aid in the precise assessment of ground conditions at the WIPP.

Room 1. Panel 1. The ground support system installed in Room 1 will safely suspend a large wedge-shaped slab similar to SPDV Room 1. The 
geomechanical instrumentation installed in Room 1, Panel 1, will provide months to years of advance warning. Convergence rates in Room 1, Panel 1, are declining and there are no indications of instability. 


\section{REFERENCES}

Brady, B.H.G., and E.T. Brown, 1993, Rock Mechanics for underground mining, 2nd Edition, Chapman \& Hall, London.

Chan, K.S., S.R. Bodner, A.F. Fossom, and D.E. Munson, 1992, "A constitutive model for inelastic flow and damage evolution in solids under triaxial compression," Mechanics of Materials Vol. 14, Elsevier.

Munson, Darrell E., Arlo F. Fossum, and Paul E. Senseny, 1989, Advances in Resolution of Discrepancies Between Predicted and Measured In Situ WIPP Room Closures, SAND88-2948, Sandia National Laboratories, Albuquerque, New Mexico. 


\section{EXTENSOMETERS}

\begin{tabular}{|c|c|c|c|c|}
\hline Fieldtag & Location & $\begin{array}{l}\text { Date of } \\
\text { Initial } \\
\text { Reading }\end{array}$ & $\begin{array}{l}\text { Date of } \\
\text { Last } \\
\text { Reading }\end{array}$ & Comments \\
\hline $51 \times$ GE-00217 & TEST ROOM 1/E RIB & 13-Apr-83 & 12-Jul-90 & INSTRUMENT MALFUNCTION \\
\hline $51 \times$ GE-00218 & TEST ROOM 1/ROOF & 14-Apr-83 & 28-Feb-89 & NO READING \\
\hline $51 \times$ GE-00219 & TEST ROOM $1 \mathrm{~W}$ RIB & 15-Apr-83 & 24-Jun-91 & INSTRUMENT MALFUNCTION \\
\hline $51 \times$ GE-00269 & TEST ROOM 1/FLOOR & 21-Jan-86 & 24-Apr-90 & INSTRUMENT MALFUNCTION \\
\hline $51 \times$ GE-00213 & TEST ROOM 2/E RIB & 17-Mar-83 & 28-Apr-89 & ANCHOR SLIPPAGE LIKELY (NO READING) \\
\hline $51 \times$ GE-00214 & TEST ROOM 2/ROOF & 22-Mar-83 & 28-Apr-89 & ANCHOR SLIPPAGE LIKELY (NO READING) \\
\hline $51 X$ GE-00215 & TEST ROOM $2 / W$ RIB & 22-Mar-83 & 29-Dec-88 & INSTRUMENT MALFUNCTION \\
\hline $51 \times$ GE-00216 & TEST ROOM 2/FLOOR & 28-Mar-83 & 26-Dec-85 & RODS BROKEN-PEPLACED BY $51 X$ GE-00270 \\
\hline & OOM 2/FLOOR & 21-Jan- 36 & 28-Feb-89 & SLIPPAGE LIKELY \\
\hline
\end{tabular}

\section{CONVERGENCE POINTS}

\begin{tabular}{|c|c|c|c|c|}
\hline Fieldtag & Location & $\begin{array}{l}\text { Date of } \\
\text { Initial } \\
\text { Reading }\end{array}$ & $\begin{array}{l}\text { Date of } \\
\text { Last } \\
\text { Reading }\end{array}$ & Comments \\
\hline TR1 B-D & TEST ROOM 1/MIDPOINT & $20-A p r-83$ & 21-Jun-89 & NOT ACCESSIBLE \\
\hline IG215-216-RS & TEST ROOM V/E RIB & 27-Apr-83 & 13-Mar-89 & " \\
\hline TR1-2 A.C & TEST ROOM 1/MIDPOINT & 06-Sep-88 & 23-Aug-89 & " \\
\hline TR1-2 E-F & & $06-S e p-88$ & 23-Aug-89 & $"$ \\
\hline TR2 B-D & TEST ROOM $2 / M I D P O I N T$ & 23-Mar-83 & 31-Mar-83 & MINED OUT-REPLACED BY TR:B-D-2 \\
\hline TR2-2 B-D & & 12-Jul-83 & 03-Oct-89 & NOT ACCESSIBLE \\
\hline IG211-212-RS & TEST ROOM 2/E RIB & 05-Apr-83 & 13-Mar-89 & " \\
\hline IG213-214-RS & TEST ROOM 2 W RIB & 05-Apr-83 & 13-Mar-89 & $"$ \\
\hline IG211-213-TC & TEST ROOM $2 / 1^{\prime}$ BELOW ROOF & 28-Nov-83 & 03-Mar-89 & " \\
\hline IG212-214-TC & TEST ROOM 2/1' ABOVE FLOOR & 28-Nov-83 & 07-Dec-88 & $"$ \\
\hline TR2-3 A-C & & 28-Nov-88 & 03-Apr-89 & $"$ \\
\hline TR2-3 E-F & $n$ & 28-Nov-88 & 03-Apr-89 & $n$ \\
\hline TR2-N1137 A-D & TEST ROOM 2/N1137 & 05-Dec-88 & 24-Aug-89 & $"$ \\
\hline TR2-N1137 B-C & & 05-Dec-88 & 03-Oct-89 & $"$ \\
\hline TR2-N1137 E-F & " & 05-Dec-88 & 03-Oct-89 & $"$ \\
\hline TR2-N1137 G-H & " & 14-Feb-89 & 03-Oct-89 & " \\
\hline TR2-N1175 A-D & TEST ROOM 2/N1175 & 05-Dec-88 & 25-Aug-89 & $"$ \\
\hline TR2-N1175 B-C & & 05-Dec-88 & 25-Aug-89 & $"$ \\
\hline TR2-N1175 E-F & " & 05-Dec-88 & 25-Aug-89 & " \\
\hline TR2-N1175 L-M & $"$ & 14-Feb-89 & 03-Oct-89 & $"$ \\
\hline TR2-N1212 A-D & TEST ROOM $2 / \mathrm{N} 1212$ & 05-Dec-88 & 25-Aug-89 & $"$ \\
\hline TR2-N1212 B-C & & 05-Dec-88 & $03-0 c t-89$ & " \\
\hline TR2-N1212 E-F & " & 05-Dec-88 & $03-0 c t-89$ & $"$ \\
\hline TR2-N1212 G-H & $"$ & 14-Feb-89 & 03-Oct-89 & $"$ \\
\hline TR2-N1287 A-D & TEST ROOM 2/N1287 & $29-$ Nov-88 & 23-Aug-89 & $"$ \\
\hline TR2-N1287 B-C & & $29-N o v-88$ & 23-Aug-89 & $"$ \\
\hline TR2-N1287 E-F & $"$ & $29-$ Nov-88 & 23-Aug-89 & $"$ \\
\hline TR2-N1287 G-H & $"$ & 14-Feb-89 & 23-Aug-89 & $"$ \\
\hline TR2-N1325 A-D & TEST ROOM 2/N1325 & $29-N o v-88$ & 23-Aug-89 & " \\
\hline TR2-N1325 B-C & & $29-$ Nov-88 & 23-Aug-89 & $"$ \\
\hline TR2-N1325 E-F & $"$ & $29-N o v-88$ & 23-Aug-89 & " \\
\hline TR2-N1325 L-M & " & 14-Feb-89 & 03-Oct-89 & " \\
\hline TR2-N1362 A-D & TEST ROOM 2/N1362 & $29-$ Nov-88 & 23-Aug-89 & " \\
\hline TR2-N1362 B-C & & 29 Nov-88 & 03-Oct-89 & $"$ \\
\hline TR2-N1362 E-F & $"$ & $29-$ Nov-88 & 03-Oct-89 & $"$ \\
\hline TR2-N1362 G.H & $"$ & 14-Feb-89 & $03-O c t-89$ & $"$ \\
\hline
\end{tabular}

TABLE 3-1

INSTRUMENTATION SUMMARY

SPDV ROOMS 1 AND 2

Sheet 1 of 2 
INCLINOMETERS

\begin{tabular}{|c|c|c|c|c|}
\hline Fieldtag & Location & $\begin{array}{l}\text { Date of } \\
\text { Initial } \\
\text { Reading }\end{array}$ & $\begin{array}{l}\text { Date of } \\
\text { Last } \\
\text { Reading }\end{array}$ & Comments \\
\hline $\begin{array}{l}51 \times 1 G-00211 \\
51 \times \mid G-00213 \\
51 \times 1 G-00214 \\
\end{array}$ & $\begin{array}{l}\text { ROOM 2-E RIB/1' FROM ROOF } \\
\text { ROOM 2-W RIB/1' FROM ROOF } \\
\text { ROOM 2-W RIB/1' FROM FLOOR }\end{array}$ & $\begin{array}{l}\text { 05-Apr-83 } \\
\text { 05-Apr-83 } \\
\text { 05-Apr-83 }\end{array}$ & $\begin{array}{l}30-J u n-89 \\
30-J u n-89 \\
30-J u n-89 \\
\end{array}$ & $\begin{array}{l}\text { NOT ACCESSIBLE } \\
" n \\
\end{array}$ \\
\hline
\end{tabular}

\section{CONVERGENCE METERS}

\begin{tabular}{|l|l|l|l|l|}
\hline & & $\begin{array}{l}\text { Date of } \\
\text { Initial } \\
\text { Reading }\end{array}$ & $\begin{array}{l}\text { Date of } \\
\text { Last } \\
\text { Reading }\end{array}$ & Comments \\
\hline 51 C CE-00202 & Location & ROOM 1/CENTERLINE & $20-A p r-83$ & $10-$ Sep-90 \\
$51 \times$ CE-00201 & ROOM 2/CENTERLINE & NO LONGER FUNCTIONING \\
\hline
\end{tabular}

\section{STRESS METERS}

\begin{tabular}{|l|l|l|l|l|}
\hline & & $\begin{array}{l}\text { Date of } \\
\text { Initial } \\
\text { Reading }\end{array}$ & $\begin{array}{l}\text { Date of } \\
\text { Last } \\
\text { Reading }\end{array}$ & Comments \\
\hline 51 X NG-00255 & Location & ROOM 2N RIB-FLOOR & 10-May-84 & 17-Mar-89 \\
51X NG-00256 & ROOM 2/CENTER FLOOR & NOT ACCESSIBLE \\
\hline
\end{tabular}

\section{WIRE CONVERGENCE METERS}

\begin{tabular}{|c|c|c|c|c|}
\hline Fieldtag & Location & $\begin{array}{l}\text { Date of } \\
\text { Initial } \\
\text { Reading }\end{array}$ & $\begin{array}{l}\text { Date of } \\
\text { Last } \\
\text { Reading }\end{array}$ & Comments \\
\hline $51 \times C W-00001$ & ROOM $1 / 175^{\prime}$ N OF N1100 & 11-Aug-89 & 04-Feb-91 & DESTROYED BY ROCKFALL (02/91) \\
\hline $51 \times C W-00002$ & ROOM $1 / 182.5^{\prime}$ N OF $N 1100$ & 11 -Aug-89 & 04-Feb-91 & DESTROYED BY ROCKFALL (02/91) \\
\hline $51 \times C W-00003$ & ROOM 1/195' N OF N 1100 & 11-Aug-89 & 04-Feb-91 & DESTROYED BY ROCKFALL (02/91) \\
\hline $51 \times C W-00004$ & ROOM $1 / 207.5^{\prime}$ N OF $N 1100$ & 11-Aug-89 & 04-Feb-91 & DESTROYED BY ROCKFALL (02/91) \\
\hline $51 \times C W-00005$ & ROOM $2 / 37.5^{\prime}$ N OF $N 1100$ & 22-Sep-89 & 03-May-93 & FUNCTIONING \\
\hline $51 \times C W-00006$ & ROOM $2 / 75^{\prime} N$ OF N1100 E RIB & 25-Aug-89 & 03-May-93 & FUNCTIONING \\
\hline $51 \times C W-00007$ & ROOM $2 / 75$ 'N OF N1100 & 25-Aug-89 & 03-May-93 & FUNCTIONING \\
\hline $51 \times C W-00008$ & ROOM $2 / 75$ 'N OF N1100 W RIB & 25-Aug-89 & 03-Мау-93 & FUNCTIONING \\
\hline $51 \times C W-00009$ & ROOM 2/112.5' N OF N1100 & 25-Aug-89 & 03-May-93 & FUNCTIONING \\
\hline $51 \times C W-00010$ & ROOM $2 / 150$ 'N OF N1100 E RIB & 22-Sep-89 & $03-$ May-93 & FUNCTIONING \\
\hline $51 \times \mathrm{CW}-00011$ & ROOM $2 / 150$ 'N OF N1100 W RIB & 24-Aug-89 & 03-Маy-93 & FUNCTIONING \\
\hline $51 \times C W-00012$ & ROOM $2 / 187.5^{\prime}$ N OF $N 1100$ & 24-Aug-89 & 03-May-93 & FUNCTIONING \\
\hline $51 \times C W-00013$ & ROOM 2/225'N OF N1100 E RIB & 24-Aug-89 & 03-May-93 & FUNCTIONING \\
\hline $51 \times C W-00014$ & ROOM $2 / 225^{\prime}$ N OF $N 1100$ & 24-Aug-89 & 03-May-93 & FUNCTIONING \\
\hline $51 \times C W-00015$ & ROOM $2 / 225^{\prime} N$ OF N 1100 W RIB & 24-Aug-89 & 03-May-93 & FUNCTIONING \\
\hline $51 \times C W-00016$ & ROOM 2/262.5' N OF N1100 & 24-Aug-89 & 03-May-93 & FUNCTIONING \\
\hline
\end{tabular}

TABLE 3-1

INSTRUMENTATION SUMMARY SPDV ROOMS 1 AND 2

Sheet 2 of 2 


\begin{tabular}{|c|c|c|c|c|c|c|c|}
\hline \multirow{2}{*}{ ARRAY } & \multicolumn{2}{|c|}{ HOLEE } & \multicolumn{2}{|c|}{ HOLE A } & \multicolumn{2}{|c|}{ HOLE C } & \multirow[t]{2}{*}{ REMARKS } \\
\hline & $>1-1 / 2 "$ & $\mathbf{R}$ & $1 "$ & $L$ & $1-1 / 2^{\prime \prime}$ & $\mathbf{L}$ & \\
\hline 2 & $>1-7 / 8^{\prime \prime}$ & $\mathbf{R}$ & $3 / 8^{\prime \prime}$ & $\mathbf{L}$ & $>1-7 / 8^{\prime \prime}$ & $L$ & \\
\hline 3 & 2" & $\mathbf{R}$ & 1-1/2" & $L$ & 2" & $\mathbf{L}$ & \\
\hline 4 & $1 / 4^{\prime \prime}$ & $\mathbf{R}$ & 1" & $\mathbf{R}$ & $1-7 / 8^{\prime \prime}$ & $L$ & \\
\hline 5 & no info. & $\mathbf{R}$ & no info. & & no info. & & \\
\hline 6 & $1-3 / 4 "$ & $\mathbf{R}$ & 2" & $\mathbf{L}$ & $1-3 / 4^{\prime \prime}$ & $L$ & 1990 info. \\
\hline 7 & $1-1 / 4^{\prime \prime}$ & $\mathbf{R}$ & $1 / 8^{\prime \prime}$ & $\mathbf{R}$ & $1-1 / 4^{\prime \prime}$ & $L$ & 1989 info. \\
\hline 8 & $1-1 / 4^{\prime \prime}$ & $\mathbf{R}$ & 1" & $\mathbf{L}$ & $1-1 / 2^{\prime \prime}$ & $\mathbf{L}$ & 1989 info. \\
\hline 9 & $1-1 / 2^{\prime \prime}$ & $\mathbf{R}$ & 0 & & $1-3 / 8^{\prime \prime}$ & $\mathbf{L}$ & 1989 info. \\
\hline 10 & $>1-7 / 8^{\prime \prime}$ & $\mathbf{R}$ & $1 "$ & $\mathbf{R}$ & $>-7 / 8 "$ & $\mathbf{L}$ & 1989 info. \\
\hline 11 & $1-1 / 2^{\prime \prime}$ & $\mathbf{R}$ & $1 "$ & $\mathbf{L}$ & $>1-7 / 8^{\prime \prime}$ & $L$ & intersection array \\
\hline 12 & $>1-7 / 8^{\prime \prime}$ & $L$ & $1-1 / 2^{\prime \prime}$ & $\mathbf{L}$ & $>1-7 / 8^{\prime \prime}$ & $L$ & intersection array \\
\hline $13 w$ & no hole & & $>1-7 / 8^{\prime \prime}$ & $\mathbf{R}$ & $>1-7 / 8^{\prime \prime}$ & $L$ & \\
\hline $14 e$ & $1 / 2^{\prime \prime}$ & $\mathbf{R}$ & 0 & & $1-1 / 2^{\prime \prime}$ & $\mathbf{L}$ & \\
\hline 15 & $1-7 / 8^{\prime \prime}$ & $\mathbf{R}$ & $1 / 4^{\prime \prime}$ & $\mathbf{L}$ & $1-5 / 8^{\prime \prime}$ & $\mathbf{L}$ & \\
\hline 16 & $\mathrm{n} / \mathrm{a}$ & & $\mathrm{n} / \mathrm{a}$ & & $n / a$ & & floor only \\
\hline 17 & 0 & & 0 & & 0 & & \\
\hline 18 & $1-1 / 2^{\prime \prime}$ & $\mathbf{R}$ & 0 & & $1-1 / 4^{\prime \prime}$ & $\mathbf{L}$ & clay $H$ \\
\hline 19 & 0 & & 0 & & $\begin{array}{l}1 / 4^{\prime \prime} \\
(1989)\end{array}$ & $\mathbf{L}$ & clay $\mathrm{H}$ \\
\hline 20 & $>1-7 / 8^{\prime \prime}$ & $\mathbf{R}$ & $1 / 4^{\prime \prime}$ & $L$ & 1-1/2" & $\mathbf{L}$ & \\
\hline $21 w$ & $1 "$ & R & 0 & & $3 / 4^{\prime \prime}$ & $\mathbf{L}$ & \\
\hline 22 & $1 / 8^{\prime \prime}$ & $\mathbf{L}$ & $3 / 4^{\prime \prime}$ & $L$ & $3 / 4^{\prime \prime}$ & $L$ & intersection array \\
\hline 23 & $1 / 2^{\prime \prime}$ & $\mathbf{R}$ & 0 & & $1 / 8^{\prime \prime}$ & $\mathbf{L}$ & \\
\hline 24 & $1 / 2^{\prime \prime}$ & $\mathbf{R}$ & 0 & & $3 / 4^{\prime \prime}$ & L & intersection array \\
\hline 25 & $1-7 / 8^{\prime \prime}$ & $\mathbf{R}$ & $1-1 / 4^{\prime \prime}$ & $\mathbf{R}$ & $1-7 / 8^{\prime \prime}$ & $L$ & \\
\hline 26 & $\mathrm{n} / \mathbf{a}$ & & $\mathrm{n} / \mathrm{a}$ & & $n / a$ & & floor only \\
\hline
\end{tabular}

TABLE 3-2

Excavation Effects Program Data Horizontal Offset Distribution

Sheet 1 of 2 


\begin{tabular}{|c|c|c|c|c|c|}
\hline ARRAY & HOLEE & HOLE A & \multicolumn{2}{|c|}{ HOLE C } & REMARKS \\
\hline 27 & $n / a$ & $n / a$ & $n / a$ & & floor only \\
\hline 28 & 1-1/2" & $n / a$ & $1-1 / 4^{\prime \prime}$ & $L$ & \\
\hline 29 & no info. & $\begin{array}{l}\text { lower portion } \\
\text { of hole } \\
\text { pushed in } \\
\text { along clay G } \\
\text { from both } \\
\text { sides }\end{array}$ & $1-7 / 8^{\prime \prime}$ & $L$ & \\
\hline $30 e$ & 0 & no hole & 0 & & clay 1 \\
\hline $31 e$ & $1 / 4^{\prime \prime}$ & 0 & $1 / 4^{\prime \prime}$ & $L$ & clay I \\
\hline 32 & $1 / 4^{\prime \prime}$ & 0 & $1 / 4^{\prime \prime}$ & $\mathbf{L}$ & clay 1 \\
\hline 33 & 0 & 0 & 0 & & clay I \\
\hline 34 & $3 / 8$ & 0 & $1 / 4^{\prime \prime}$ & $\mathrm{L}$ & \\
\hline 35 & 1/4" & 0 & $3 / 8^{\prime \prime}$ & $L$ & \\
\hline 36 & $1 / 4^{\prime \prime}$ & 0 & $1 / 4^{\prime \prime}$ & $L$ & \\
\hline
\end{tabular}

Notes: 1. Offsets occur at clay G unless otherwise noted.

2. Arrays are oriented north unless othenwise noted e (east) or w (west).

3. Holes are arranged as shown below when the viewer is facing the direction

indicated

in 1.

4. $R=$ bottom of hole moved to the right. $L=$ bottom of hole moved to the left.

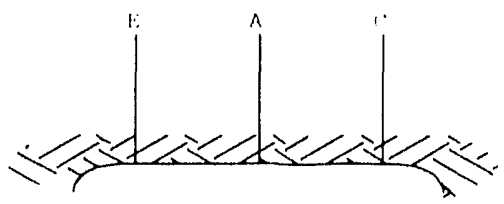

11+1 I.

TABLE 3-2

Excavation Effects Program Data Horizontal Offset Distribution

Sheet 2 of 2 


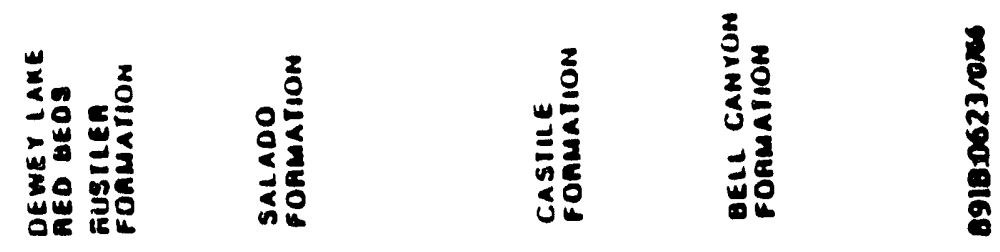

$E$
$\vdots$

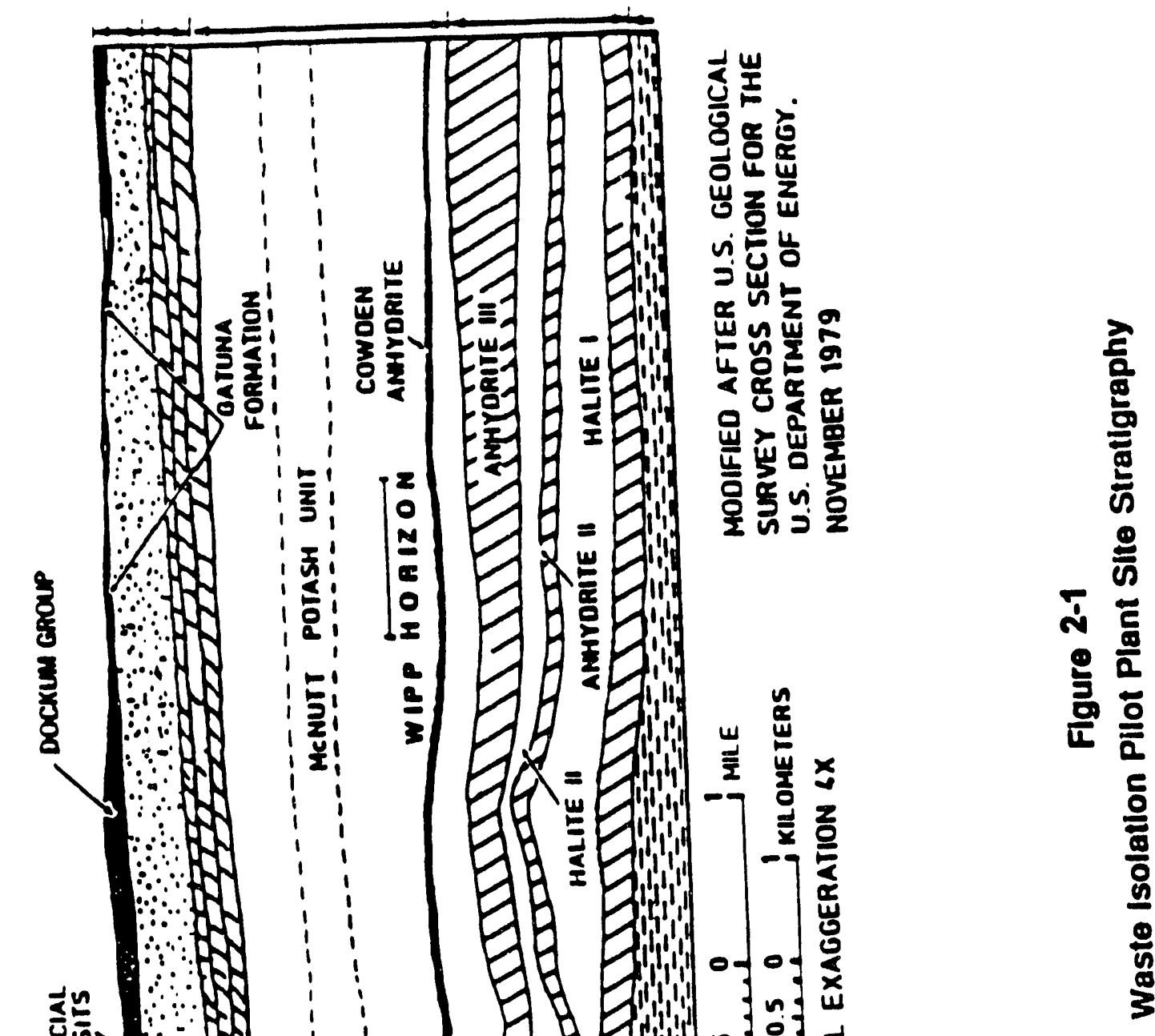

2

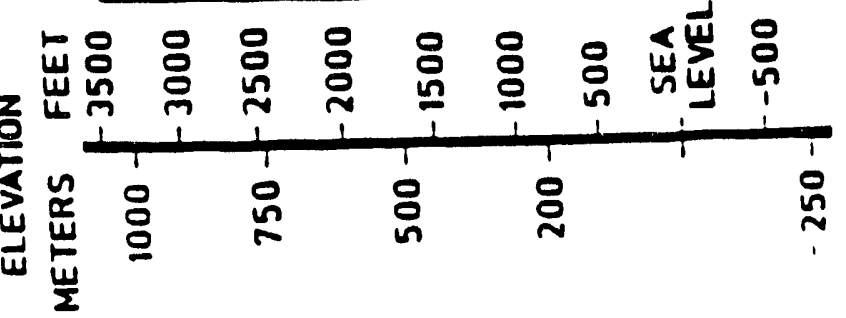




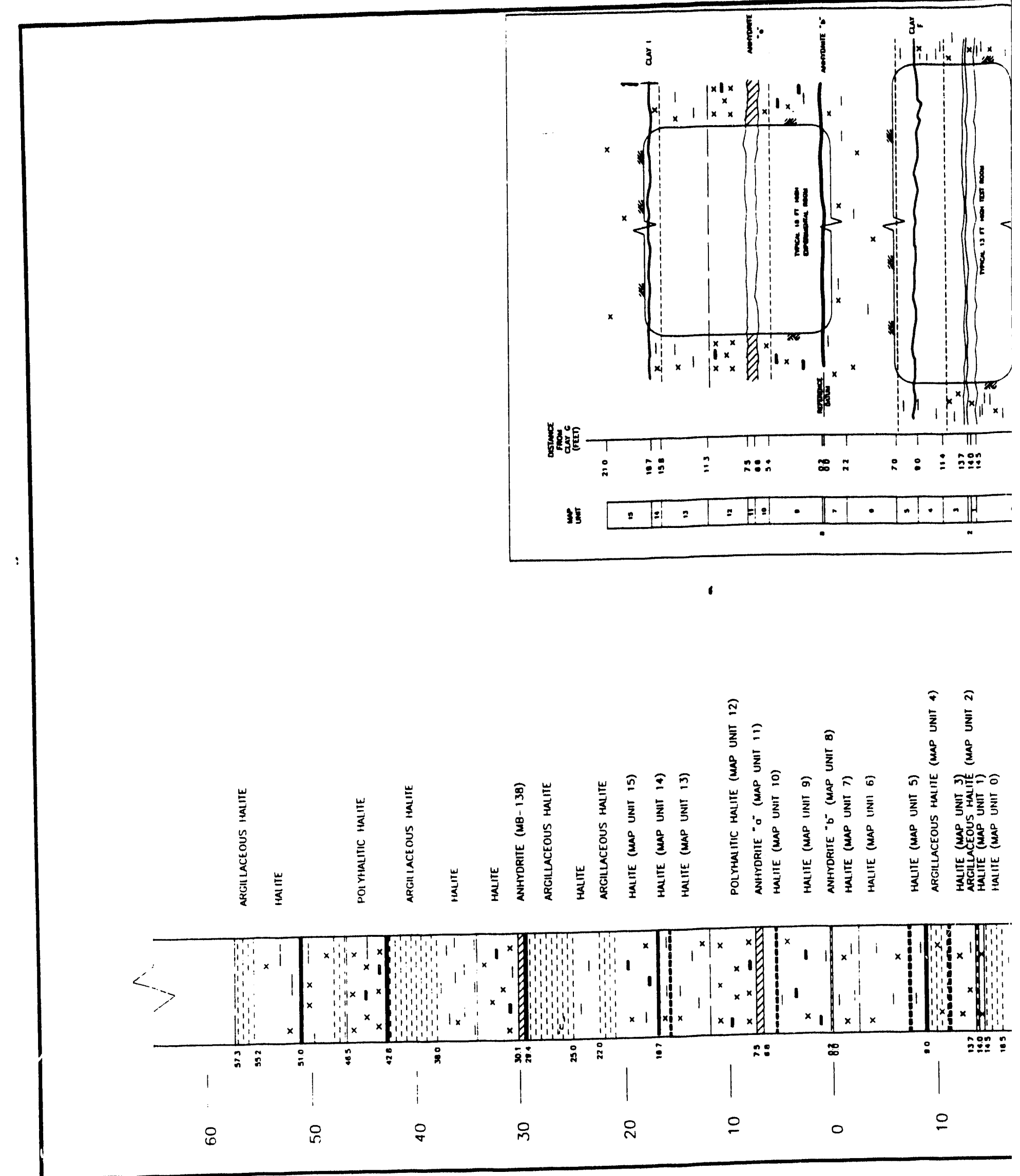




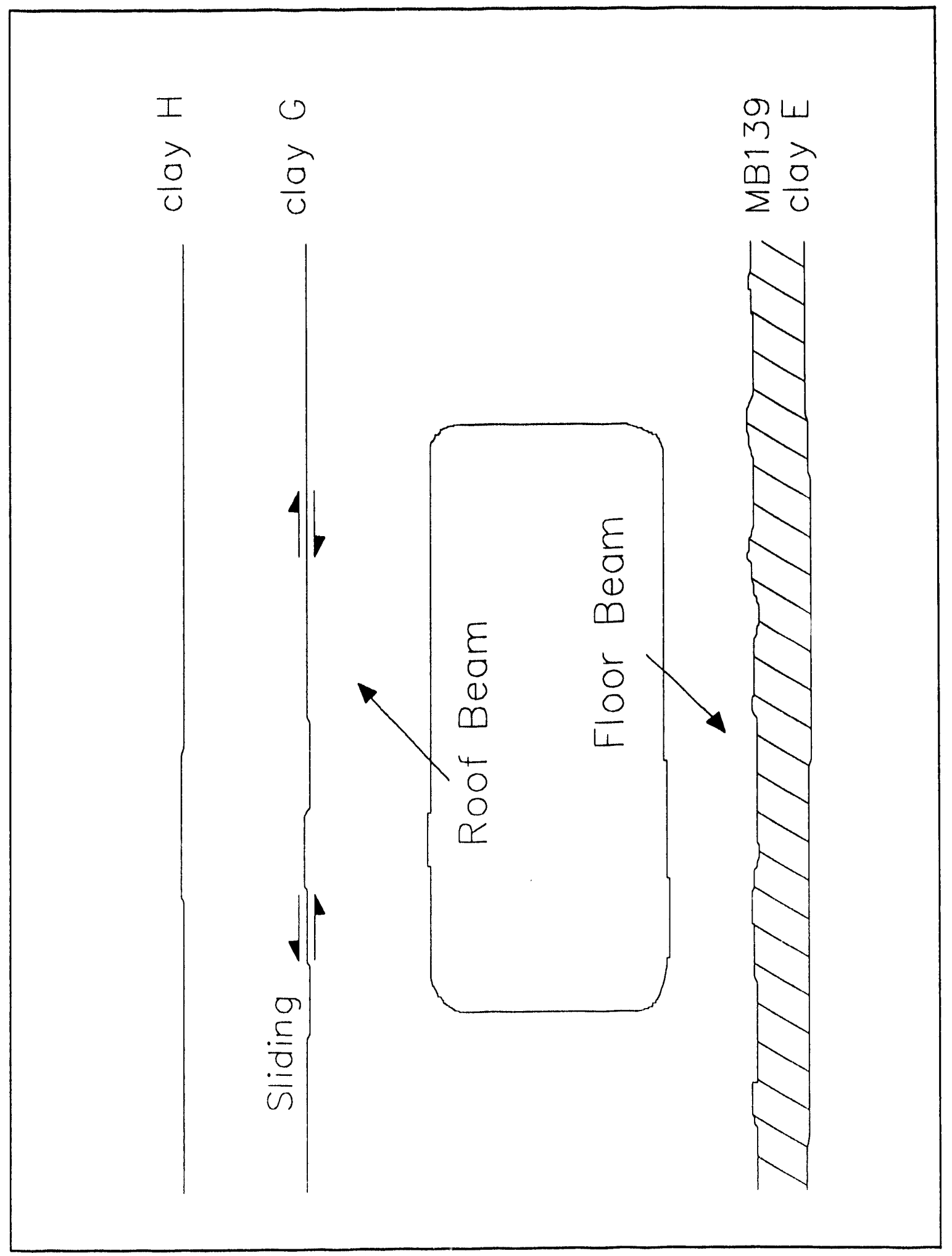

FIGURE 2-3

Formation of a Roof Beam 


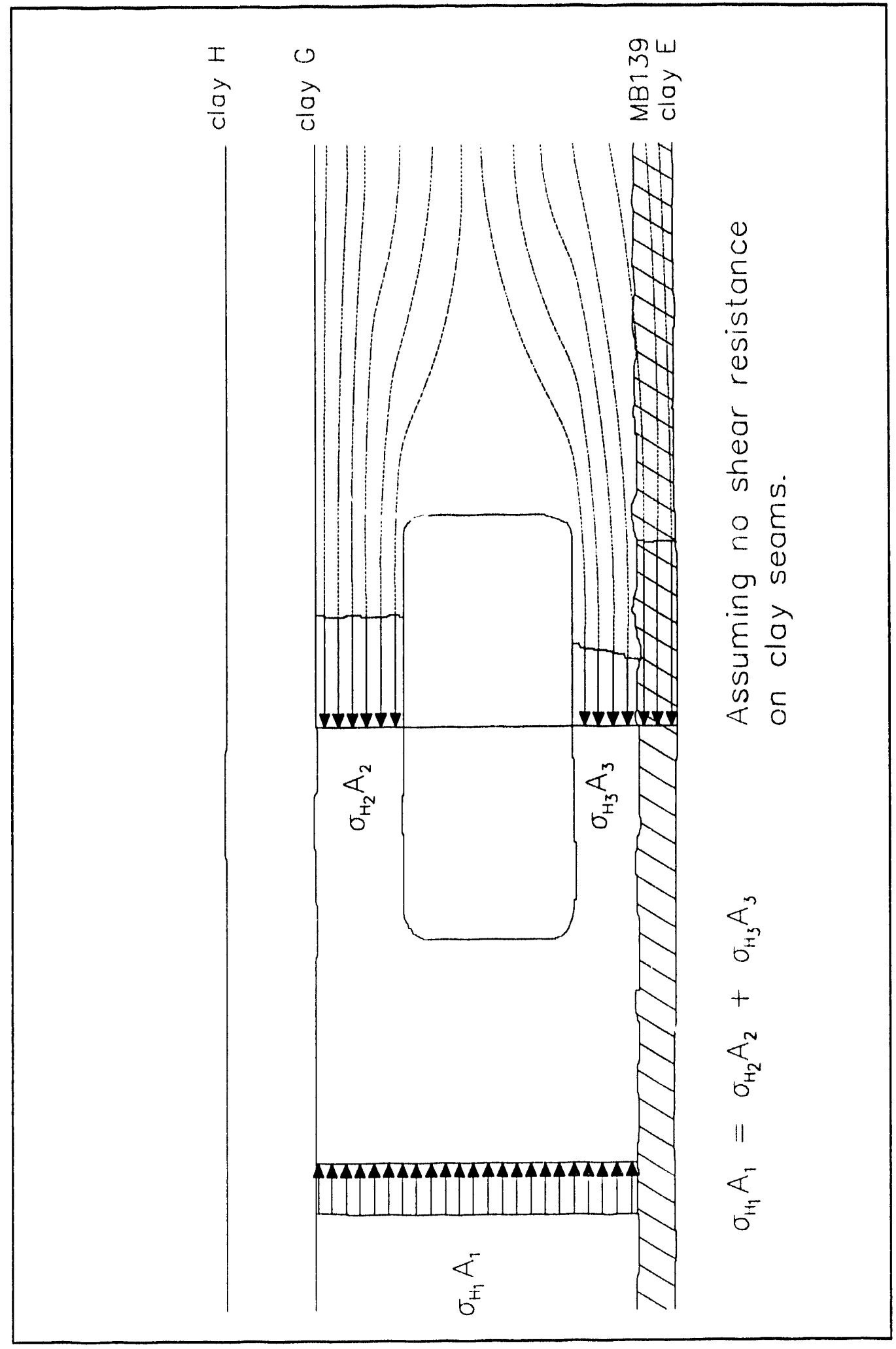

FIGURE 2-4

Concentration of Compressive Stresses in the Roof Beam 


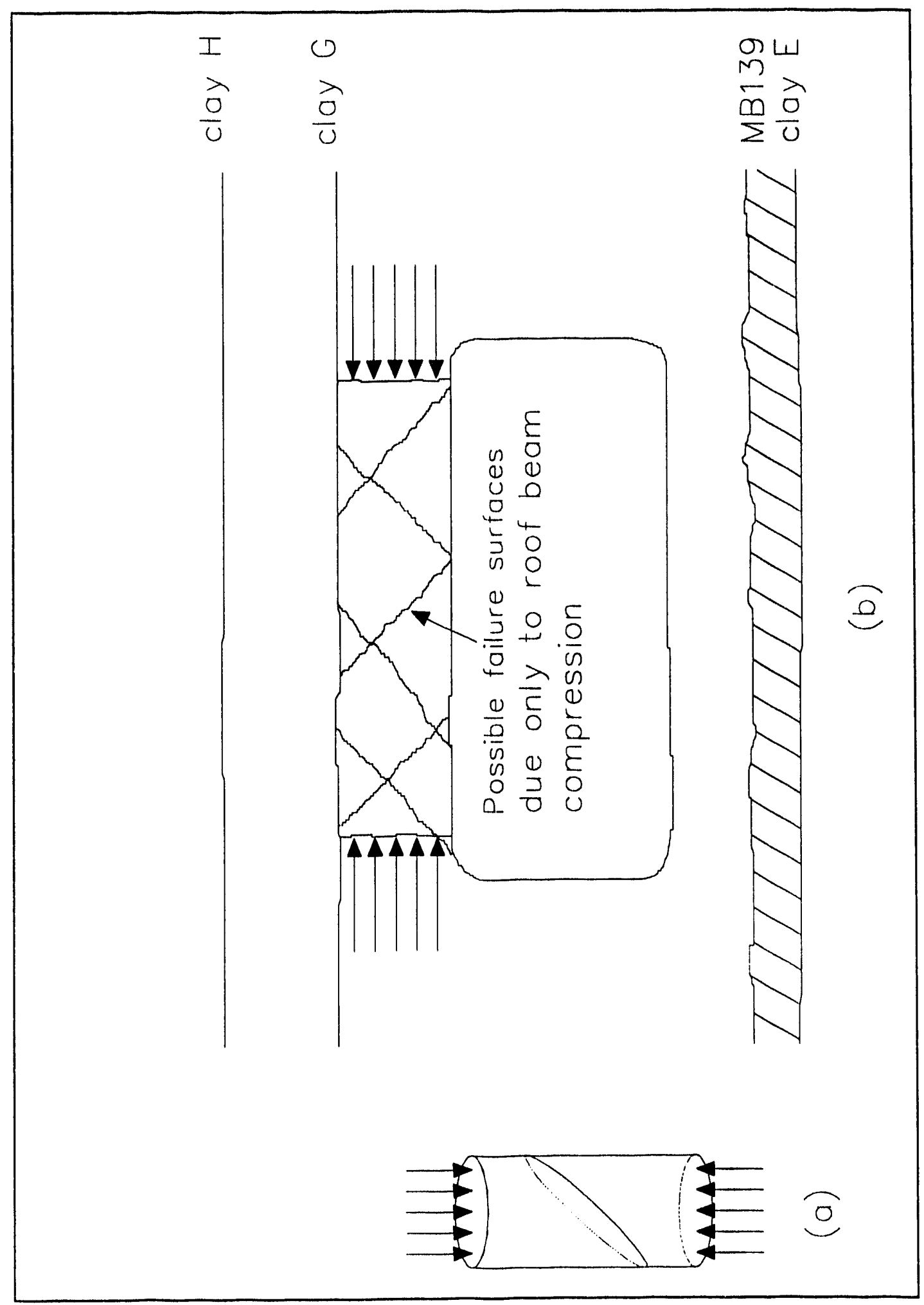

FIGURE 2-5

a) Failure Mode of a Rock Sample in Uniaxial Compression

b) Failure Mode of the Roof Beam Under Compressive Forces 


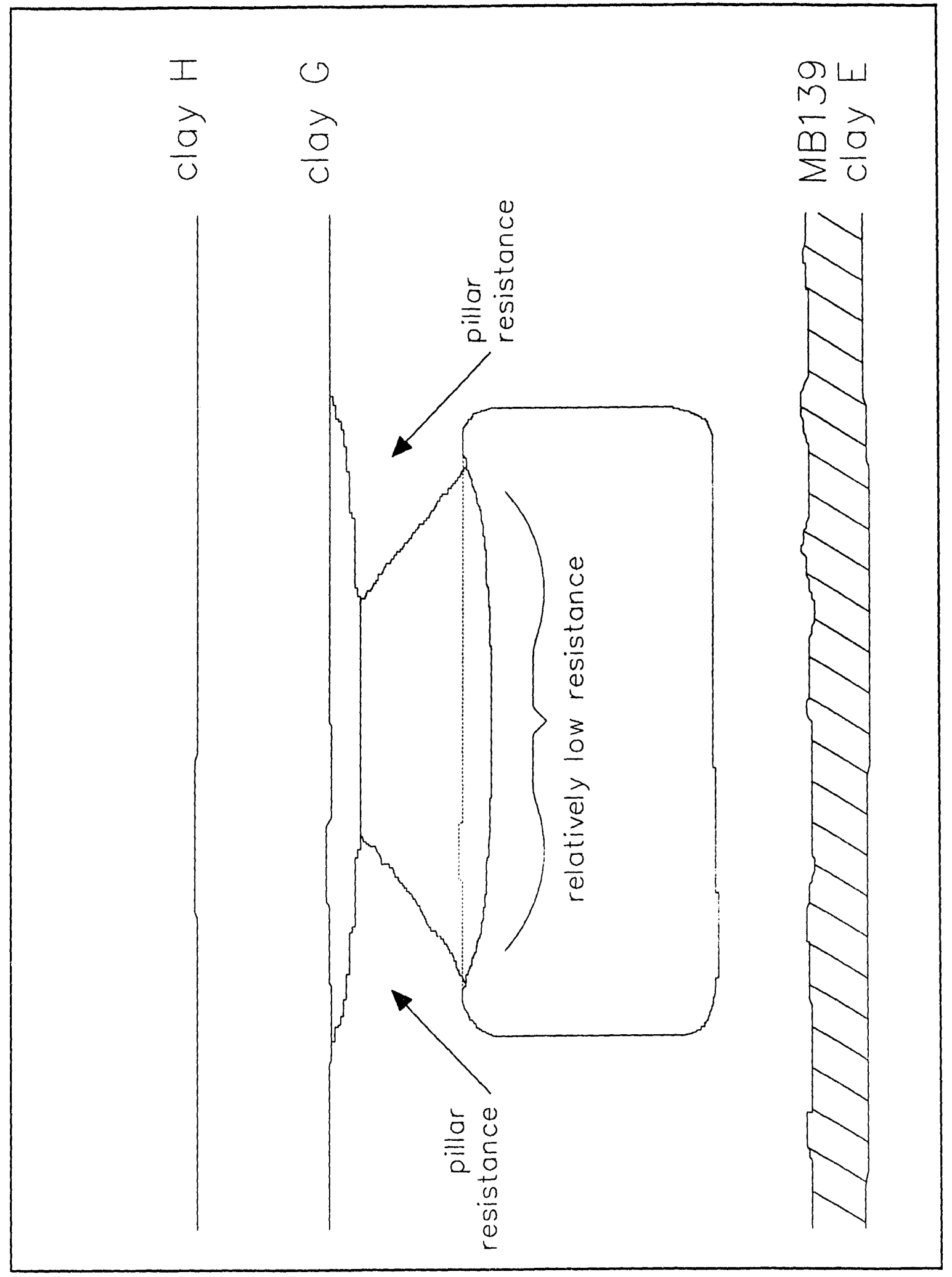

FIGURE 2-6

Fracture Development Due to Roof Creep Mechanism 


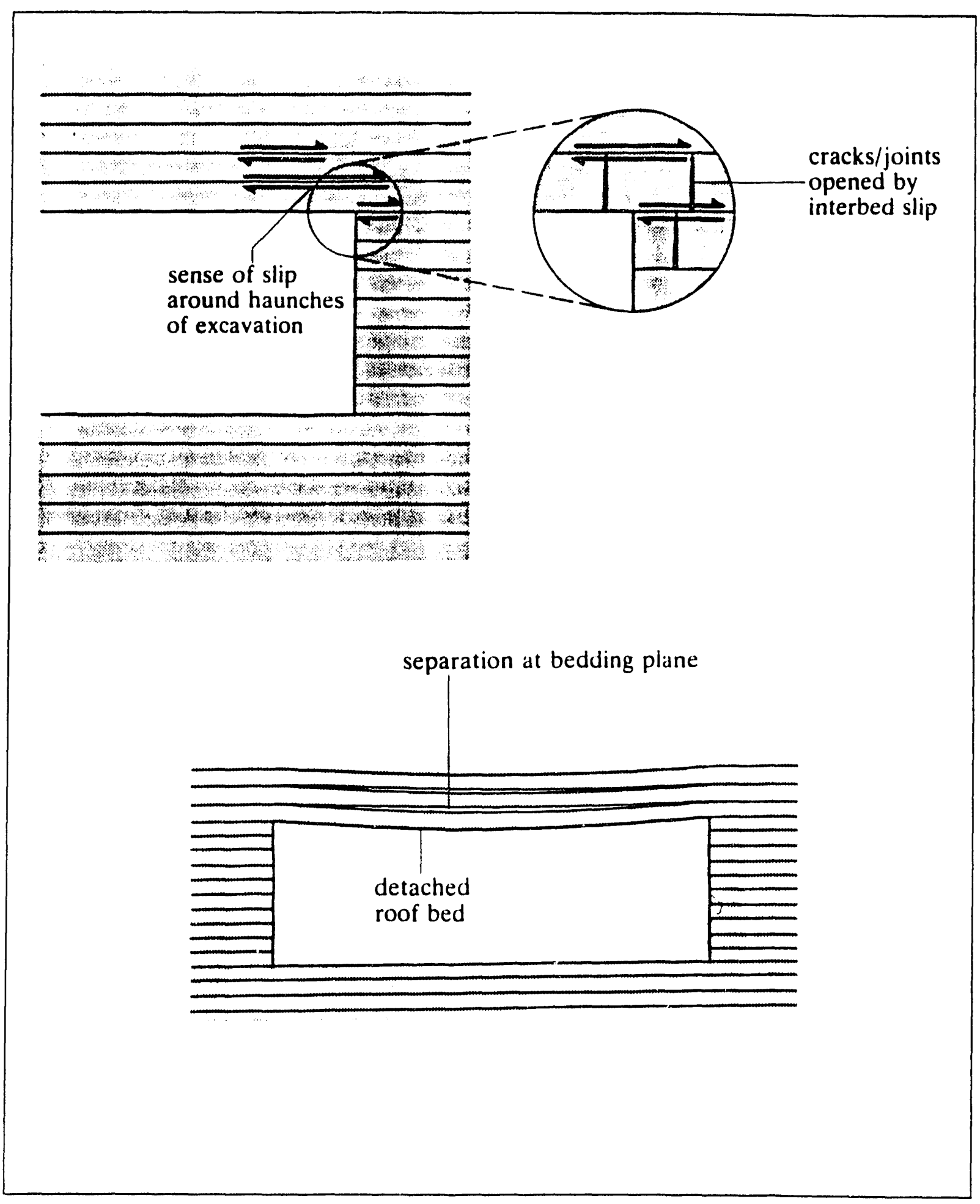

FIGURE $2-7$

Failure of the Roof Beam in a Layered Rock Mass

(after Brady and Brown, 1993) 


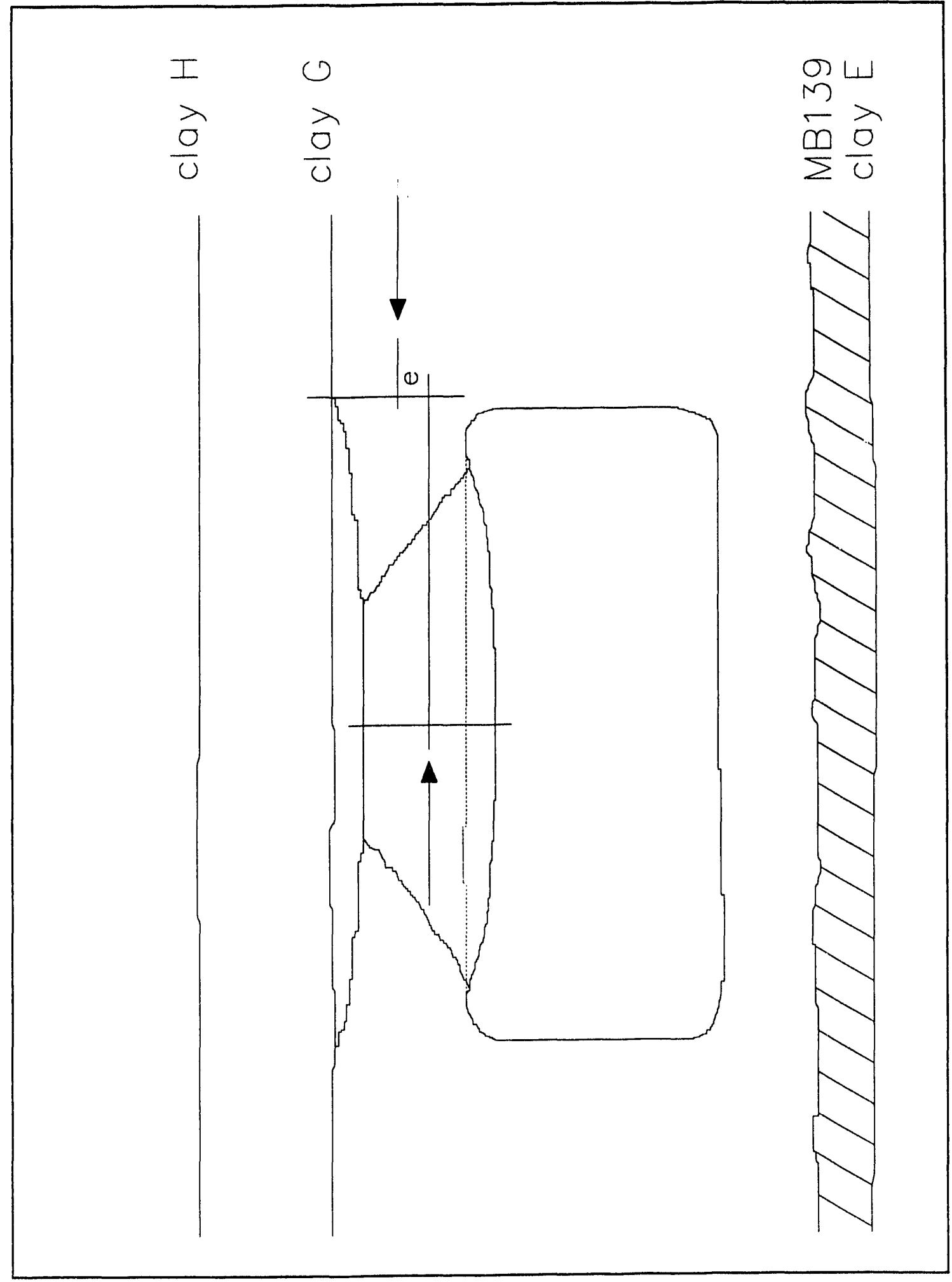

FIGURE 2-8

Axial Force in the Roof Beam Acting Eccentrically on the Roof Beam 


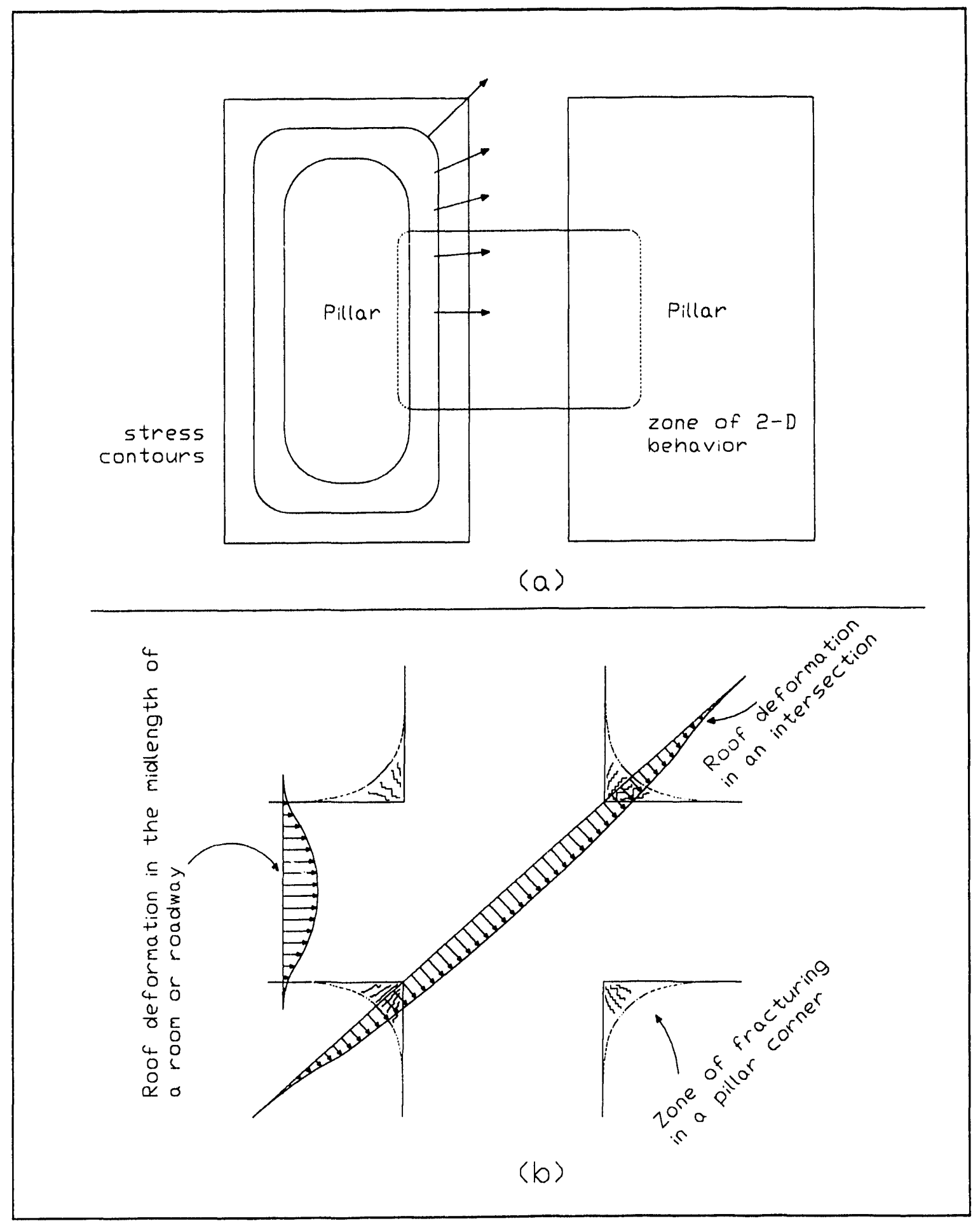

FIGURE 2-9

Effect of Intersections 
abutment $\overbrace{}^{\text {pillar }}$ pillar cillar

(a) local arches

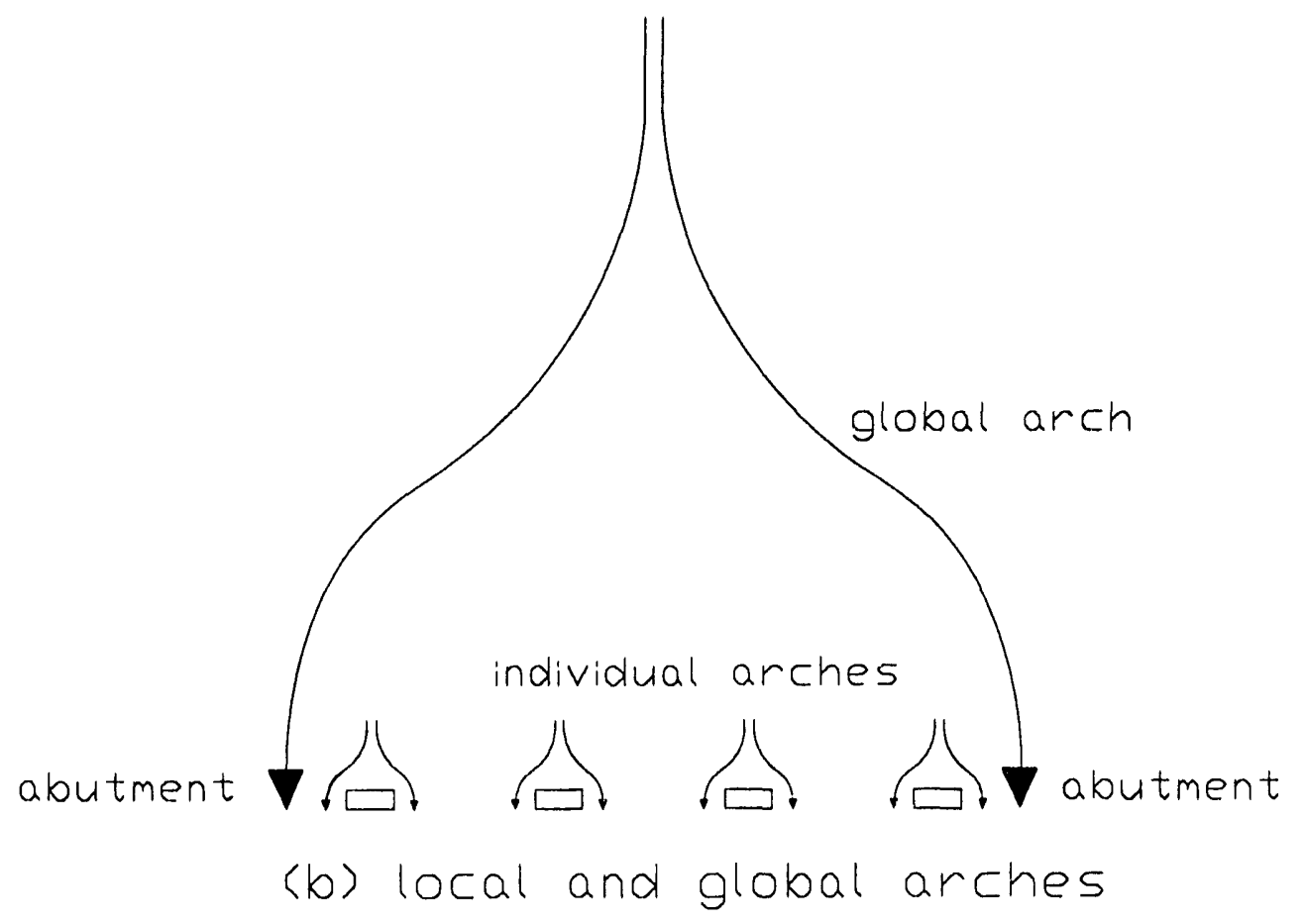

FIGURE 2-10

Local and Global Stress Arches 


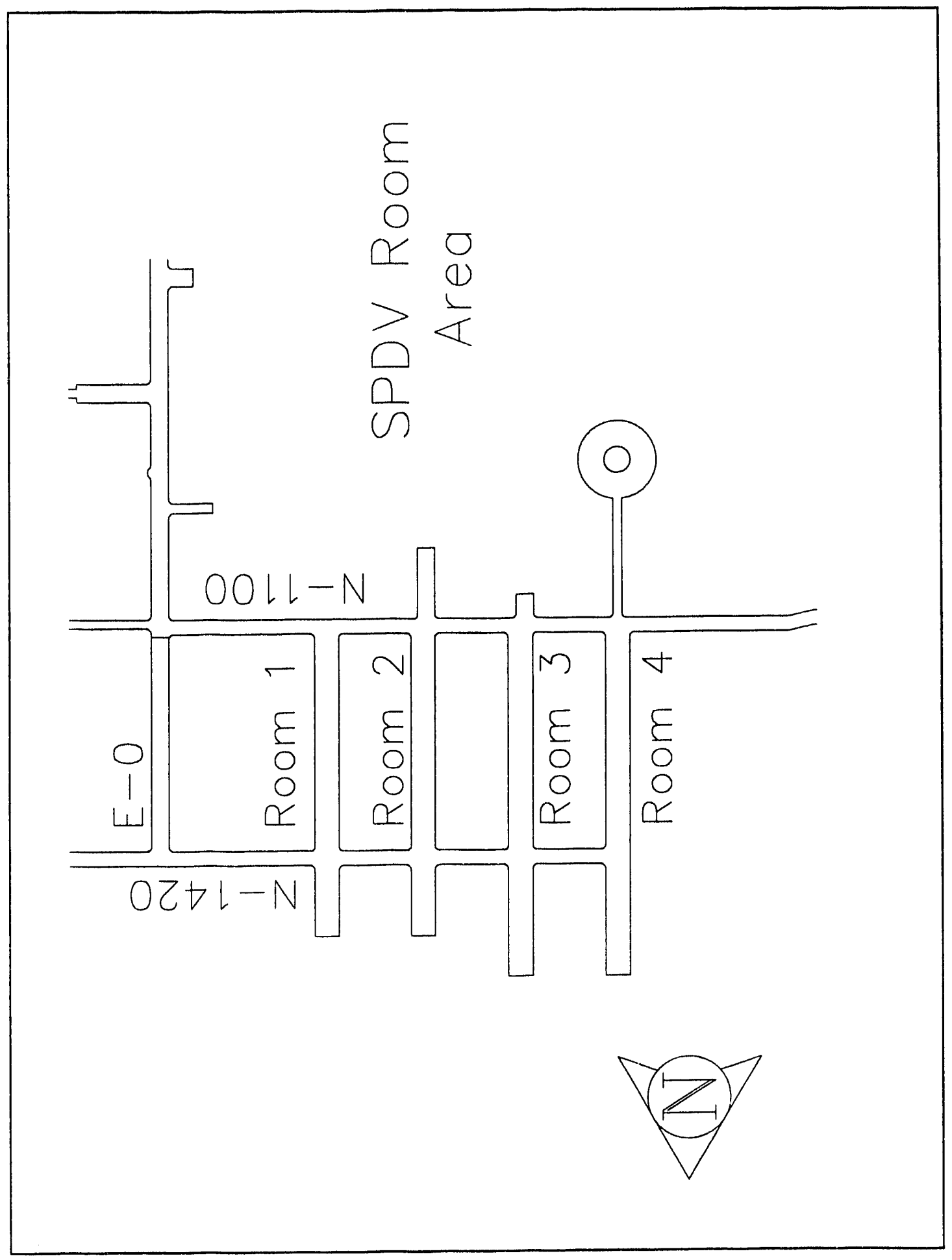

FIGURE 2-11

SPDV Room Panel 


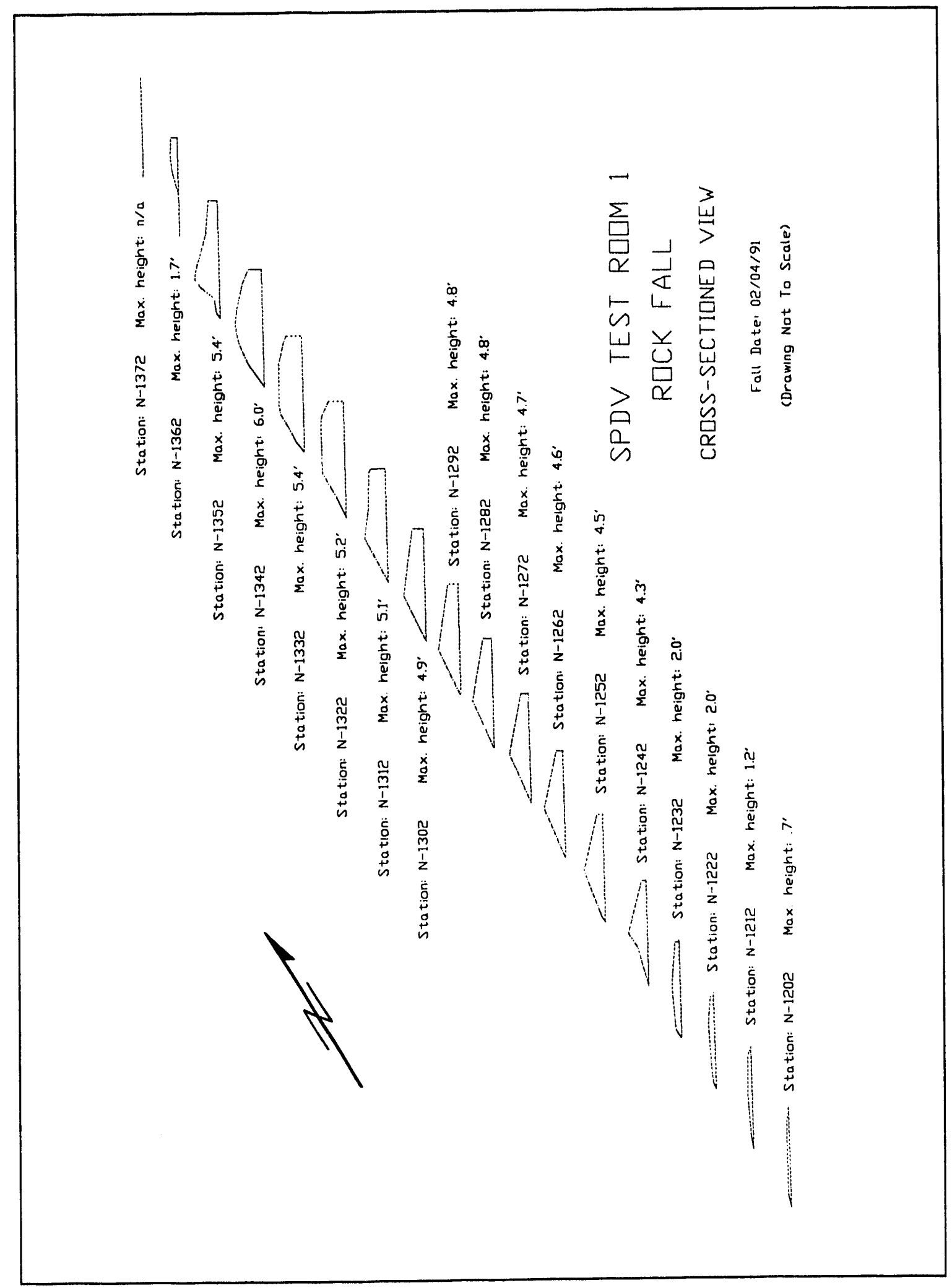

FIGURE 3-1

Shape of Roof Fall in SPDV Room 1 


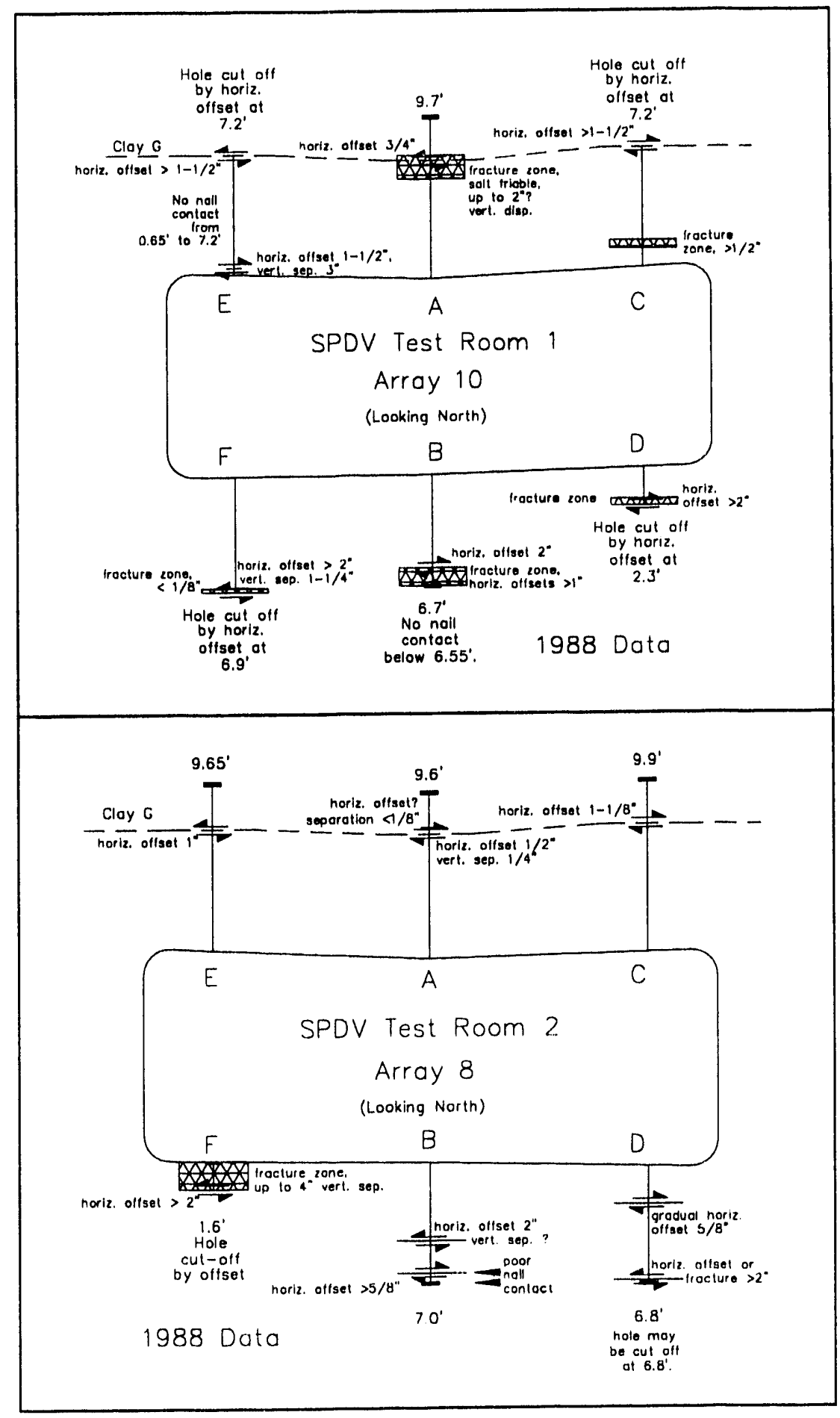

FIGURE 3-2

Excavation Effects Program Data

SPDV Rooms 1 and 2 

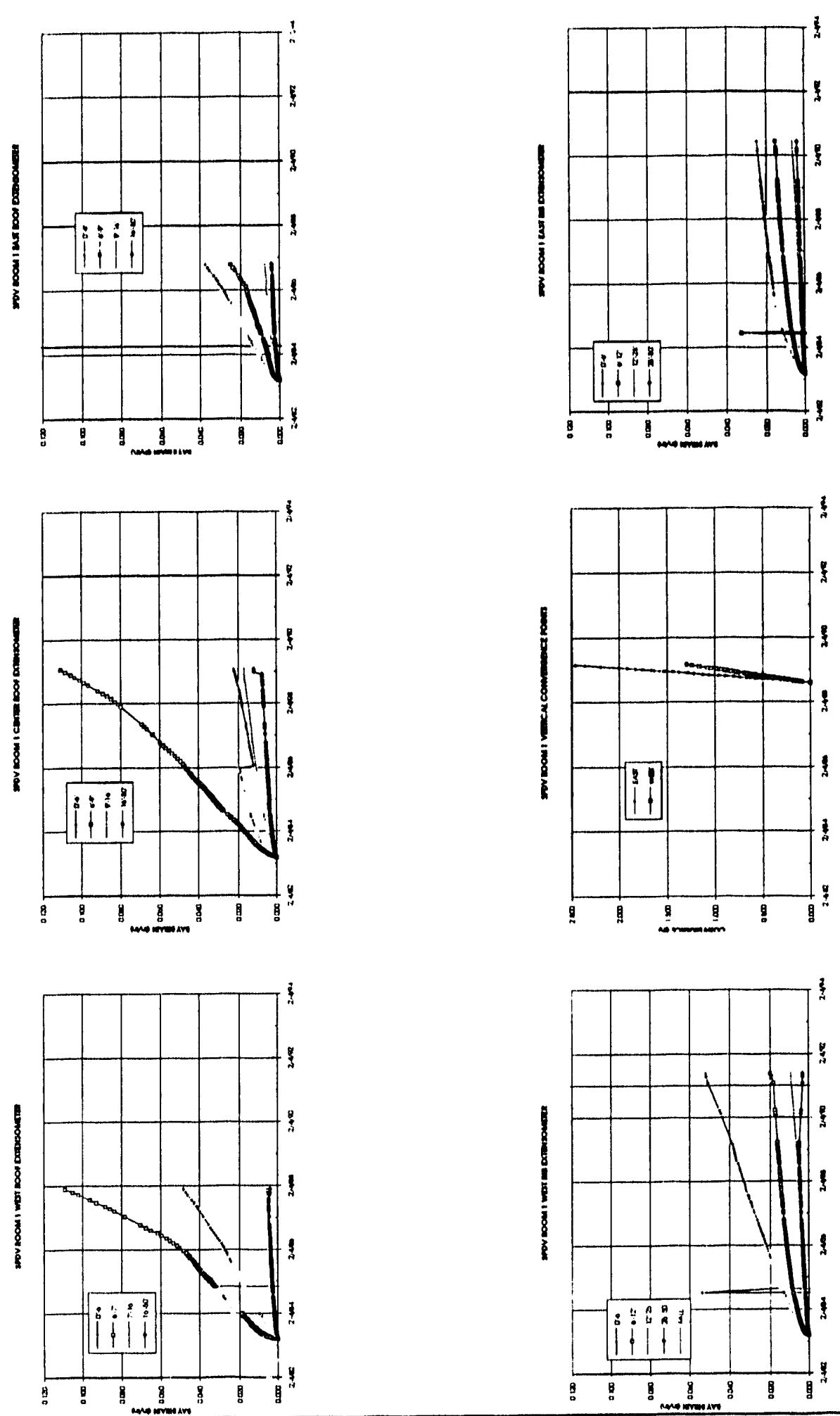

FIGURE 3-3

Deformation Around SPDV Room 1 

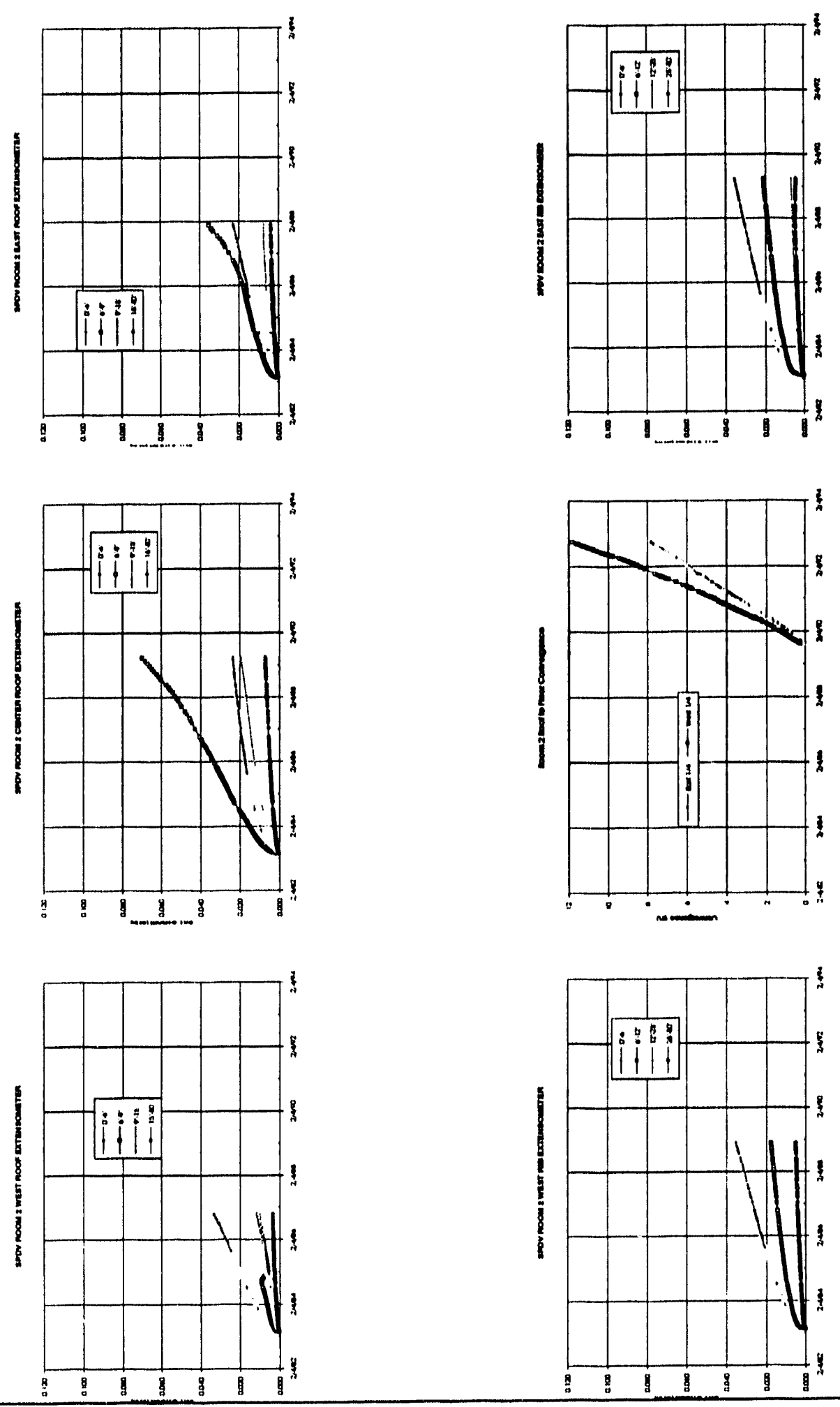

FIGURE 3-4

Deformation Around SPDV Room 2 


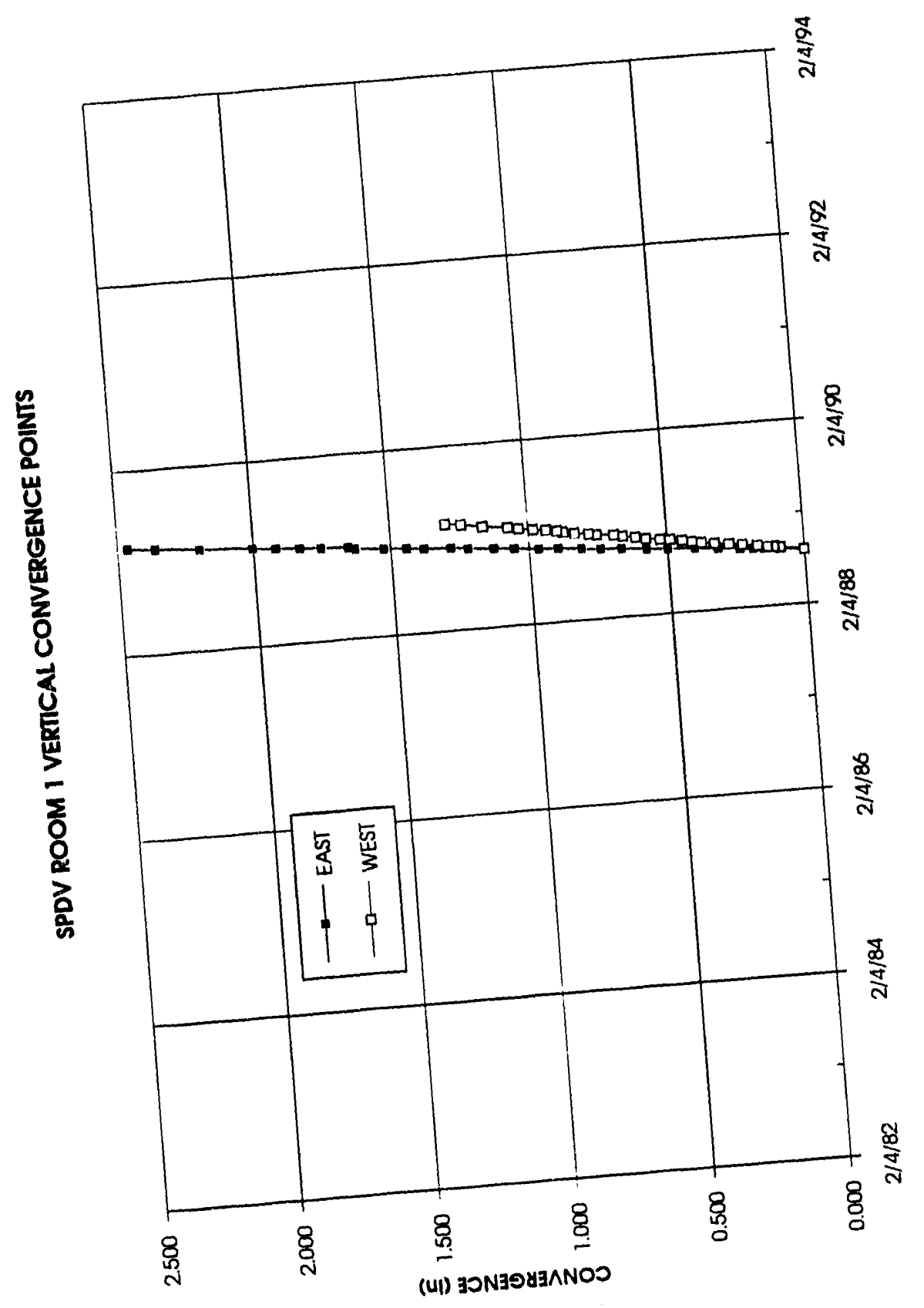

FIGURE 3-5

Asymmetric Convergence in SPDV Room 1 


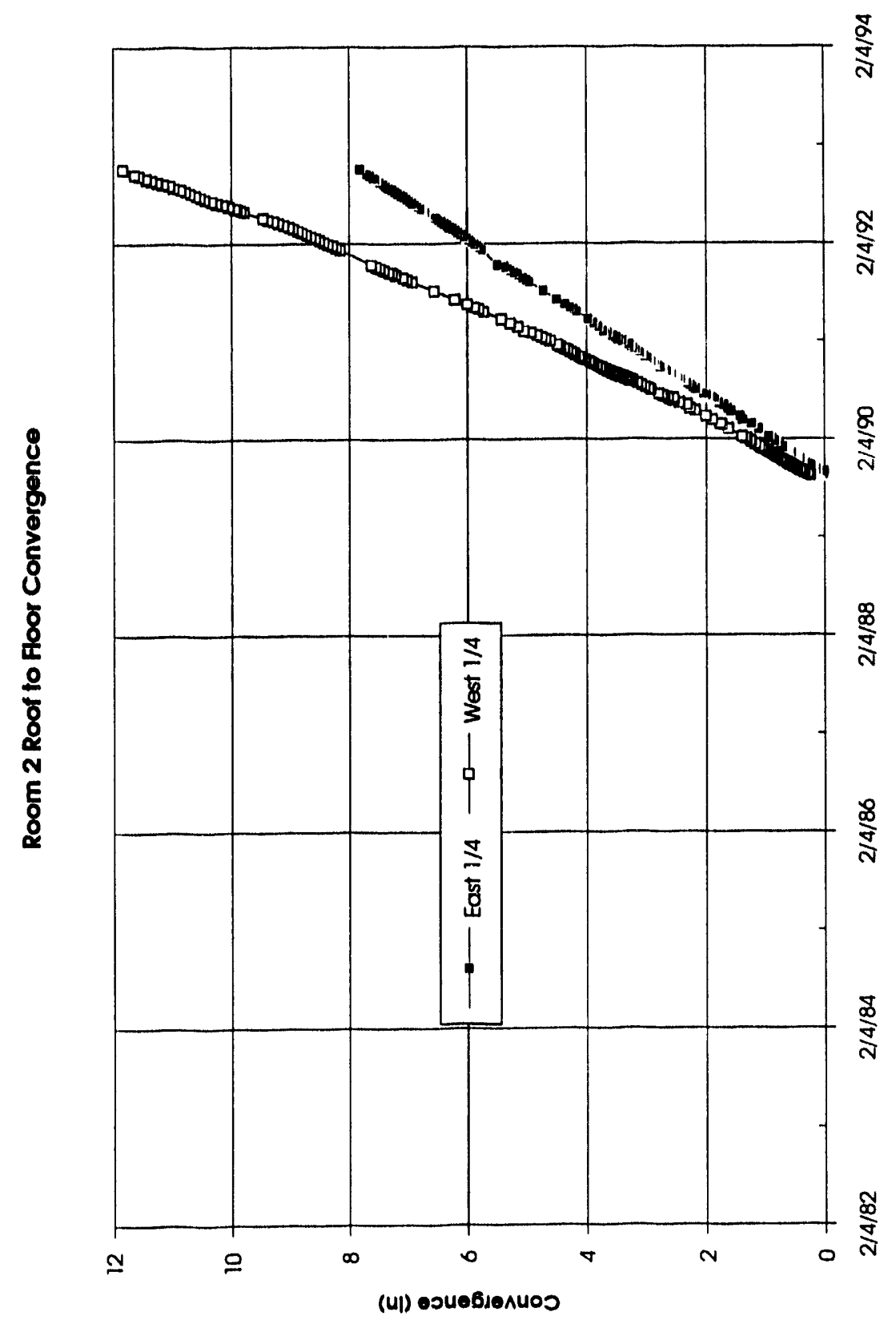

FIGURE 3-6

Asymmetric Convergence in SPDV Room 2 


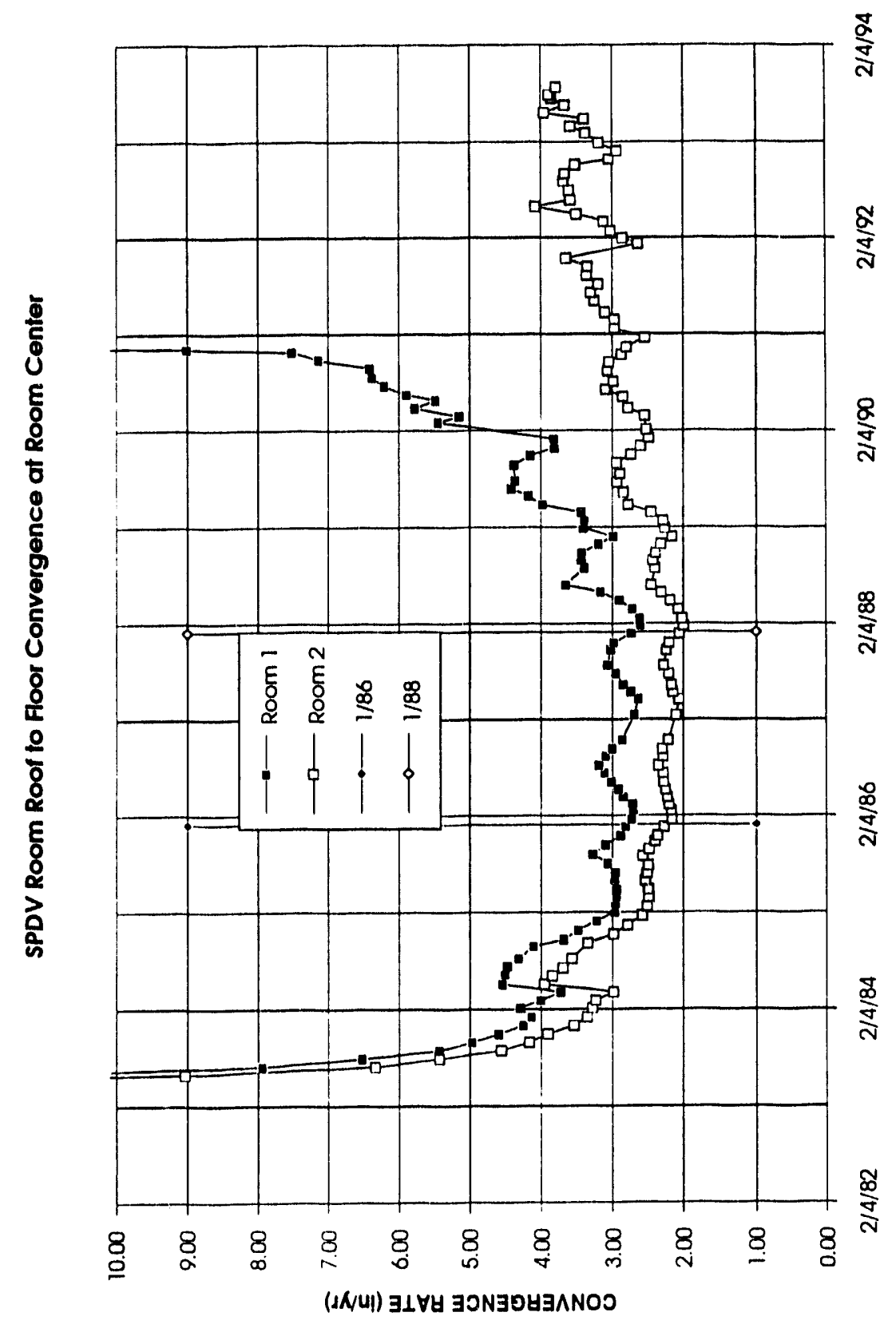

\section{FIGURE 3-7}

Roof To Floor Convergence Rates

SPDV Rooms 1 and 2 


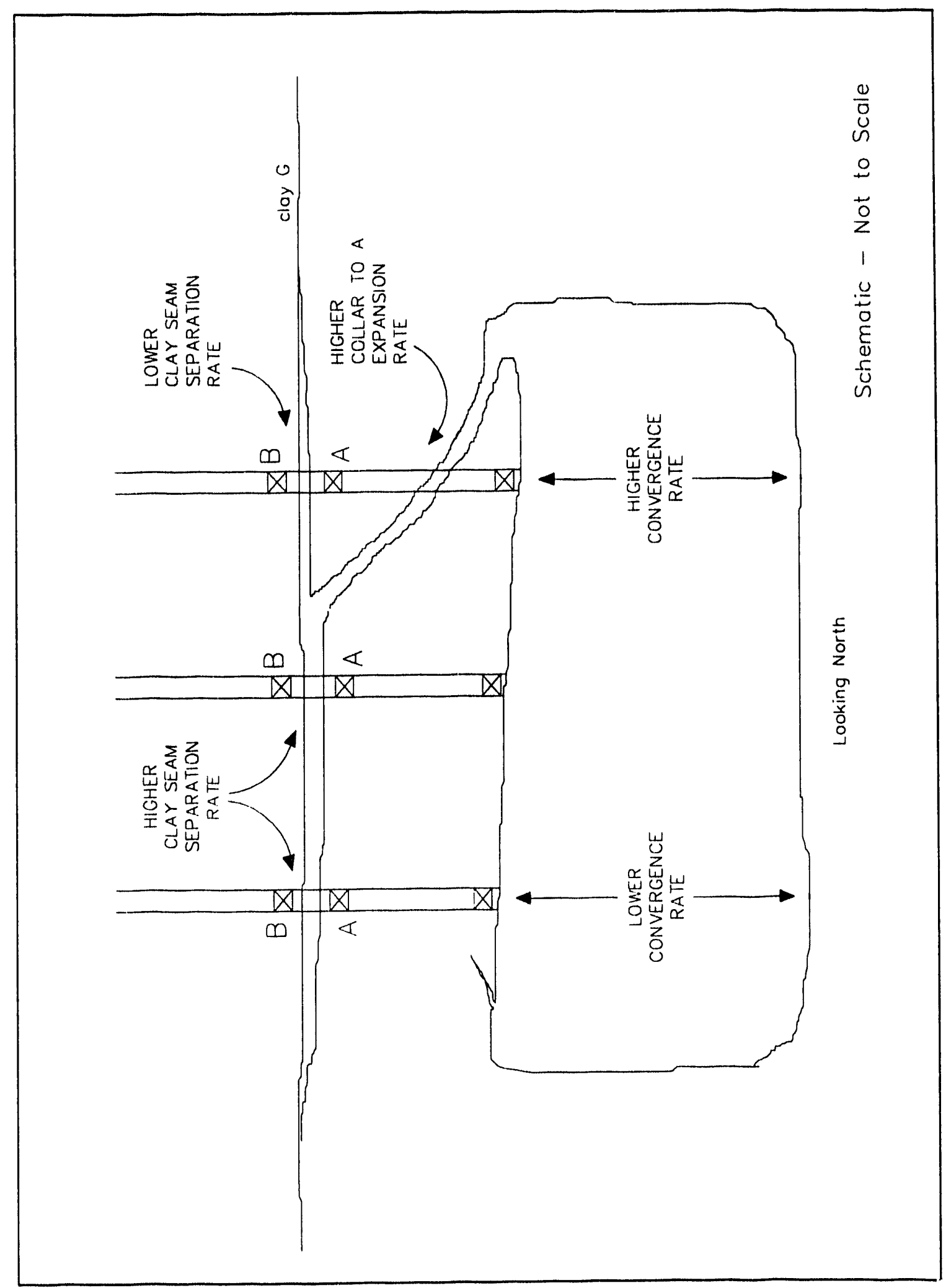

\section{FIGURE 3-8}

Fracture Formation in Roof of SPDV Room 1 


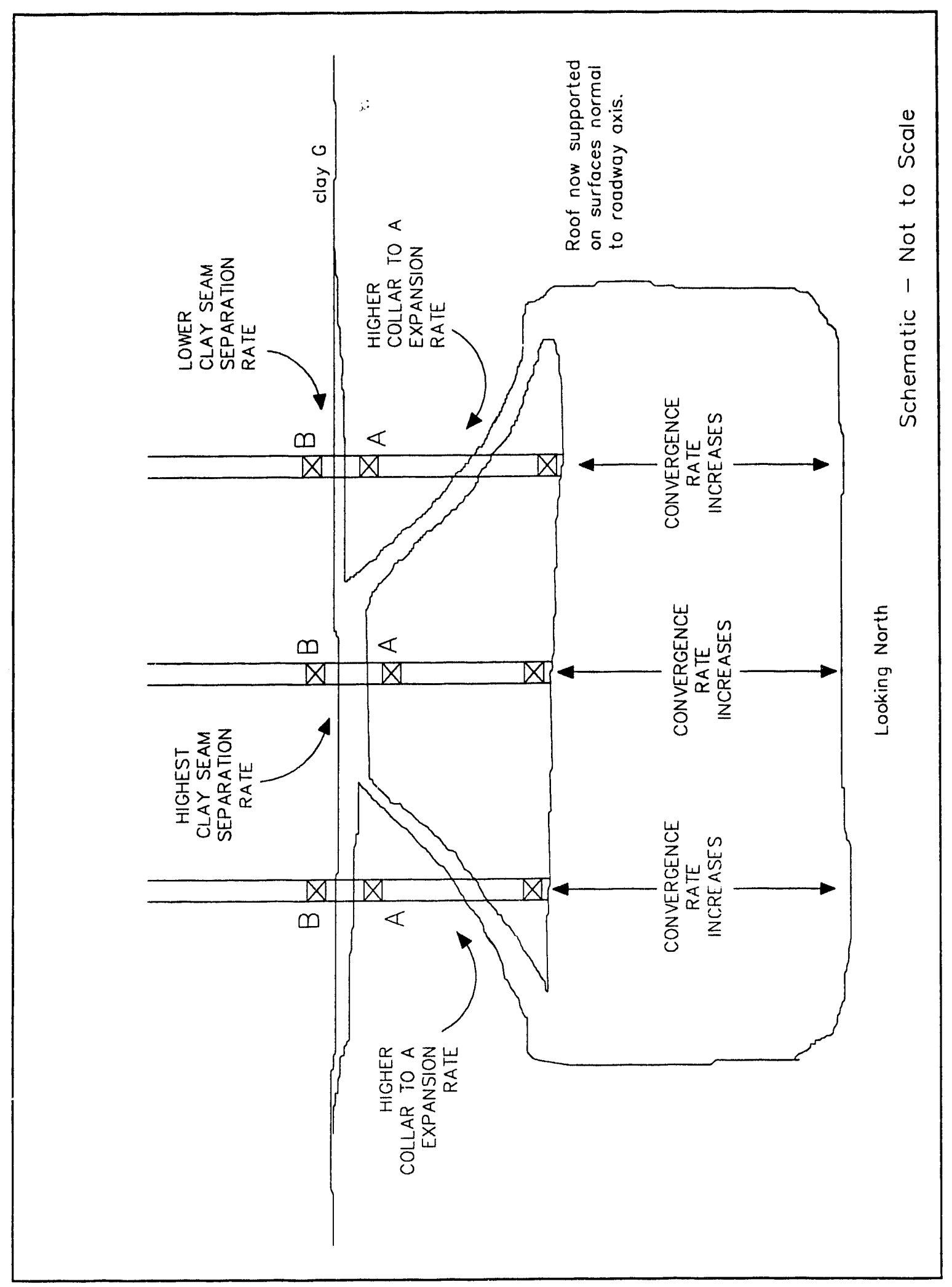

FIGURE 3-9

Advanced Fracture Formation in Roof of SPDV Room 1 


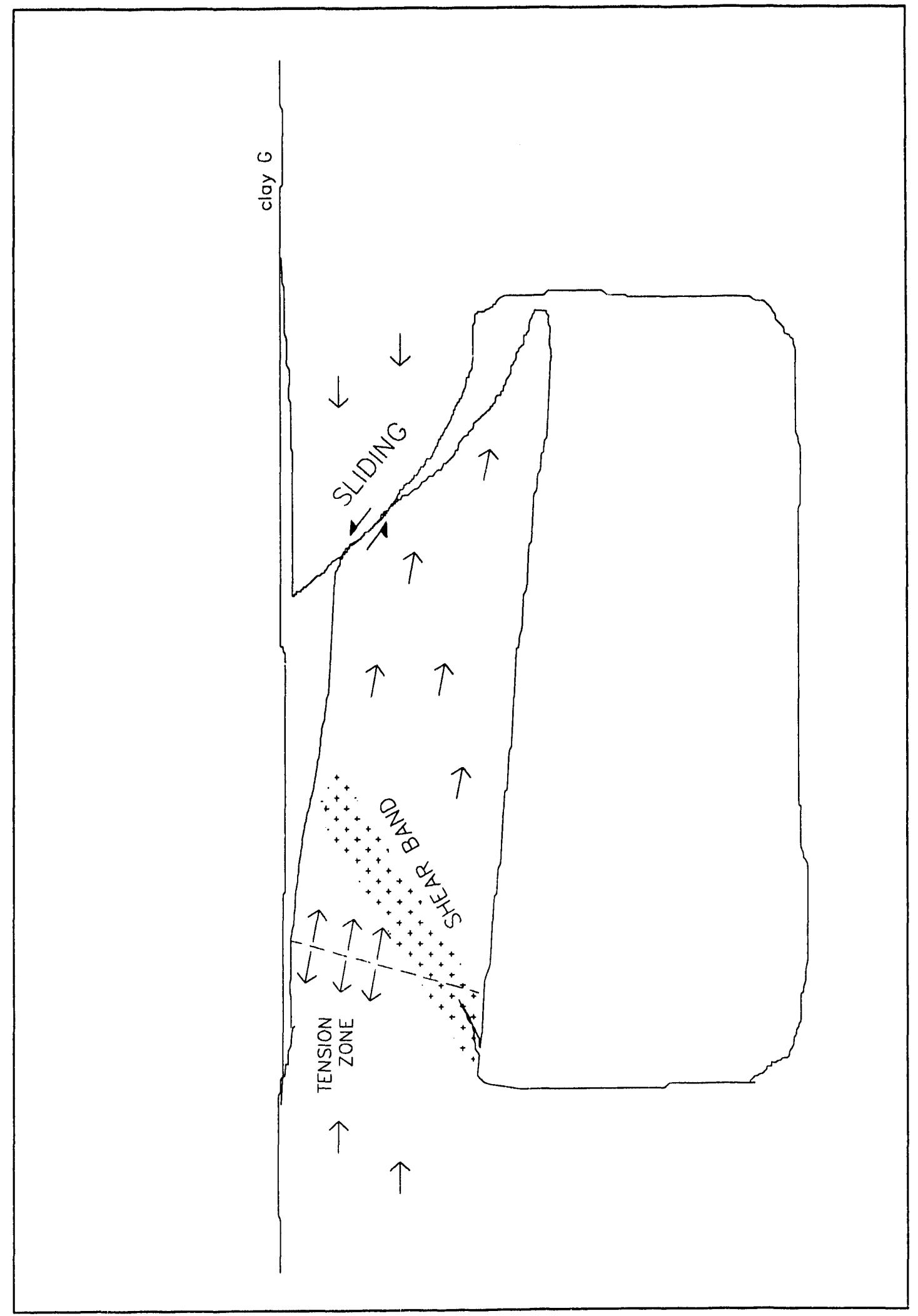

FIGURE 3-10

Deformation of Roof Beam After Initial Fracturing 


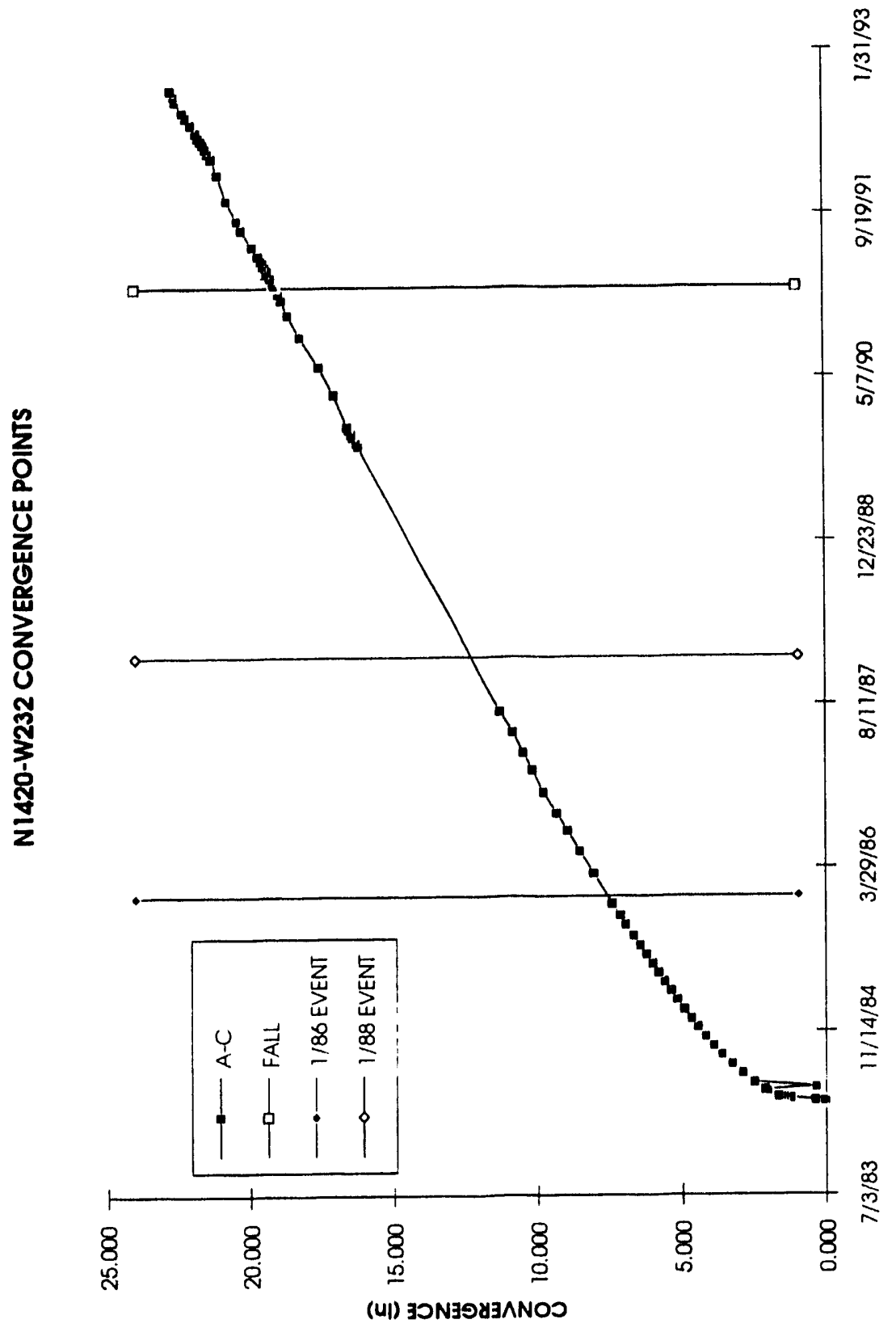

FIGURE 3-11

Convergence Data From N1420 Dritt 


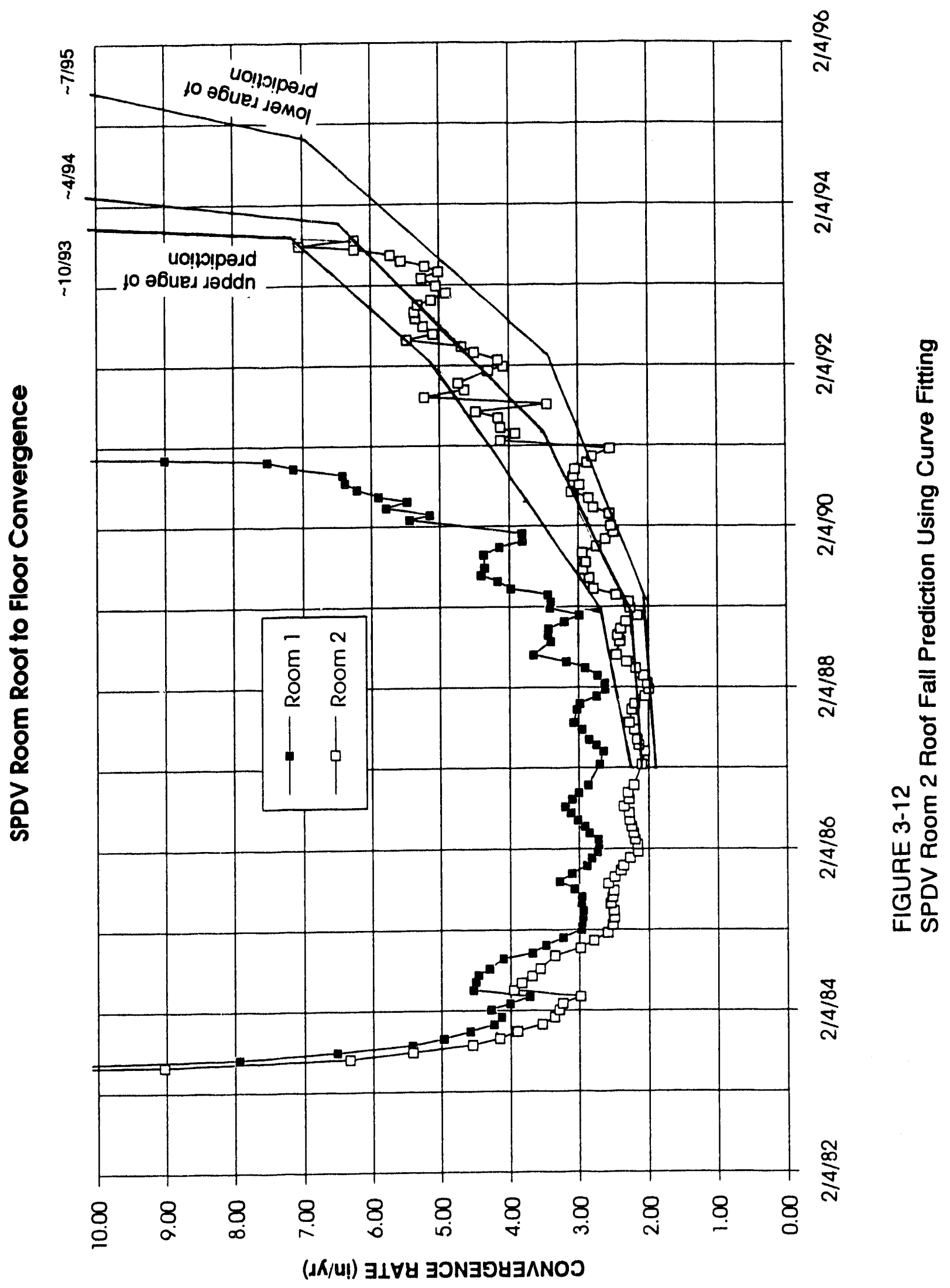




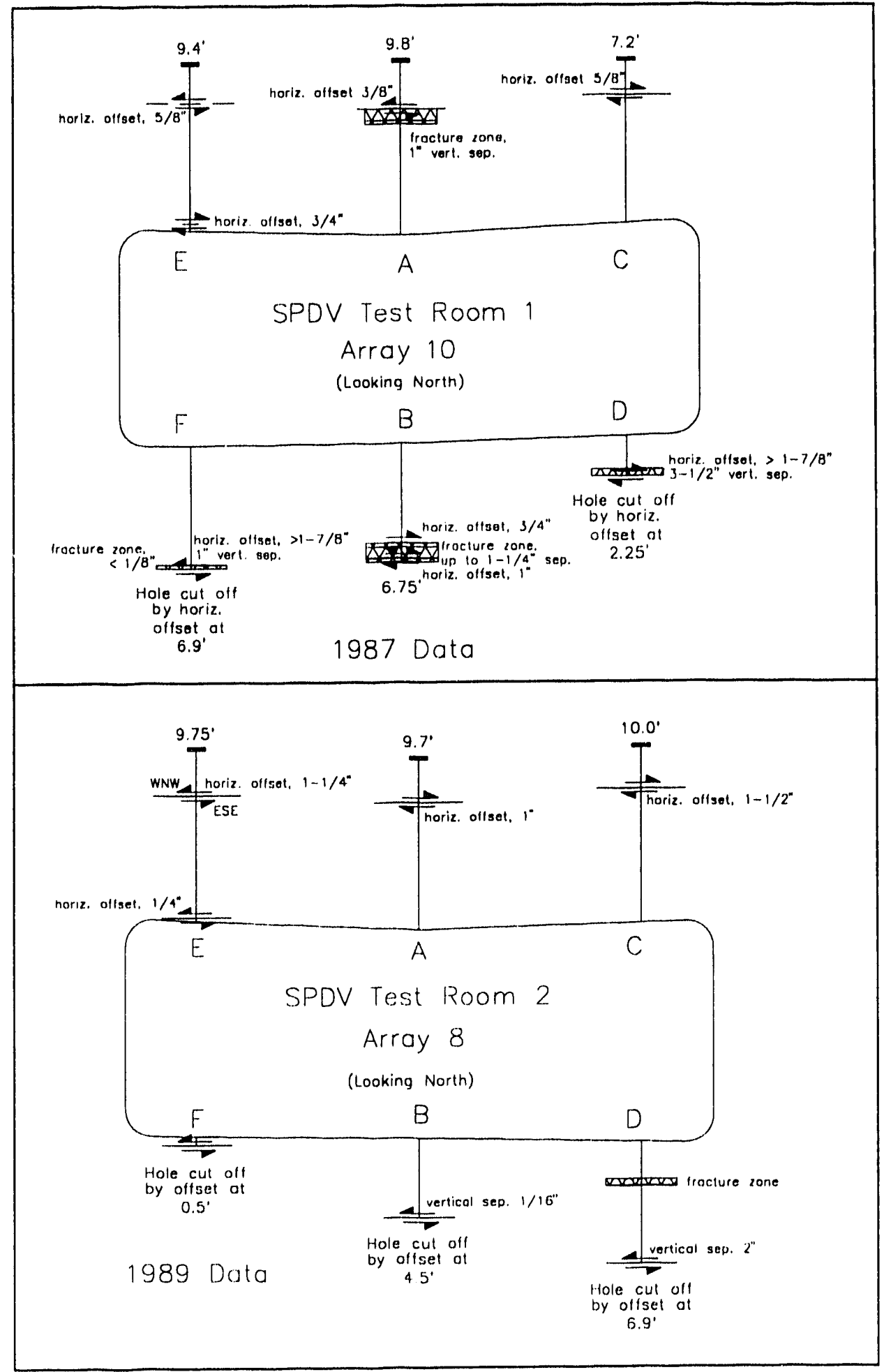

FIGURE 3-13 
APPENDIX A 


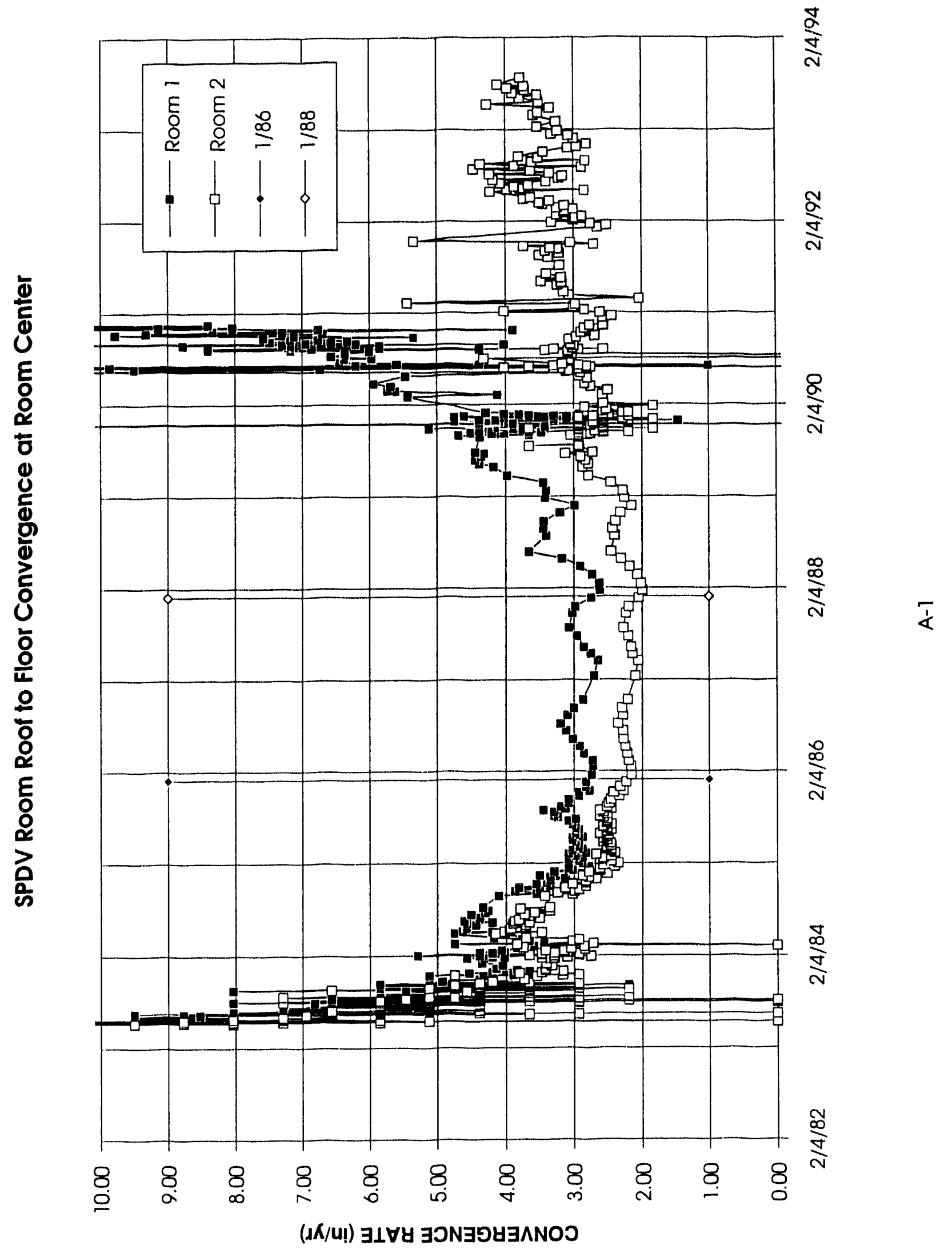




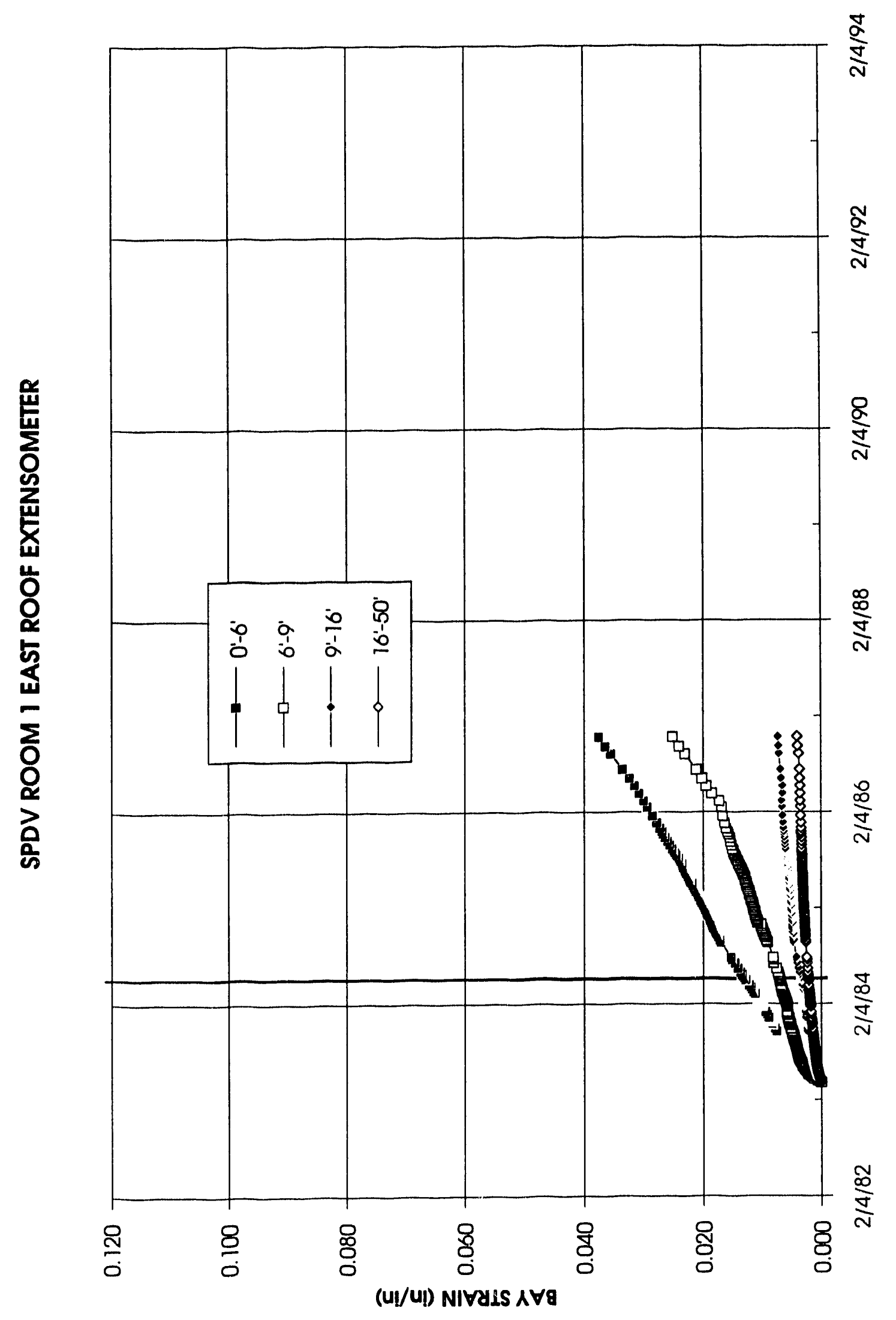

$\frac{N}{4}$ 


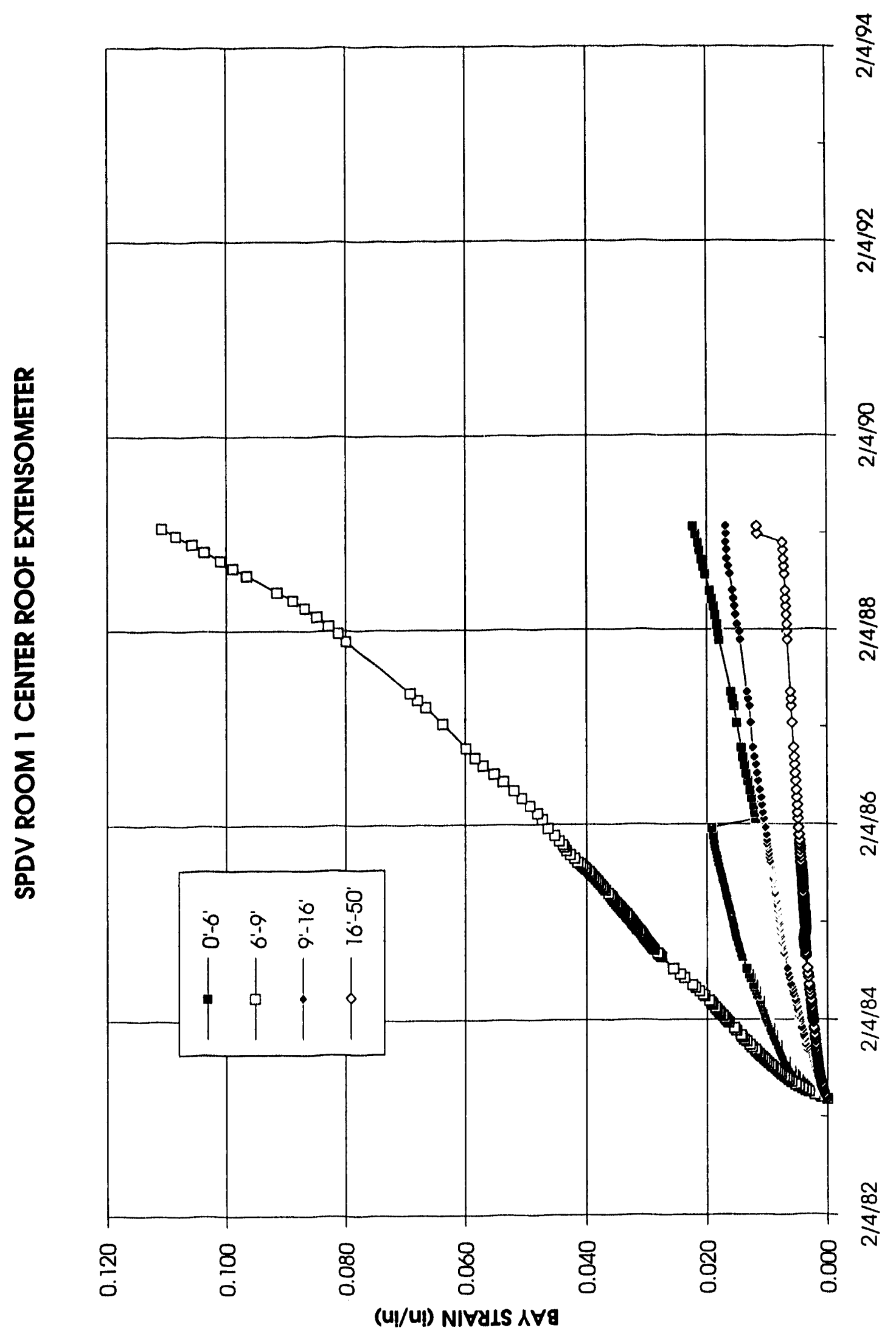

$\dot{r}$ 


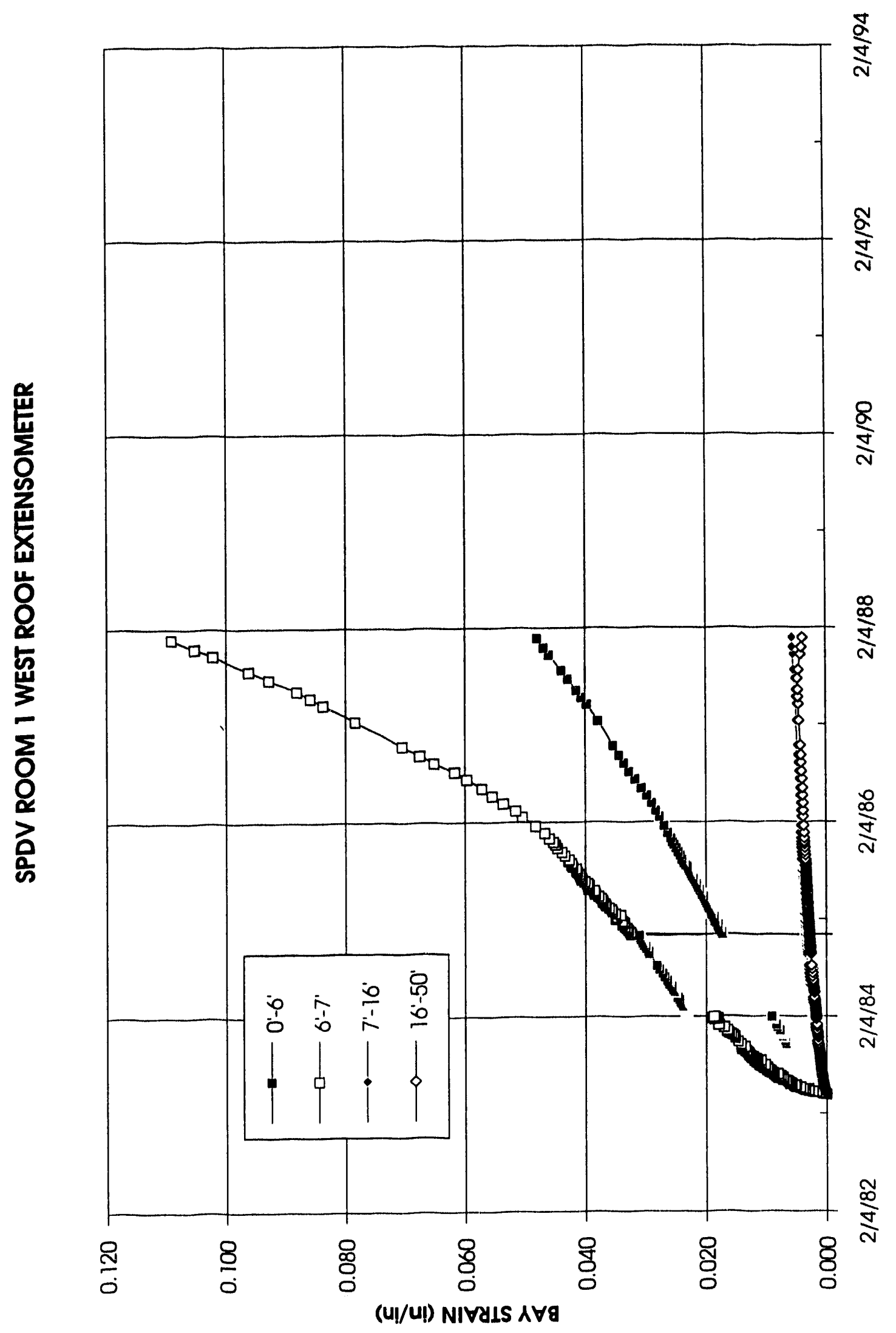

$\frac{1}{4}$ 


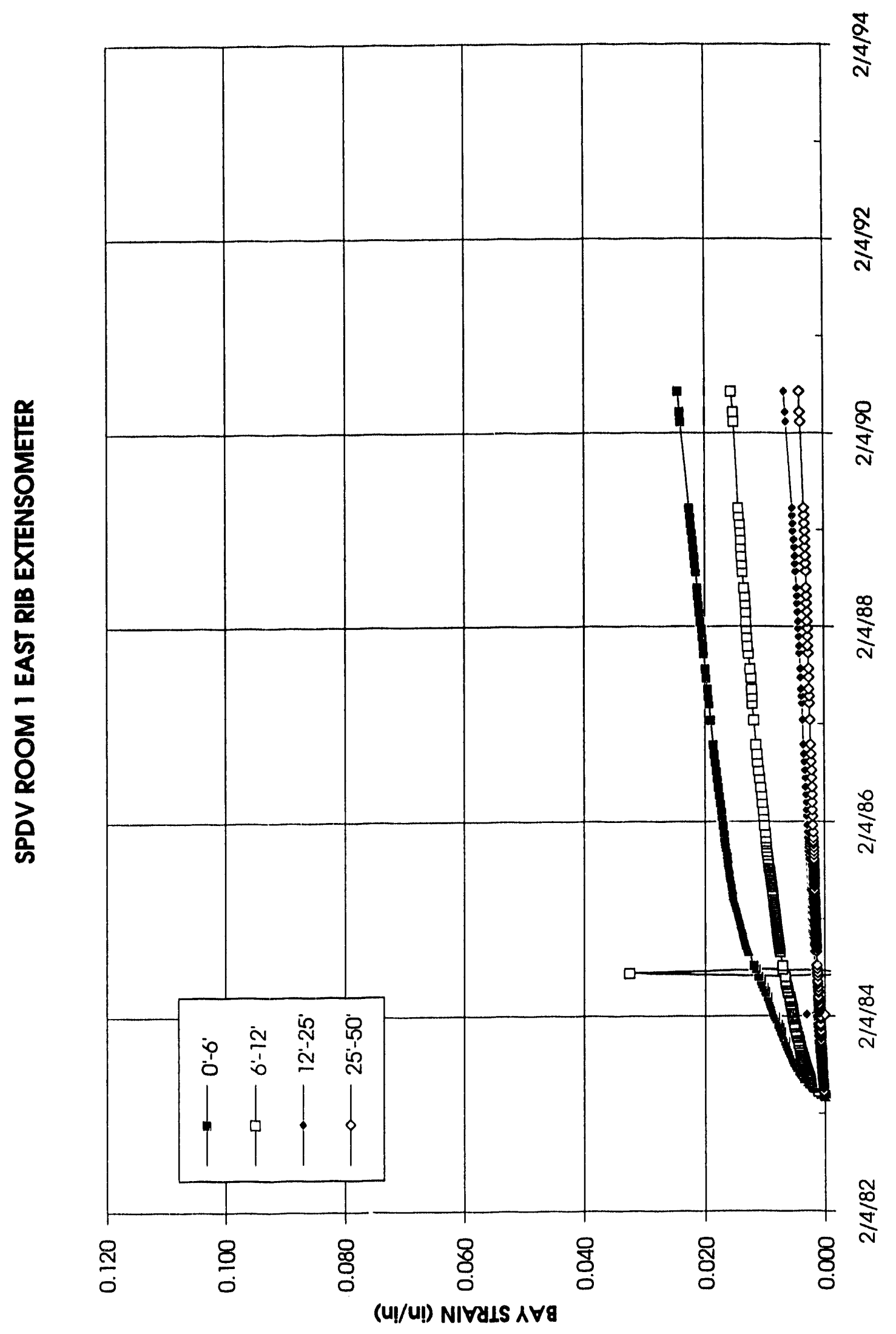

妟 


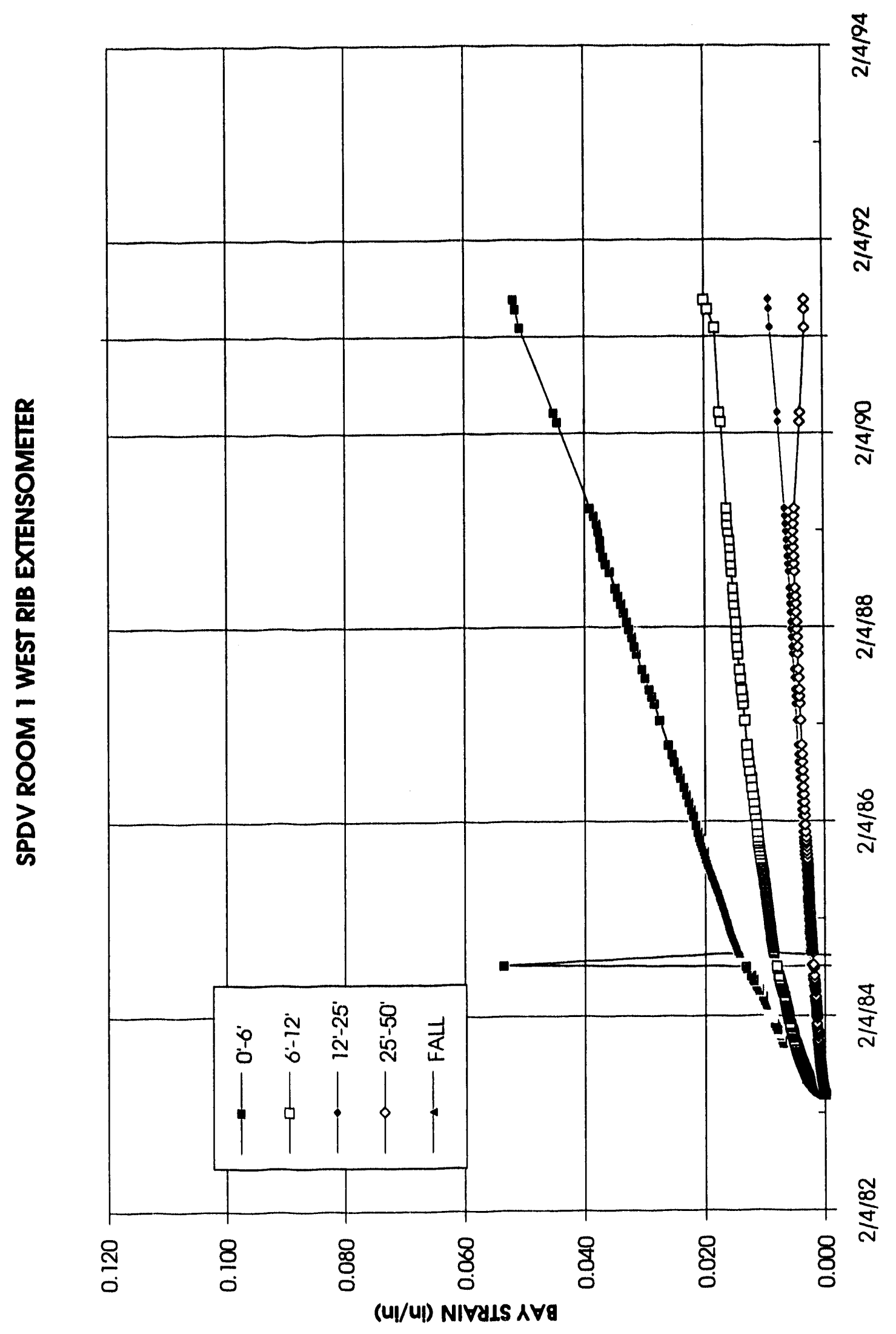

$q$ 


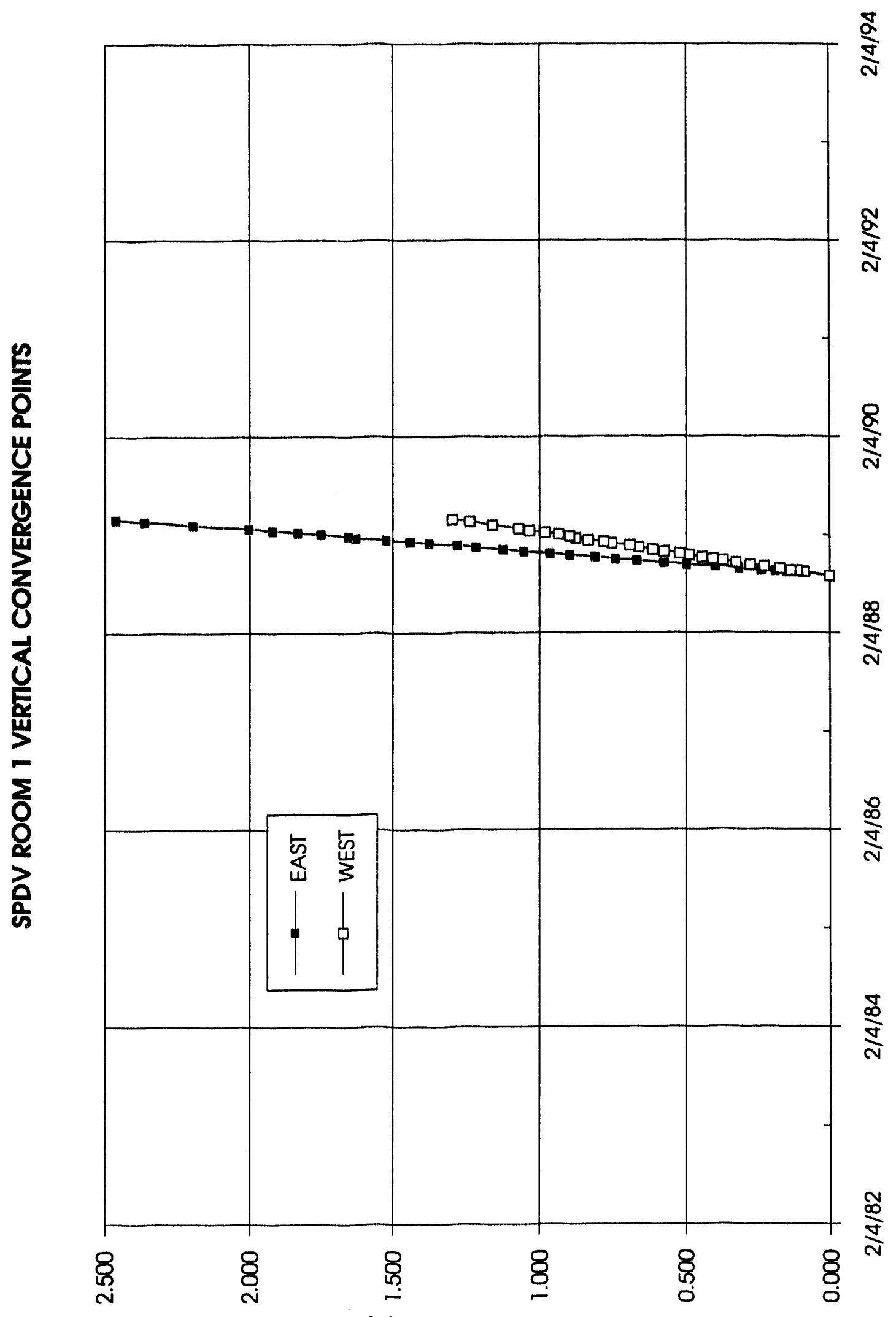

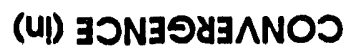




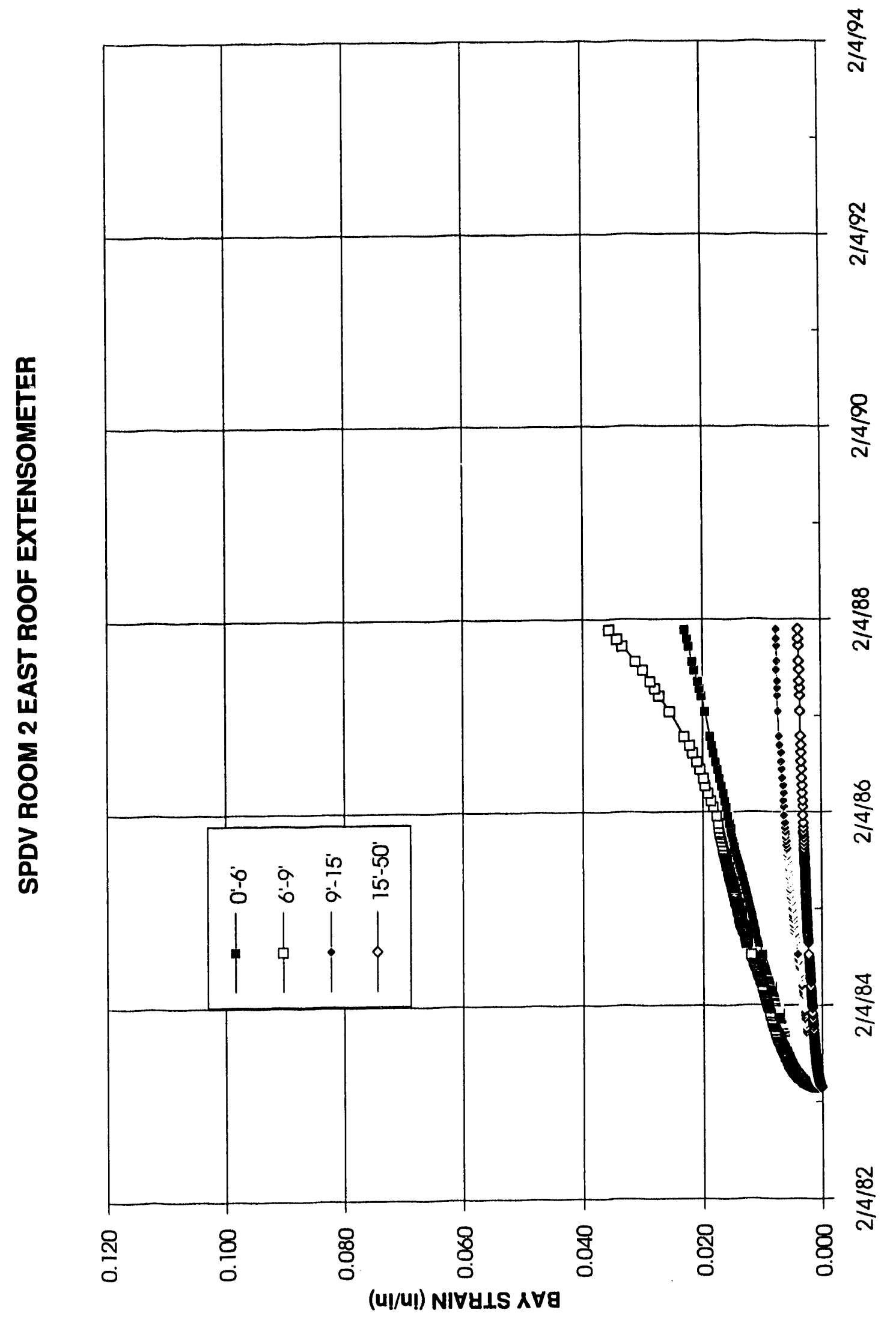

\& 


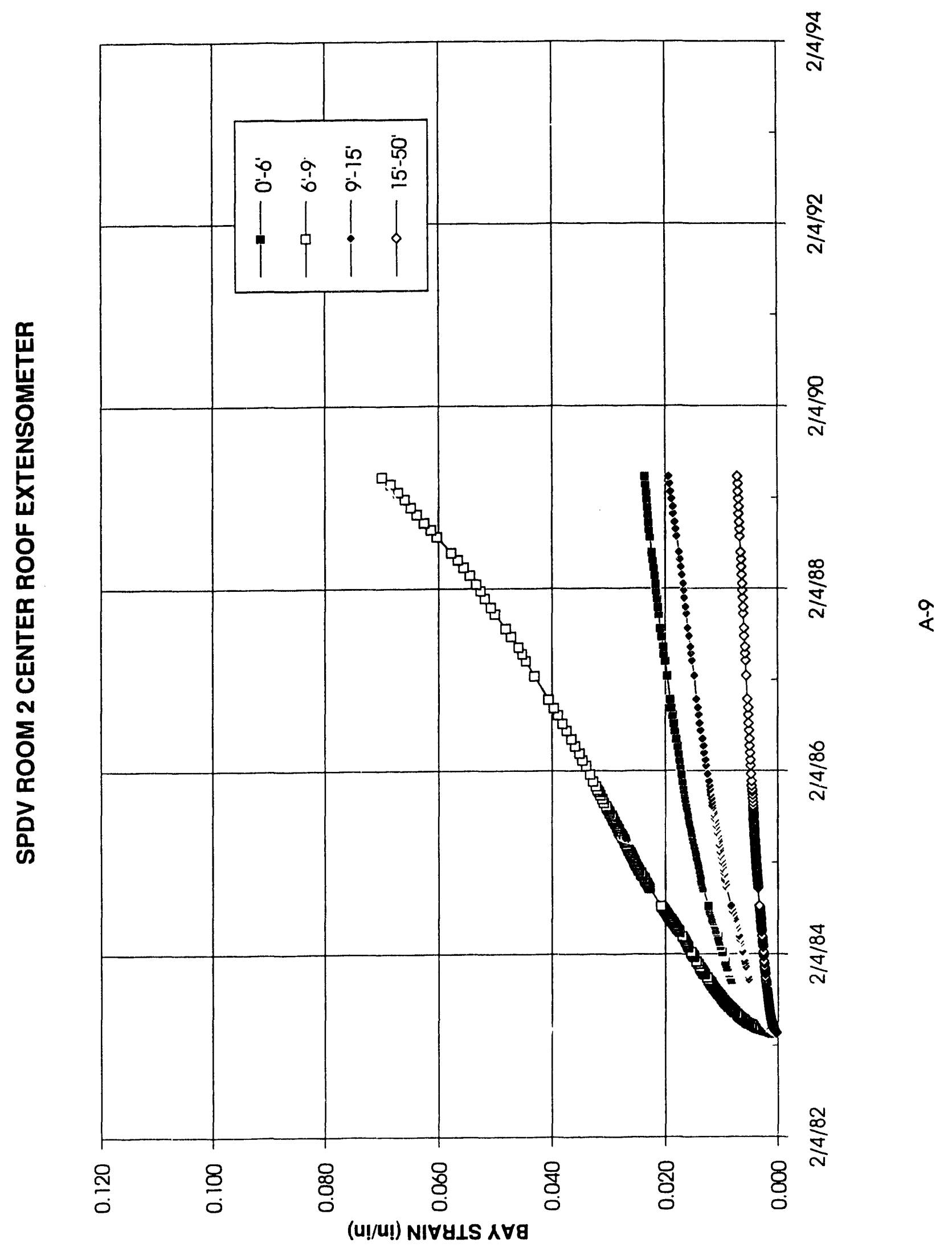




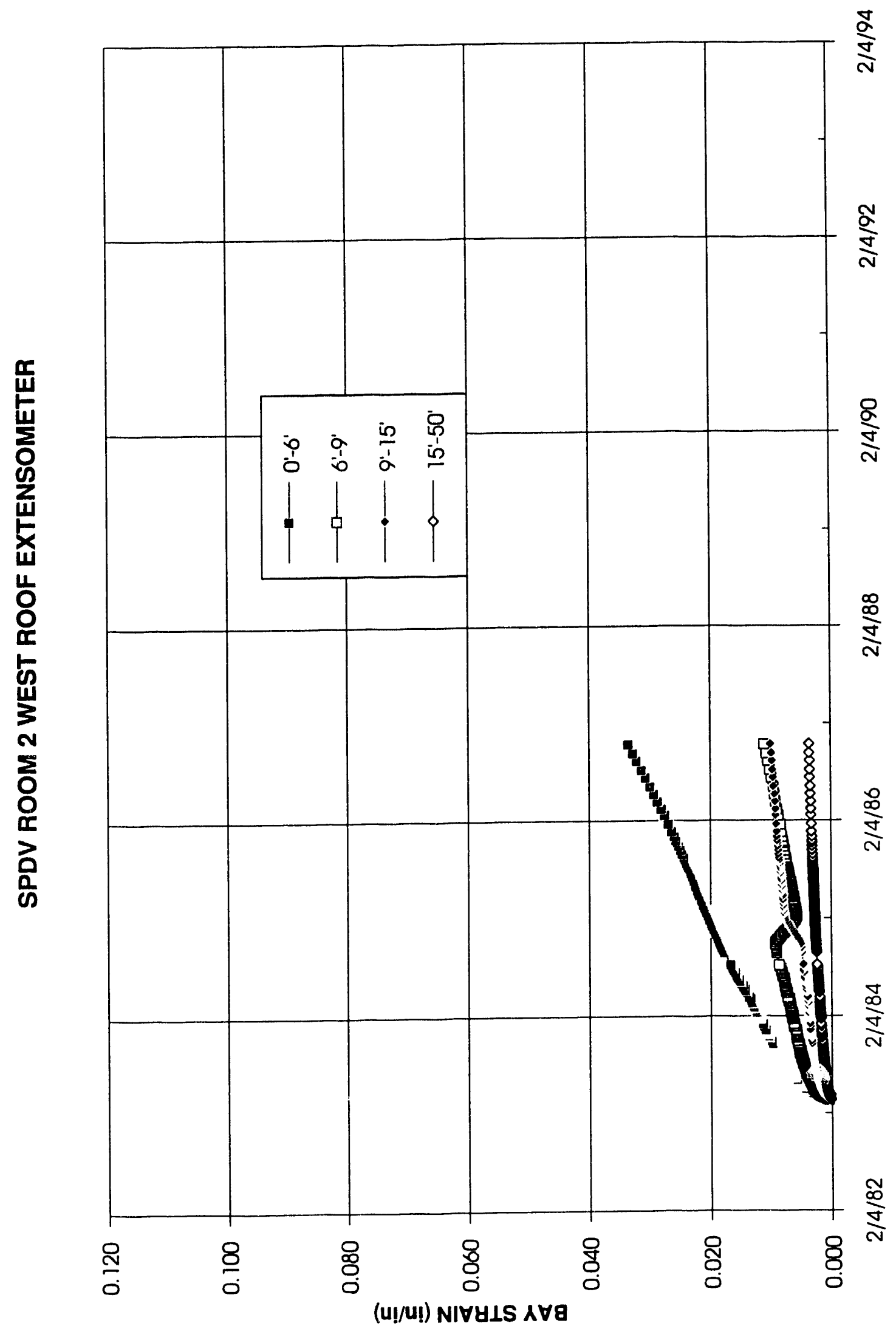

$\frac{0}{4}$ 


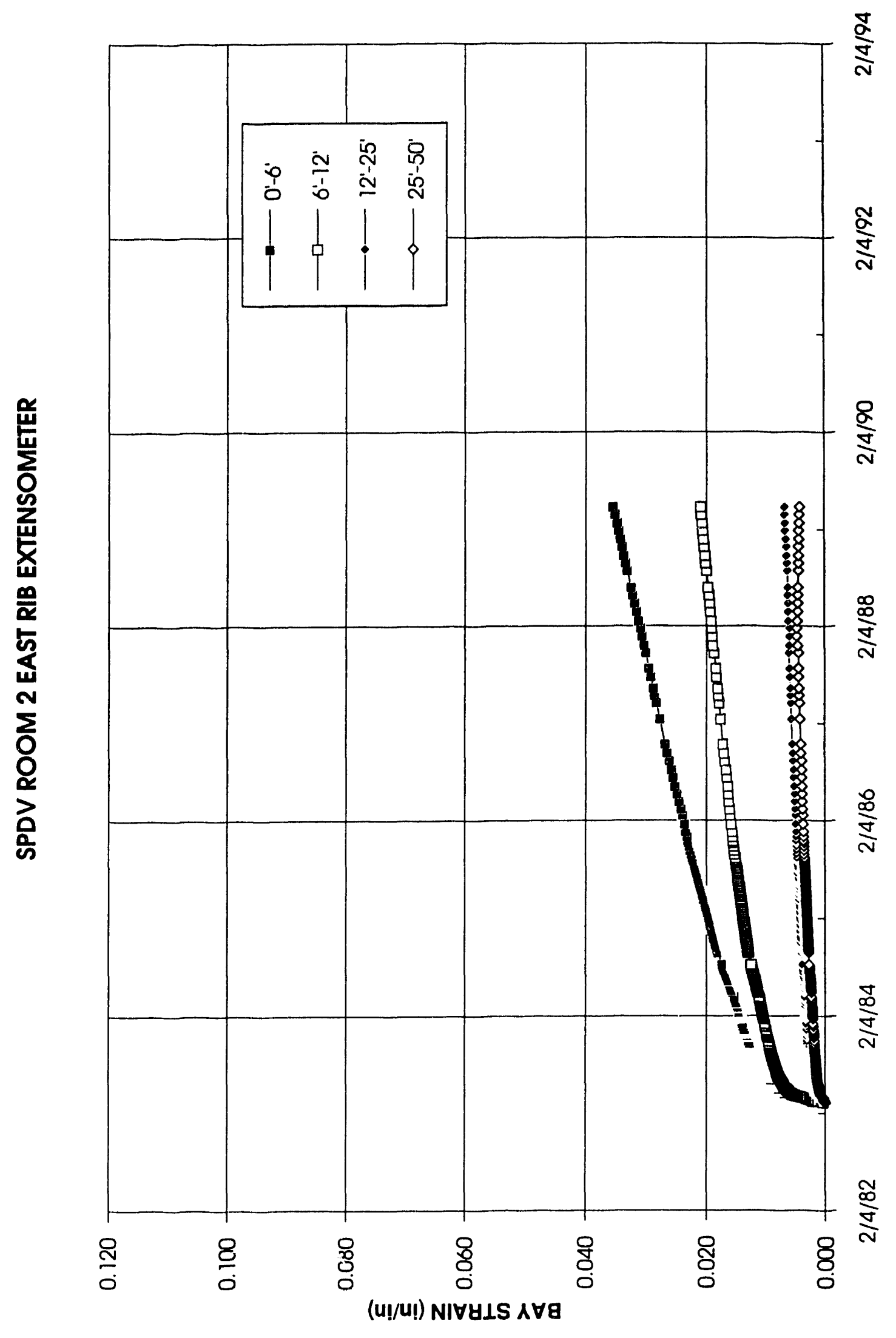

$\frac{7}{4}$ 


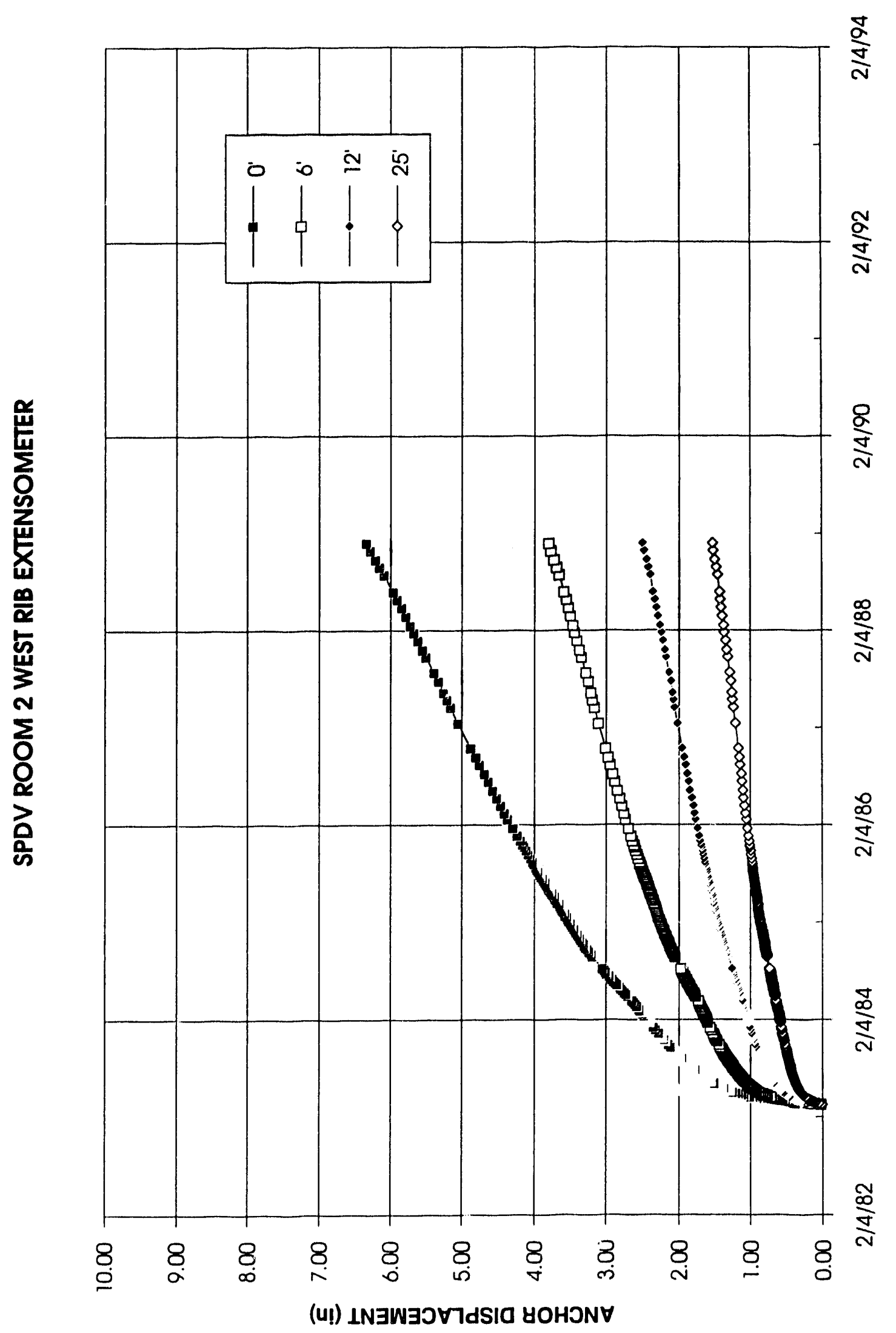

$\frac{N}{4}$ 


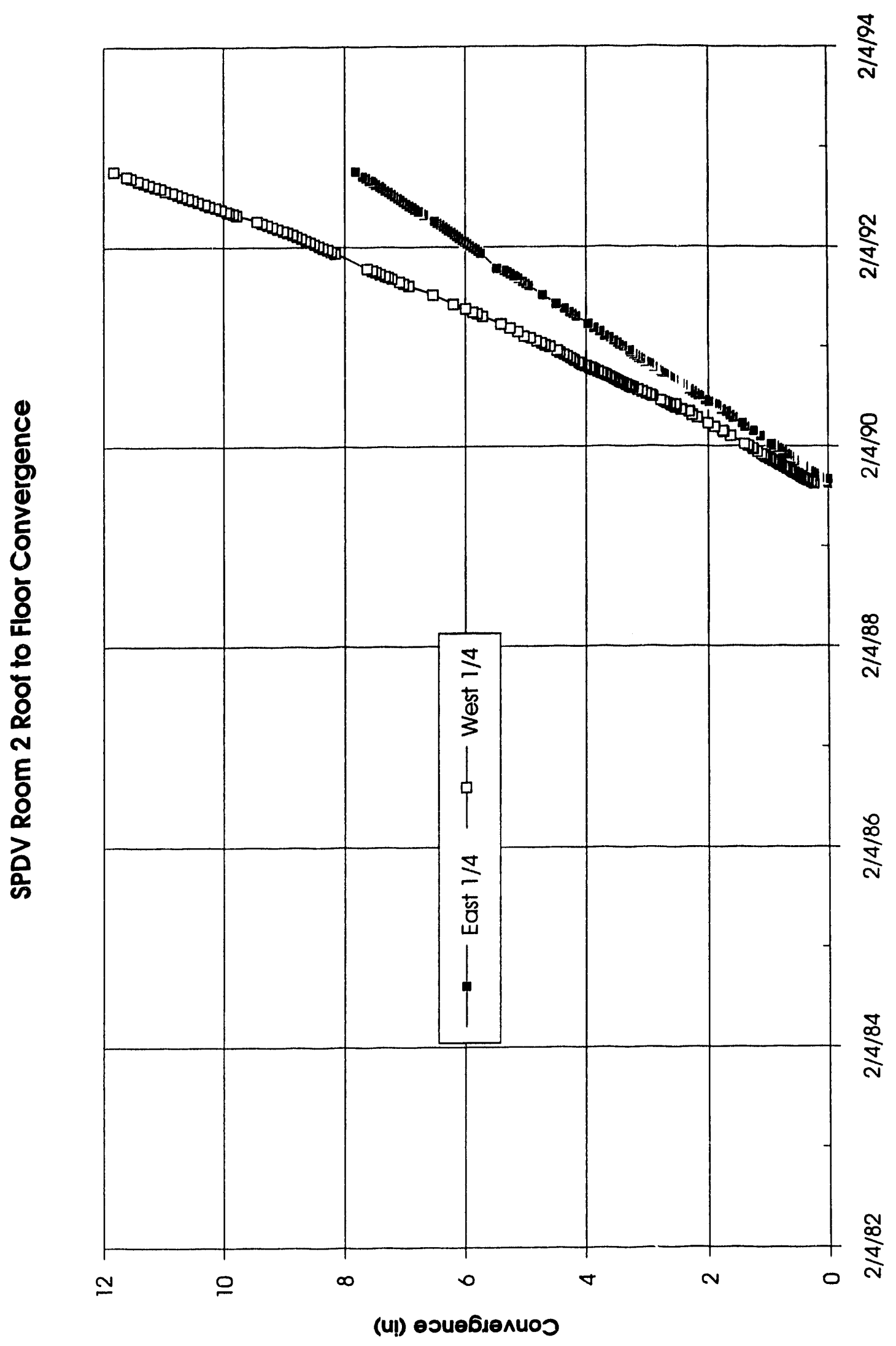



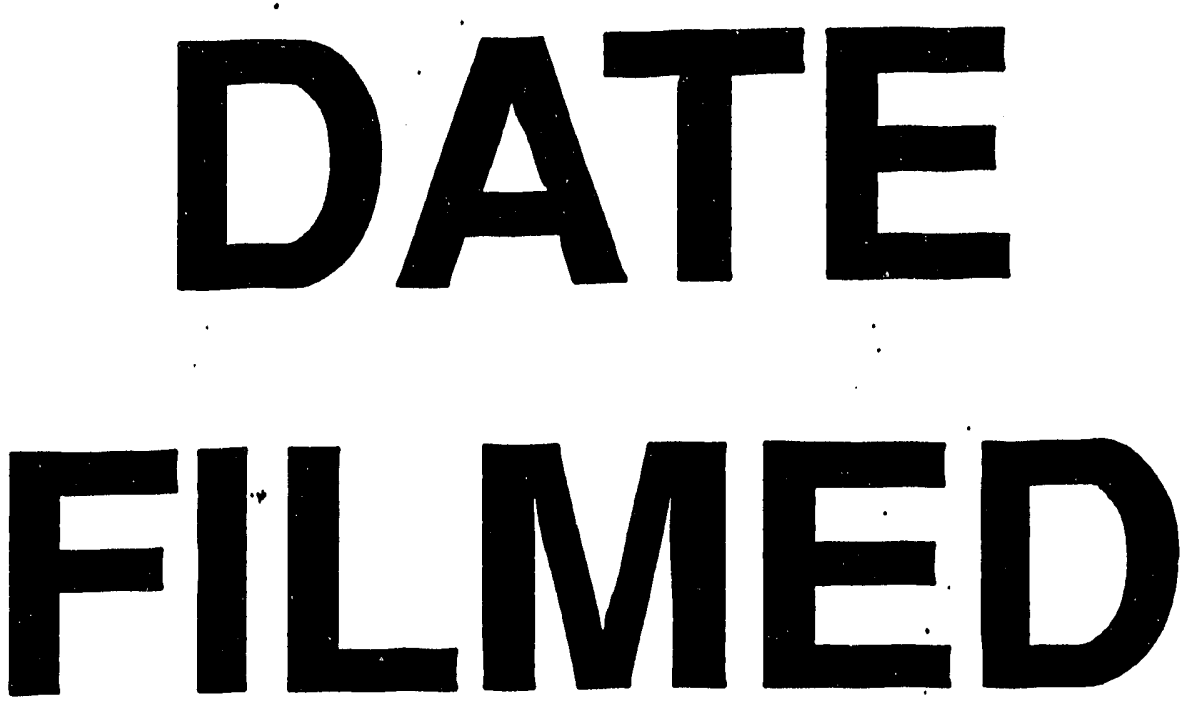

$12 / 13 / 93$
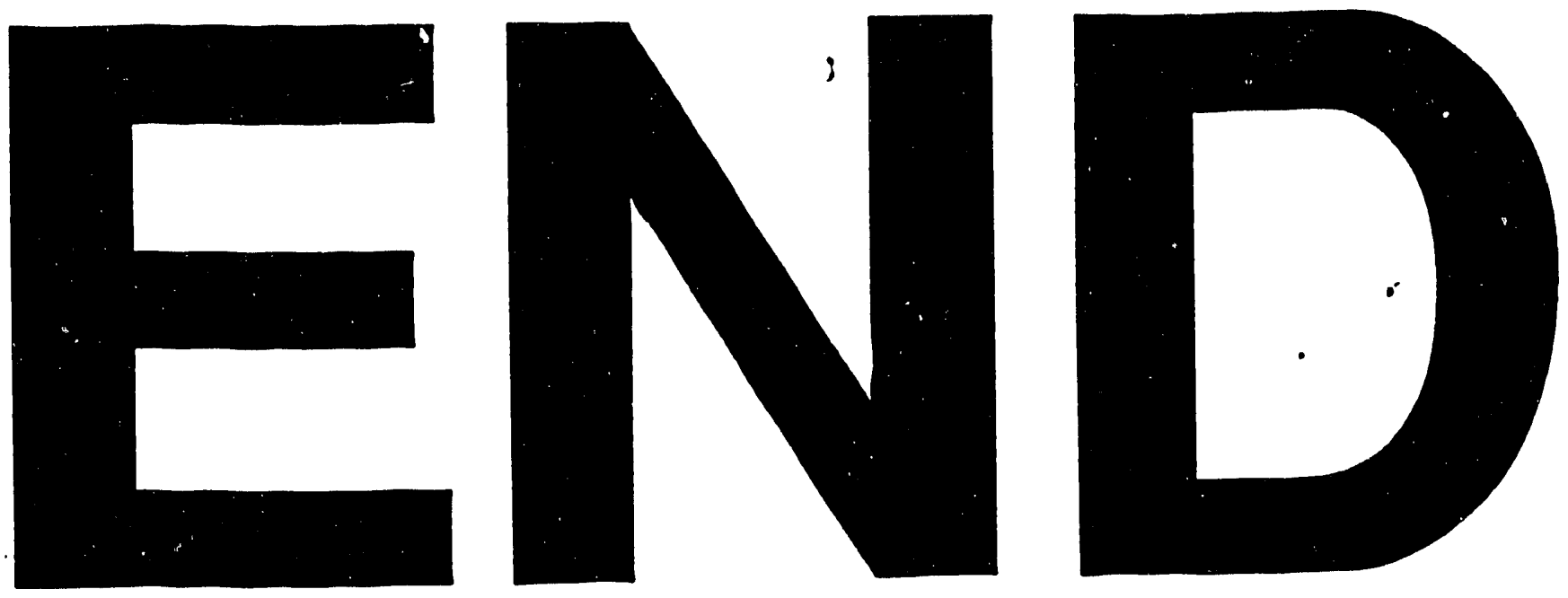
